Revised Manuscript RSER-D-13-00539 Submitted to

Renewable and Sustainable Energy Reviews

\title{
Melting and Convection of Phase Change Materials in Different Shape Containers: A Review
}

\author{
Nabeel S. Dhaidan* and J. M. Khodadadi** \\ Department of Mechanical Engineering, Auburn University, 1418 Wiggins Hall
}

Auburn, AL 36849-5341, USA

\begin{abstract}
A review of analytical, numerical and experimental investigations of melting and ensuing convection of phase change materials within enclosures with different shapes commonly used for thermal energy storage is presented. The common shapes of the containers being rectangular cavities, spherical capsules, tubes or cylinders (vertical and horizontal depending on orientation of gravity) and annular cavities are covered. Studies focusing on melting within rectangular cavities are categorized into two groups. The first one is melting due to isothermal heating on one or more boundaries, whereas the second is the constant heat flux-assisted melting. Moreover, constrained and unconstrained melting in both spherical and horizontal cylindrical containers were discussed. The effects of the concentric geometry and location of the heating source on melting in horizontal annular spaces are presented. The review concentrated on elucidating the heat transfer mechanisms (conduction and convection) during the multiple stages of the melting process and the effects of these mechanisms on the liquid-solid interface shape and its progress, melting rate, charging time of the storage system, etc. The strength of buoyancy driven-convection varies greatly with the dimensionless Rayleigh or Stefan numbers and depends somewhat on the location of heat source and imposed boundary condition. High dimensionless numbers and/or side position of the heat source ensure the dominant role of natural convection melting, otherwise conduction will be responsible for major melting within the container. Furthermore, the geometrical parameters such as the aspect ratio in rectangular containers and vertical cylindrical ones, diameter or radius in spherical capsules and horizontal cylindrical vessels, and eccentricity in annular cavities are reviewed. In addition, the parameters affecting the thermal behavior of the melting process in various enclosures, i.e. the Nusselt, Rayleigh, Stefan, Prandtl and Fourier numbers and are reviewed.
\end{abstract}


KEYWORDS: Annular Containers; Cylindrical Containers; Convection; Melting; Phase Change Materials; Spherical Containers; Thermal Energy Storage.

* Department of Mechanical Engineering, Karbala University, Karbala, IRAQ.

** Alumni Chair Professor; Corresponding Author, E-mail: khodajm@ @auburn.edu; Tel. 1-334-8443333; Fax: 1-334-844-3307.

\section{Nomenclature}

$C_{p} \quad$ Specific heat of the phase change material, $\mathrm{J} \mathrm{kg}^{-1} \mathrm{~K}^{-1}$

Fo Fourier number or dimensionless time, $\frac{t \alpha}{H^{2}}$

$g \quad$ Gravitational acceleration, $\mathrm{m} \mathrm{s}^{-2}$

$H \quad$ Characteristic length that depends on the container geometry, m

$k \quad$ Thermal conductivity of the phase change material, $\mathrm{W} \mathrm{m} \mathrm{m}^{-1} \mathrm{~K}^{-1}$

$L \quad$ Latent heat, i.e. heat of fusion, $\mathrm{J} \mathrm{kg}^{-1}$

$\mathrm{Nu} \quad$ Local Nusselt number, defined as $\left(\frac{H \nabla T}{T_{h}-T_{c}}\right)$ for the isothermal walls cases and $\left(\frac{q^{\prime \prime} H}{k\left(T-T_{r e f}\right)}\right)$ for the constant wall heat flux cases

$\operatorname{Pr} \quad$ Prandtl number, $\frac{v}{\alpha}$

$q " \quad$ Constant wall heat flux, $\mathrm{W} \mathrm{m}^{-2}$

$R a \quad$ Rayleigh number, $\frac{g \beta \Delta T H^{3}}{\alpha v}$

Sc Subcooling parameter, defined as $\left(T_{m}-T_{i n i}\right)$ or $\frac{C_{p}\left(T_{m}-T_{i n i}\right)}{L}$ 
Ste Stefan number, $\frac{C_{p} \Delta T}{L}$

$t \quad$ Time, s

$T \quad$ Temperature, $\mathrm{K}$

$T_{c} \quad$ Temperature of the cold wall where heat is rejected isothermally, $\mathrm{K}$

$T_{h} \quad$ Temperature of the hot wall where heat is supplied isothermally, $\mathrm{K}$

$T_{i n i} \quad$ Initial temperature of the solid phase change material, $\mathrm{K}$

$T_{m} \quad$ Melting temperature of the phase change material, $\mathrm{K}$

$T_{\text {ref }} \quad$ Reference temperature, $\mathrm{K}$

$\Delta T \quad$ Temperature difference, defined as $\left(T_{h}-T_{c}\right)$ for the isothermal walls cases and $(q " H / k)$ for the constant wall heat flux cases, ${ }^{\circ} \mathrm{C}$

\section{Greek Symbols}

$\alpha \quad$ Thermal diffusivity, $\mathrm{m}^{2} \mathrm{~s}^{-1}$

$\beta \quad$ Thermal expansion coefficient, $\mathrm{K}^{-1}$

$v \quad$ Kinematic viscosity, $\mathrm{m}^{2} \mathrm{~s}^{-1}$ 


\section{Introduction}

The ongoing and rapid increase in the economic development worldwide is accompanied by a strong demand for an uninterrupted supply of energy. Conventional fossil energy sources are limited and serious uncertainties associated with their stable supply/pricing persist. Moreover, greater use of fossil fuels is linked to emission of harmful gases that in turn are responsible for climate change and environmental pollution. These serious challenges represent the main driving forces behind efforts to utilize various sources of renewable energy more effectively. Scientists and engineers all over the world are in search of new technologies that will lead to greater adoption of renewable energy sources. A very critical technology that is related to the greater adoption of renewable energies is development of energy storage systems. The varying and unpredictable gap between the supply and demand of all types of renewable energy can be eliminated through adoption of responsive, robust and effective energy storage approaches. Therefore, storage of energy and its conversion/reclamation remains a major challenge to the technologists.

Thermal energy can be stored in three ways, i.e. sensible heat, latent heat, and thermochemical heat storage. Among these, storage through latent heat offered by a great number of phase change materials (PCM) is considered to be a very promising option due to the high density of thermal energy storage and operation at an approximately isothermal condition. Thermal energy is stored in a material as latent heat upon melting (thawing), whereas the stored energy is utilized later when needed by freezing (solidifying) the material. PCM are also relevant to other engineering applications including electronic cooling technology, thermal comfort in dwellings, waste heat recovery, textiles and heating, ventilation and air conditioning (HVAC). For example, electronic cooling systems utilize PCM storage containers as heat sinks to control the temperature of the surface of electronic components that release instantaneous or periodic high density heat fluxes. Abhat [1] reviewed a number of desirable properties for choosing PCM such as melting/freezing temperature near the desired usage/demand temperature, high values of specific heat, latent heat of fusion and density, low vapor pressure at the operational temperature, a small variation in density between the solid and liquid phases, high thermal conductivity, insignificant supercooling, chemical stability, being non-corrosive in relation to containment materials, non-poisonous, non-flammable, non-explosive, and abundant supply at a low cost. There are a number of review articles [2-9] devoted to discussing various PCM types, specific applications, thermophysical properties, encapsulation, heat transfer enhancement and system-related issues. A serious disadvantage of PCM 
is their low thermal conductivity that leads to reduced rate of heat transfer and long time for melting (charging) and freezing (discharging). Fan and Khodadadi [10] reviewed both experimental and computational studies that concerned enhancing the thermal conductivity of phase change materials through introduction of highly-conductive, meso-scale and stationary inserts, structures, fibers, etc.

In addition to its inherent transient behavior, the characteristics of melting of PCM are greatly affected by the dominant heat transfer mechanisms (conduction and/or convection). From a thermal system performance point of view, evolving isotherms, velocity vectors, solid-liquid interface, in addition to the melting rate, melting time and dimensionless parameters that describe the rate of heat transfer (i.e. the Nusselt number) can be analyzed for a specific melting problem. However, these quantities are strongly influenced by the specific geometric configurations and thermal boundary conditions for a specific melting problem. The geometric configuration and orientation with respect to gravity of the containers holding PCM affect the heat transfer mechanisms which play a significant role in evolution the shape, movement and morphology of solid-liquid interface and in turn affect the thermal characteristics of the melting process of PCM. The melting rate is higher in the upper portion of all containers where natural convection dominates. Therefore, increasing the height/width ratio of the enclosure for the same volume augments the buoyancy effect and results in expediting of the melting process and decreasing of the charging time.

\subsection{Common features of the PCM-container systems}

In general, melting of phase change materials in any generic container can be presented schematically, as shown in Fig. 1. An arbitrary-shaped container holds a PCM (melting temperature of $\left.T_{m}\right)$ which is initially in solid phase at an initial temperature $\left(T_{i n i}\right)$ and part of the volume of the container is a gas void. The gas within the void has a low thermal conductivity and the void has assumed its initial position and volume in relation to the gravitational field and details associated with the prior process of freezing of the container. In order to melt the PCM, the container needs to be heated and this can be accomplished through isothermal heating (establishing hot and cold temperature boundaries maintained at $T_{h}$ and $T_{c}$, respectively) and/or supplying a constant wall heat flux $(q)$ on the boundary of the container. Such active thermally boundaries are identified in Fig. 1, whereas the remaining boundaries will be thermally insulated. Upon initiation of heating, the solid phase begins to melt next to the "hot" boundary and the volume of the liquid zone increases. An evolving liquid/solid interface is formed that is at temperature $T_{m}$ if the PCM is a pure material and 
the distance $H$ that is the length scale of the liquid zone in Fig. 1 will increase. The ensuing convection currents within the liquid phase depend on the spatial extent of the region occupied by the liquid phase, orientation of the gravitational field and the established temperature difference. This transient melting problem that is accompanied by buoyancy-driven convection is governed by the Rayleigh number that describes the relative importance of the buoyancy force in comparison to the diffusion force. This dimensionless grouping needs to be defined in accordance with the imposed thermal boundary condition, i.e.:

$R a=\frac{g \beta \Delta T H^{3}}{\alpha v}$

where:

$$
\Delta T=\left\{\begin{array}{l}
T_{h}-T_{c} \quad \text { for isothermal heating } \\
\frac{q^{\prime \prime} H}{k} \text { for isoflux heating }
\end{array}\right.
$$

Note that the time-dependent Rayleigh number increases markedly due to its cubic dependence on $H$ and both laminar and turbulent regimes might be encountered. Another important dimensionless number is the Stefan number:

$$
\text { Ste }=\frac{C_{p} \Delta T}{L}
$$

with $\Delta T$ given by equation (2).

The subcooling parameter also plays an important role in the melting process as it is a measure of the difference between the melting and initial temperatures. This parameter is defined as:

$$
S c=\left\{\begin{array}{l}
T_{m}-T_{i n i} \\
\frac{C_{p}\left(T_{m}-T_{i n i}\right)}{L}
\end{array}\right.
$$

In many practical thermal energy storage systems, heat exchange is promoted through utilization of a pipe within the PCM through which a heat transfer fluid is circulated. In effect, charge/discharge of thermal energy is improved. Such a feature is not shown in Fig. 1 but has been studied by many research studies reviewed in this paper. 


\subsection{Scope of the present review}

In this review, melting and the ensuing natural convection within PCM that are contained in enclosures of various shapes are discussed with emphasis on the type of the geometry of the container. These shapes include rectangular, spherical, cylindrical (both horizontal and vertical) and annular containers. The primary aim of this review is to present a description of the analytical, numerical and experimental investigations related with the melting and ensuing convection processes of phase change materials held in various containers. Geometrical features of the containers (also called capsules, cells, enclosures, vessels, shells) such as aspect-ratio, wall curvature, eccentricity etc., in addition to the location/type of the imposed thermal conditions on the boundaries are directly linked to the variety of convection cells and liquid/solid interface patterns that are encountered in phase change systems.

\section{Melting in rectangular containers}

Melting of phase change materials in rectangular enclosures has received great attention due to its wide-ranging engineering applications in such fields as casting, metallurgy and thermal energy storage. It is appropriate that the applications associated with this type of containers are categorized according to the imposed boundary conditions as: (1) constant heat flux and (2) constant temperature problems.

\subsection{Melting due to the constant heat flux (CHF) boundary}

In this class of problems, the melting process of the phase change materials occurs primarily due to constant heat flux that is supplied on one or more sides of the container. Zhang et al. [11] presented experimental results of the melting process of n-octadecane $\left(\mathrm{C}_{18} \mathrm{H}_{38}\right)$ held in a rectangular enclosure with one wall heated by discrete sources at a constant rate and the other surfaces being adiabatic. Their study aimed to explore the possibility of using the melting process for cooling of periodically-operating electronic components. The results indicated that natural convection has a significant effect on the shape of the solid-liquid interface that becomes more pronounced with increasing of the Stefan number. Also, the effect of subcooling on the melting process was 
described and an empirical correlation predicting the relationship between the liquid phase fraction and subcooling was introduced. The obtained results suggested that the cooling of heat sources using PCM melting and the ensuing natural convection leads to a drop of the mean temperatures of heat sources as much as $50 \%$ compared to natural convection cooling with air. Moreover, the highest surface temperature was recorded at the uppermost heat source.

Ho and Chu [12] simulated numerically using the finite difference method (FDM) the transient heat penetration through a vertical rectangular composite cell filled with a solid-liquid phase change material and air layer. Within the composite cell, the PCM layer was separated from the air layer by a solid partition of finite thickness as shown in Fig. 2. The numerical results for the composite cell with a thin diathermal partition demonstrated that by means of latent-heat absorption inside the PCM layer, heat penetration across the composite cell can be greatly retarded over an effective time duration until a critical instant at which the melting front of the PCM reaches the partition wall. Such an effective thermal protection duration was found to be a strong function of the modified Rayleigh number, the modified Stefan number, the subcooling factor, the relative PCM thickness ratio, and the aspect-ratio $(A R)$ of the composite cell ( $A R$ is defined as the ratio of the width to the height). A geometry of a shallow rectangular composite cell having a larger PCM/air thickness ratio was found to be preferable for effective thermal protection applications. In addition, the effect of a solid partition of finite thickness and conductivity on the thermal protection efficacy of the PCM/air composite cell was also examined.

Jianhua et al. [13] studied experimentally the melting process of n-octadecane in a rectangular cavity with three discrete protruding heat sources on its bottom surface. The surface temperatures of the heat sources were measured by thermocouples and the solid-liquid interface motion was recorded photographically. It was observed that fixed melting (solid between heaters) and contact melting (solid above heaters) occurred simultaneously. The impacts of the Stefan number, initial subcooling and the aspect-ratio (initial PCM height/PCM width) on the melting process were reported. The experimental findings revealed that for higher values of the Stefan number and smaller aspect-ratio, melting proceeds more rapidly and contact melting occurs with greater frequency. The impact of the initial subcooling on the melting process existed only during the very early stages and disappeared after the melting process entered the contact melting stage.

The fusion mechanism of a pure substance (gallium) was examined numerically by Mbaye and Bilgen [14]. The rectangular enclosure was subjected to a constant heat flux on its left vertical 

horizontal walls. The enthalpy formulation with the finite difference-control volume method was developed to study phase change process where the solid-liquid change region is controlled by natural convection. It was found that an important parameter controlling the heat transfer and melting velocity was the applied heat flux, whereas heat transfer attained a maximum value at an optimal value of the aspect-ratio of about unity. Also, the melted volume was independent of the aspect-ratio in the conduction regime, but it became a decreasing function of the aspect-ratio as natural convection in the liquid develops.

Pal and Joshi [15] studied computationally and experimentally (Fig. 3) the melting of an organic phase change material, i.e. n-triacontane $\left(\mathrm{C}_{30} \mathrm{H}_{62}\right)$ in a tall enclosure with an aspect-ratio of 10 by supplying a constant heat flux on one side while the other sides were thermally insulated. Good agreement was obtained between experimental and computational heat transfer data and melt interface locations. They reported that natural convection played a dominant role during the initial stages of melting and at a later time, the strength of natural convection diminished as melting was completed. Correlations for variations of the heat transfer rate and melt fraction with time were obtained.

An analytic study was presented by Hamdan and Al-Hinti [16] for melting process of a solid phase change material contained in a rectangular enclosure heated from a vertical side at a constant heat flux. The propagation and the inclination of the solid-liquid interface along with the time evolution of the melted fraction were studied and evaluated. It was found that the model predicted the propagation of the interface during the initial stages of the melting process very well, while it under-predicted the movement of the interface during the later stages of melting. However, accurate predictions were obtained for the variation of the melted fraction. The results relating to the position, inclination, propagation and the melted fraction were found to be in a good agreement with published experimental and numerical results.

Faraji and El Qarnia [17] studied numerically the melting of n-eicosane $\left(\mathrm{C}_{20} \mathrm{H}_{42}\right)$ in a rectangular enclosure heated with three protruding heat sources with a constant and uniform volumetric heat generation on one side while the other sides were thermally insulated (Fig. 4). The power supplied to the heat sources was equal to that generated within the actual Pentium microprocessor (CPU) Centrino Duo $4(2.8 \mathrm{GHz})$. Their model used the control volume approach and the enthalpy method for solving the momentum and energy equations. The results indicated that conduction was predominant at the bottom part of the PCM at early stage of the melting process. 


\subsection{Melting due to the constant wall temperature (CWT) boundary}

Conduction and free convection-dominated melting along a heated isothermal wall in a rectangular enclosure has attracted considerable research attention due to its fundamental importance 
in various technological applications. Melting is initiated when one or more walls are maintained at a temperature above the melting temperature of phase change materials.

Brent et al. [20] investigated numerically the melting of pure gallium in a rectangular cavity using the enthalpy-porosity approach for modeling combined convection-diffusion phase change. The left wall was maintained at a hot temperature of $38{ }^{\circ} \mathrm{C}$ while the right boundary was at an initial temperature of $28.3{ }^{\circ} \mathrm{C}$, and the other walls were adiabatic. The approach was validated through the excellent agreement between the numerical predictions and experimental findings available in literature. The results indicated the features of enthalpy-porosity method such as its validity in comparison to the experimental work, applicability, convergence speed, and the ability to predict accurately both the position and morphology of the melt front at various times.

Beckermann and Viskanta [21] reported a combined experimental and numerical study of melting of a pure metal inside a vertical rectangular enclosure (Fig. 6) with natural convection in the liquid region and conduction in the shrinking solid portion. The numerical predictions were verified through a number of experiments, covering a range of the Rayleigh numbers and subcooling parameters. It was found that solid subcooling significantly reduced the melting rate when compared to melting with the solid initially at the fusion temperature. Additionally, the melting process consisted of a sequence of four regimes (an initial conduction-dominated regime, a regime characterized by developing convection in the upper portion and conduction prevalence in the lower part, a convection-dominated regime, and a regime where melting process is highly influenced by heat extraction by cold wall) and eventually approached to the steady-state condition. For small solid subcooling, the first three regimes were found to be similar to the ones observed in melting without subcooling, whereas for moderate subcooling, significant differences can be observed after the first two regimes and the steady-state interface is almost vertical and parallel to the cold wall. Large values of the subcooling parameter led to an early termination of the melting process and the last two regimes may never take place.

Asako et al. [22] introduced a numerical study to investigate the melting of an unfixed rectangular PCM in a low-gravity environment. An enthalpy method was applied to solve the transport processes with the governing equations discretized by using a control-volume-based finite difference scheme with a new iterative method to correct the downward solid-phase velocity. The PCM, initially at its melting temperature, was placed inside a rectangular enclosure. The lower surface of the container was then exposed to a uniform temperature higher than the PCM's melting temperature. The difference in densities of the solid and liquid phases caused a force imbalance on 
the solid in the gravitational and low-gravity environments. In the case where the density of the solid phase exceeded that of the liquid, the solid continually moved downward as melting progressed and hence generated a flow field within the liquid. The results were presented in the form of a parametric study of the effects of the Archimedes, Stefan and Prandtl numbers, and geometric parameters such as aspect ratio. The results revealed that the melt thickness increases with time and decreases with increasing Archemides, Stefan, and Prandtl numbers, while the effect of aspect ratio on the melt thickness was small. They showed that the rate of solid volume reduction increases with increasing Archimedes and Stefan numbers, and in a low-gravity environment, the melting rate is very slow.

Wang et al. [23] conducted an experimental investigation (Fig. 7) to examine the thermal characteristics of the melting process in a rectangular enclosure heated from a vertical side. A flat plate heat pipe was utilized to provide a uniform wall temperature at any given time. The presentation of the results clearly captured the development of the distinct structure of the liquidsolid interface in the presence of natural convection. The temperature distributions in the PCM along the top wall, horizontal mid-plane, and the bottom wall were presented. Correlations, developed for the melted volume fraction and the time-averaged Nusselt number as a function of the parametric variables $(R a$, Ste, $\operatorname{Pr}$ and $F o$ ), were found to yield good agreement with the experimental data. It was shown that the temporal variation of the Nusselt number distinguishes three different heat transfer regimes during the melting process (conduction-dominated regime, transition regime, and convection-dominated regime).

Gong et al. [24] studied numerically the free convection-dominated melting of a phase change material in a rectangular cavity with an isothermally-heated vertical wall with the aid of the streamline Upwind/Petrov-Galerkin finite element technique in combination with a fixed-grid primitive variable method to solve the governing two-dimensional conservation equations. The enthalpy-porosity model was employed to account for the physics of the evolution of the flow at the solid/liquid interface leading to a good agreement with previous experimental and numerical results. The melting process was divided into two periods. The first one (isotherms not parallel with the effect of thermal stratification being low and high rate of free convection and melting) is presented in Fig. 8a, where the isotherms corresponding to Fourier $(F o)$ numbers of 0.108, 0.194 and 0.302 are shown. As time progressed, the second period will appear with significant thermal stratification and low rate of convection and melting (Fig. 8a) for $F o=0.432$ and 0.562 . The authors suggested inverting the container in the second stage (Fig. 8b) for augmenting the effect of natural convection. 
The results indicated more than 50\% increase of the energy charge rate during the melting process for some specific cases (Table 1) due to inversion of the container.

Ghasemi and Molki [25] investigated numerically isothermal melting in a rectangular cavity using the fixed-grid enthalpy formulation. The solid phase was unfixed and could move during the melting process. All walls of the cavity were maintained at a constant temperature higher than the melting temperature of the PCM. Falling of the solid in the melt and buoyancy were the main factors affecting the liquid motion and the melting process. The problem was studied numerically and the findings were validated by a comparison with the available analytical, numerical and experimental results. It was found that for low values of the Rayleigh and Archimedes numbers, the melting rate and the solid velocity were both very small, and the melting pattern was almost symmetric. Operating at higher values of the Rayleigh and Archimedes numbers, enhanced melting, faster falling velocity of the solid and distortion of the symmetry of the interface were observed.

Zivkovic and Fujii [26] presented a simple computational model for isothermal phase change of a PCM encapsulated in rectangular and cylindrical containers. The theoretical model was verified with a test problem and an experiment was performed in order to assess the validity of the assumptions of the mathematical model. Based on very good agreement between experimental and computational data, it was concluded that conduction within the PCM in the direction of heat transfer/fluid flow, thermal resistance of the container's wall, and the effects of natural convection within the melt can be ignored for the conditions investigated in the study. The computational results indicated that the rectangular container required nearly half of the melting time when compared to the cylindrical container of the same volume and heat transfer area (Fig. 9).

Lacroix [27] introduced a mathematical model for the contact melting of a subcooled PCM inside a parallelpipedic capsule where heat was supplied isothermally from the upper and lower sides, while the other sides were adiabatic. Numerical results indicated that the melted fraction from close contact melting at the bottom of the capsule was greater by an order of magnitude than that from the conduction-dominated melting near the top. Also, the melting process is positively governed by the magnitude of the Stefan number and strongly influenced by the side dimensions of the capsule, whereas the total melting time increased linearly with the degree of subcooling.

Jiji and Gaye [28] investigated analytically the problem of one-dimensional melting and solidification of a slab with uniform volumetric energy generation. Analytic solutions were obtained using a quasi-steady approximation by neglecting the transient term in the heat conduction equation under certain conditions such as the low Stefan number. This approach simplifies phase change 

case is characterized by a pure liquid phase and a mixture of solid and liquid at the fusion temperature. The solution was governed by a single energy generation parameter. Temperature profiles, interface location and steady-state conditions were presented for both melting and solidification cases. Results were applied to two examples of solidification of a nuclear material and melting of ice.

Yanxia et al. [29] reported on an experimental study designed to investigate the thermal characteristics of the melting process of ethanolamine-water binary mixture used as PCM in a rectangular enclosure heated from a vertical side (Fig. 10a). The empirical correlations of molten fraction and time-averaged Nusselt number in convection-dominated melting were established and compared with pure conduction model. The experimental results indicated that natural convection enhanced the melting process compared with the conduction-only cases. The higher the Rayleigh number, greater differences between the molten fraction data of the natural convection-dominated and conduction-dominated cases were observed (Fig. 10b). Mechanism of pure conduction only occurred during the initial stage of melting and a conduction-convection coupled model was necessary for predicting melting process accurately at later stages.

Jellouli et al. [30] reported a numerical investigation of the moving boundary problem during melting process driven by natural convection in the liquid and conduction in the solid within a rectangular cavity heated from below (Fig. 11a) by using an elliptic procedure and a control volume scheme. The agreement between numerical results and those of earlier reported studies was found to be good. During the early stage of melting, buoyancy forces cannot overcome the resistance imposed by viscous forces. The presence of convection with its temperature signature observed in the bottom panel of Fig. 11b exhibited a clear departure from the horizontal distribution of the isotherms associated with pure conduction (top panel of Fig. 11b). As the thickness of the melt layer increased with time, natural convection dominated in the liquid phase and the melting front reached a steady position (end of the melting process) when heat transfer from the liquid phase was compensated by heat transfer to the solid phase.

Chen et al. [31] introduced a two-dimensional theoretical model based on the enthalpy formulation and a fully-implicit finite difference method to predict the melt fraction of PCM which were magnesium nitrate hexahydrate, stearic acid, acetamide, acetanilide and erythritol. Different materials such as glass, stainless steel, tin, aluminum alloy (called "mixed" in the paper), aluminum and copper were used as the heat exchanger's container materials in the numerical calculations. One 
side of the cubic container was maintained at a constant temperature, whereas the other sides were adiabatic. The predicted results revealed that the selection of the thermal conductivity of the heat exchanger container material and the effective thermal conductivity of the PCM had an important influence on the melt fraction, while the thickness of the heat exchanger's container material and the initial PCM temperature did not have very significant effect on the melt fraction. Also, the temperature of the wall boundary played an important role during the melting process and has a strong impact on the observed melt fraction.

Younsi et al. [32] conducted a numerical investigation to study the thermal characteristics of the melting process of a PCM (hydrated salt) heated on a vertical wall of a rectangular enclosure. An enthalpy-based mathematical model was proposed to analyze PCM for latent storage. Solution of the governing equations was obtained by using the finite volume method (FVM). The numerical implementation was done by using a 1D FVM which was used as a comparison method for the proposed 2D FVM. The convection-dominated melting in a rectangular cavity was also investigated numerically using the commercial code FLUENT 6. The findings of the study proved that the 1D solution (pure conduction) should not be used even though the value of the aspect-ratio is very low due to the relatively large discrepancy in progress of the melting patterns predicted by the two approaches, as presented in Fig. 12. Also, both numerical methods (2D FVM and FLUENT code) provided excellent correspondence with experimental results.

Wang et al. [33] developed a comprehensive finite volume model for solving the problem of 2D melting in a square cavity involving natural convection for four different cases (Fig. 13). In the model, the energy balance associated with phase change was represented by the temperature transforming model, and the velocity-pressure coupling is solved by the consistent update technique (CUT) algorithm. Furthermore, a new solid velocity correction scheme that does not employ large numbers to force the velocity in the solid phase to be negligibly small, along with an explicit update for the melting front and buoyancy force was proposed. This scheme proved to be very effective in eliminating the inconsistencies previously discussed and was able to accelerate convergence significantly. The predictions of the proposed numerical model were compared with previous theoretical, modeling and experimental results, and reasonable agreement was achieved among various approaches. It was found that melting phenomena of octadecane $\left(T_{m}=30^{\circ} \mathrm{C}\right)$ and sodium nitrate $\left(T_{m}=306.8{ }^{\circ} \mathrm{C}\right)$, both melting in a square cavity with a Rayleigh number of $10^{8}$ and a Stefan number of 0.1 were essentially identical. Such a similarity can be used as a foundation for 

high-temperature phase change materials.

Through comparison of reliable experimental data and numerical modeling, Joulin et al. [34] studied the energy storage and the energy recovery accommodated by using a phase change material. An experimental setup (Fig. 14a) was used to measure the temperatures and heat fluxes in order to characterize the phase change effects. A 1-D finite difference method (FDM) incorporated in an inhouse FORTRAN code and the 2-D commercial CFD software FLUENT were applied for the computation of the thermal behavior of the PCM. Predictions based on both methods exhibited a very good agreement with the experimental observations for the melting process with a deviation of less than 5\%, as shown in Fig. 14b. Findings of the numerical modeling suggested that the supercooling phenomenon must be taken into account correctly in order to predict the PCM thermal behavior since the numerical results of $1 \mathrm{D}$ and $2 \mathrm{D}$ simulations ignoring subcooling were very far away from the experimental ones.

Murray and Groulx [35] performed a 2-D numerical study using the COMSOL Multiphysics package (versions 4.0a and 4.1) to simulate melting of a PCM including both conduction and convection heat transfer in a square enclosure containing octadecane as the PCM. The vertical walls were maintained at constant high and low temperatures, and the other walls were insulated. The impact of the melting temperature range $\left(T_{\text {liquidus }}-T_{\text {solidus }}\right)$ used in the simulation was demonstrated. Moreover, the effect of the numerical assignment of viscosity on the onset and strength of natural convection and the resulting melting interface position was discussed. The effects of viscosity and thermal conductivity of the PCM were studied as well, and changes in those material properties resulted in variations in the amount of PCM melted, as well as the shape of the melting front. The results pointed to the importance of accounting for natural convection during melting in a PCM.

A summary of the investigations devoted to melting of phase change materials contained within rectangular vessels [11-35] are provided in Table 2. Specifically, the imposed boundary conditions (BC), PCM type, adopted methodologies/techniques, along with the highlights of the findings are summarized. It is clear from literature reviewed above that conduction heat transfer associated with high temperature gradient, high melting rate, parallel-wall isotherms and symmetric melting at upper and lower part of the containers is the characteristic of the initial period of melting for both CWT and CHF boundary conditions. Later on as buoyancy-driven convection develops, the thickness of melt liquid increases resulting in decay of temperature gradient and melting rate which is accompanied with asymmetric melting between upper and lower parts and formation of curvature 
in isotherms. Therefore, these two mechanisms of heat transfer are important in any analytical and numerical investigations. Also, the operating conditions ( $R a, S t e, S c)$ and geometrical parameter (aspect ratio) influence the heat transfer mechanisms which in turn affects the melting behavior of PCM. Commonly, the aspect ratio is defined as the container's variable height to constant width, thus the height determines the magnitude of this ratio. Greater melted volume is achieved at higher values of Ra and Ste, and lower levels of Sc and aspect ratio. Moreover, the orientation of the heat source and specific boundary condition play a significant role on the heat transfer modes and resulting melting characteristics. Lower positioning of a heat source ensures close-contact melting at a high rate.

\section{Melting in spherical capsules}

Two-dimensional melting in a spherical shell can be classified into two groups: constrained and unconstrained melting. Constrained melting (also known as inward or fixed) is unavoidable in experimental studies when thermocouples are positioned inside the spherical containers. In effect, the thermocouples hold the solid PCM in place and prevent it from sinking/rising to the bottom/top of the sphere due to gravity. For cases when there is no difference in densities between the liquid and solid phases, constrained melting will also persist. In effect, there is no direct contact melting next to the wall of the container. Unlike constrained melting, unconstrained melting (also called close-contact, unfixed) is encountered when there is no anchor inside the capsule for the solid PCM to cling to with the existence of difference in density between the liquid and solid phases. Therefore, the solid PCM will sink/rise to the bottom/top of the sphere and will experience thermal contact with the surface of the cell. Consequently, direct contact melting next to the wall of the container will be observed.

Saitoh and Hoshi [36] presented an approximate analytical solution for the close-contact melting heat transfer characteristics including melt flow in the liquid film subject to an inner wall temperature distribution in cylindrical or spherical capsules with neglecting the effect of natural convection in the upper liquid region. The effects of the Stefan number and variable temperature profile were clarified in detail. In addition, the effects of the variable inner wall temperature on the molten mass fraction were investigated. The analytical results were compared with the numerical solutions for molten mass fraction and melt layer thickness. Agreement between the two approaches 
was excellent. They concluded that the progress of melting is faster than the constant temperature conditions if the capsule's wall temperature distribution is exactly accounted for. Also, the same authors [37] reported details of an experimental setup (Fig. 15) used to investigate the combined close-contact and natural convection melting in both horizontal cylindrical and spherical capsules immersed in a high-temperature environment. The shape of the interface and the complete melting time under various ambient temperatures were observed. In addition, the effects of the variation of the inner wall temperature and the molten mass fraction on melting characteristics were investigated experimentally. Their findings indicated that the molten mass fraction is strongly dependent on the Stefan number. Also, the inner wall temperature varies in a complicated manner with time, and there is temperature distribution along the peripheral direction that influences the complete melting time.

Fomin and Saitoh [38] researched numerically (boundary fixing method) and analytically (perturbation technique) the close-contact (unconstrained) melting process of unfixed solid in a spherical capsule. The approximate analytical solutions were found to be in good agreement with the numerical solutions of the complete mathematical model. The discrepancy in the results did not exceed $10-15 \%$ due to primarily neglecting the melting in the upper part in the analytical solution. Computed results reveal that ignoring the effect of streamwise convection in the liquid layer leads to overestimating of melting rate. Moreover, they concluded that the assumption of the constant temperature wall of the capsule can lead to the results which significantly differ from those obtained for the actual conditions of melting where the wall of the capsule is non-isothermal.

Khodadadi and Zhang [39] conducted a numerical study of the effects of buoyancy-driven convection on constrained melting of phase change materials within spherical containers by using the finite volume procedure with a single-domain enthalpy formulation for simulation the phase change phenomenon. At the beginning of the melting process, the conduction mode of heat transfer is dominant, giving rise to concentric temperature contours. As buoyancy-driven convection is strengthened due to the growth of the melt zone, melting in the top region of the sphere is much faster than in the bottom region. The findings indicated that the strength of natural convection during the melting process is clearly dependent on the Rayleigh number when compared to the Stefan number. In addition, the Prandtl number plays an important role in the melting process. A melting experiment was also conducted to support the validity of the computational findings through comparison of the instantaneous melting patterns.

Assis et al. [40] explored experimentally and numerically the process of unfixed melting of a phase change material in a spherical vessel. The numerical simulations followed the melting process 
from the beginning to the end and incorporated such phenomena as convection in the liquid phase, volumetric expansion due to melting, sinking of the solid in the liquid, and close contact melting. The experimental findings included visualization of melting that compared favorably with the numerical results and thus served to validate the numerical approach. The computational results showed how the transient phase change process depended on the thermal and geometrical parameters of the system, including the temperature difference between the wall and the mean melting temperature (impact of the Stefan number), and the diameter of the sphere. They reported that the melting time was slightly shorter in the results of simulation due to an additional thermal resistance of the glass container, albeit small, in the experiments. Dimensional analysis of the results was performed and presented as variations of the mean Nusselt numbers and PCM melt fractions depending on an appropriate combination of the Fourier, Stefan and Grashof numbers. This analysis led to generalizations that encompassed the cases of melting in spherical capsules.

Tan [41] investigated experimentally the constrained and unconstrained melting (Fig. 16a) of phase change materials inside a sphere using n-octadecane for multiple wall temperatures and subcooling ranges. He reported that in unconstrained melting, the melting of PCM at the beginning is dominated by heat conduction across the wall. As the PCM melts, it sinks to the bottom of the sphere due to the density difference of the two phases. Thus, melting at the bottom half is much faster due to heat conduction at the inner wall (close-contact melting), while the buoyancy effect is responsible for melting in upper half. In constrained melting, heat conduction only exists at the beginning of the melting process; therefore melting is mainly through natural convection in the liquid at the top and bottom halves of the liquid part of the PCM. This effect causes the melting PCM to melt almost concentrically inward. An oval shape of the solid PCM is formed within the top half of the sphere due to natural convection heat transfer in the liquid PCM. The top half of the sphere melted at a faster rate than the bottom half. Natural convection cells were also formed in the bottom half, thus causing the wavy profile on the bottom of the solid phase, as shown in Fig. 16b. Thereafter, Tan et al. [42] studied numerically and experimentally the constrained melting of noctadecane inside a spherical capsule. The computations were based on an iterative, finite-volume numerical procedure that incorporated a single-domain enthalpy formulation for simulation of the phase change phenomenon. The results revealed that conductive heat transfer dominates during the early period, as evident by the near-spherical shape of the PCM. As buoyancy-driven convection was strengthened due to the growth of the melt zone, it was observed that melting in the top region of the sphere is much faster than in the bottom region of the sphere. Waviness of the bottom surface 
of the PCM was also observed due to unstable fluid layer that supports chaotic fluctuations and high discrepancy between numerical and experimental readings of temperatures, while this discrepancy in relatively low in the stable molten liquid layer in the top half of the sphere (Fig. 17). Thermal stratification within the constant temperature bath that encloses the capsule may play a role in the experiments. They reasoned that the underestimated experimental observations of waviness and excessive melting of the bottom region of PCM due to existence a support structure that held the sphere could have also inhibited heat from reaching the bottom of the sphere.

Veerappan et al. [43] presented an analytical model based on quasi-steady approximations for solidification and melting of PCM in a spherical container under isothermal boundary conditions on the external surface of the spherical shell. The study involved five kinds of PCM which were 65 mol\% capric acid and $35 \mathrm{~mol} \%$ lauric acid, calcium chloride hexahydrate, n-octadecane, nhexadecane, and n-eicosane. The problem of melting inside a PCM can be treated as a problem of natural convection inside concentric spheres. Movement of the solid phase due to density difference was neglected. The problem was solved by defining conduction as the dominant mode of heat transfer and merging the convective effects in the thermal conductivity of the liquid. The results of the analytical models were validated against the previous experimental results and the deviations were found to be within $15 \%$ for solidification and $20 \%$ for melting. The transient interface positions and complete charging time predicted by the model that included conduction, natural convection, and heat generation effects matched with the experimental measurements as shown in Fig. 18. Initially, the experimental data closely matched the results of the pure-conduction model which is the dominant mode of heat transfer. After that, melting is greatly influenced by natural convection phenomena. The pure-conduction model overpredicts the complete melting time. The influence of the size of encapsulation, initial temperature of the PCM, the external fluid temperature on the solidified and molten mass fraction and the total phase change time were also investigated. According to the melting and solidification characteristics of PCM, the results revealed that the 65 mol\% capric acid with 35 mol\% lauric acid and calcium chloride hexahydrate were better options for melting and solidification, respectively.

Hosseinizadeh et al. [44] explored numerically and experimentally the unconstrained melting of n-octadecane paraffin wax as PCM encapsulated in a hot spherical container with different operating conditions and various diameters of the container. The results showed that heat conduction to the PCM is dominant at the beginning through contact melting next to the surface of container where the melt fraction and the Nusselt number vary sharply. With progressing time, a 
thin layer of melted PCM was observed between the hot container's wall and the solid PCM. The solid PCM sinks and the liquid rises up to the top half of the sphere. Then, natural convection becomes dominant at the top half of sphere where the melting rate is lower than the bottom half causing a reduction of the heat transfer and melting rate, in general. Although the Stefan number is an important parameter in the melting process, the simulation results indicate that the geometrical parameter such as the diameter of the sphere has more influence on the melting rate and heat release compared to the operating condition.

Rizan et al. [45] studied experimentally the melting of n-octadecane in a spherical flask under the constant heat flux condition. The flask was immersed in a water tank and subjected to 690,850 and $950 \mathrm{~W}$ power-rated heater, respectively, until full melting was obtained as shown in Fig. 19. The melt-fraction versus time results indicated that melting was primarily dependent on the temperature level to which the PCM is subjected to and the area of the contact plane surface. Conduction heat transfer from the flask walls dominates the initial melting condition with increasing liquid boundary layer shifting dominant heat transfer mode to internal convection. Furthermore, it was found that the surface area in contact with the liquid front plays a major role as a larger surface area of the same volume will yield a higher melting rate due to internal convection.

Outline of studies [36-45] associated with melting inside spherical capsules are listed in Table 3 and include information on the melting type (constrained and unconstrained), the imposed boundary conditions, PCM type, adopted methodologies/techniques, along with the highlights of the reported findings. The studies report on two melting modes which are constrained and unconstrained. Conduction heat transfer with concentric isotherms identifies the initial stages of PCM melting for both modes. After time progresses, buoyancy-driven convection will develop and dominate in constrained melting causing faster melting rate in the upper region of spherical capsule compared to the lower zone. In contrast, conduction and high rate of melting are registered at the lower part of the vessel where close-contact between solid PCM and wall dominates in unconstrained melting, while natural convection and low melting rate are dominant within the upper region. Furthermore, thermally stable melt layer of PCM in the upper half of sphere and unstable melt liquid with waviness in lower half are recorded in inward melting. The melting behavior is affected by operating parameters $(R a$, Ste) and geometrical factor (diameter and thickness of the spherical capsule), Moreover, variation of prescribed constant wall temperature boundary condition due to free natural currents through outside medium has some effect on the melting rate. 


\section{Melting in cylindrical vessels}

Melting in cylindrical containers (having circular cross sections) is affected by the orientation of the symmetry axis of the cylindrical vessel with the gravity vector, i.e. vertically-oriented containers correspond to colinearity of the two vectors (section 4.1), whereas these two vectors are normal to each other for horizontally-oriented containers (section 4.2). Moreover, melting is categorized as constrained or unconstrained similar to the two-dimensional melting in a spherical shell discussed in section 3. It will be observed that melting in a horizontal cylinder or tube is similar to spherical containers due to the curvature effects common to both shapes.

\subsection{Vertical cylindrical containers}

Melting of phase change materials in a vertical tube or vertical cylinder somewhat resembles the developing patterns associated with the two phases in tall rectangular enclosures. For these configurations, the cylinder is heated from the side and/or base or both.

Sparrow and Broadbent [46] conducted experimental study for melting of phase change material (n-eicosane) in a vertical tube heated isothermally from its side, insulated thermally from the bottom, while an air space was presented above the PCM for accommodating the volume change during melting. Numerical solutions based on pure conduction analytical model were also performed for comparison purposes. It is found that the melting process is significantly affected by fluid motions in liquid melt induced by the volume change and natural convection. Experimental findings indicated that the melting process with no subcooling displayed melting-related energy transfers and melting fraction were about $50 \%$ greater than that predicted by a model based on pure conduction. This deviation reflects the enhancing effects of fluid motions and natural convection in the liquid melt. In addition, they correlated the experimental results by using the Fourier, Stefan, and Grashof number. Initial subcooling substantially decreases the melting rate, the energy transfer for melting, and sensible heat storage.

Wenzhen et al. [47] studied analytically close-contact melting of phase change materials contained inside a vertical cylinder capsule which is isothermally-heated at bottom and its side (Fig. 20). They applied the liquid film theory to analyze heat transfer in the contact liquid layer and assumed that melting is dominated by heat transfer in the close-contact layer film at the bottom and by heat conduction through the stable liquid at the side with the top wall kept adiabatic. The results revealed that the effect of heat conduction through the liquid phase on the total melted mass fraction 
is not significant. The theoretical formulas of the melting rate and thickness of the liquid layer during the heat transfer process were obtained through the analysis, which were convenient for engineering predictions. Also, the effects of the Stefan number and the aspect-ratio were reported. The analytical findings indicated that increasing the Stefan number and/or reducing the aspect-ratio were advantageous to increasing the melting rate and lowering the total charging time.

$\mathrm{Wu}$ and Lacroix [48] carried out a numerical study of natural convection that controlled melting of a phase change material within an isothermal vertical cylinder heated from its top, bottom and side walls (Fig. 21a). The governing conservation equations were formulated in terms of the stream function, vorticity and temperature. Body-fitted coordinates with finite difference method were employed for tracking the irregular shape of the time-wise changing solid-liquid phase front. Results showed that heat transfer for the case of top-heated surface is dominated by conduction. Also, the Nusselt number on the top surface decreases monotonically to zero as melting progressed, showing that no heat is transferred across the top layer once natural convection is fully developed in the melt (Fig. 21b). The highest heat transfer rates were observed on the bottom surface where the Benard convective cells developed. The convective flow patterns and time evolution of the phase front, resulting from simultaneous heating from the bottom, side, and top surfaces were far more complicated than those for the melting from a single isothermal boundary. Due to the convective motion of the melt along the vertical heated wall, the onset of the Benard convection occurred at a much earlier time than that for the case of melting within a cylinder heated from below.

Jones et al. [49] conducted an experimental (Fig. 22a) study of the melting of subcooled neicosane in a vertical cylindrical enclosure, complemented by a numerical investigation of the melting process where the enclosure was heated isothermally from the sides, maintained at a constant temperature at the bottom, and insulated at the top. The numerical simulations employing the enthalpy method adopted the finite volume method. Experimental results included temperature measurements, solid/liquid interface locations and volumetric liquid fractions. A semi-automated approach for extracting the solid/liquid interface locations using digital image processing techniques was developed. Comparisons between experimental measurements and numerical predictions for both melt front locations and temperature data revealed good general agreements for the Stefan numbers up to 0.1807. It has been shown from experimental findings that four distinct regimes occurred during the melting process which are: a) pure conduction, b) mixed convection/conduction, c) convection dominant, and d) "shrinking solid", as shown in the Fig. 22b. 
Shmueli et al. [50] performed a numerical investigation of melting of PCM in vertical circular tubes insulated from bottom and isothermally heated at sides, while the upper part was exposed to air. The numerical analysis used an enthalpy-porosity formulation and was accompanied by image processing of the experimental results from the previous studies, yielding quantitative information about the local melt fractions and heat transfer rates. The model analyzed the effects of the mushy zone constant, pressure-velocity coupling and pressure discretization schemes on the thermal behavior of the melting process and quantitative agreement was obtained between the simulations and experiments. It was demonstrated that at the beginning of the process, heat transfer is governed by conduction from the tube wall to the solid phase through a relatively thin layer of already-molten liquid. As melting progresses, natural convection in the liquid dominates, changing the solid shape to conical and making it shrink from top to bottom (Fig. 23).

Wang et al. [51] developed a finite-volume model for analyzing inward (external heat source) and outward (internal heat source) melting with natural convection in vertical cylindrical enclosures. The model was verified through detailed comparison with previous experimental and numerical results. Although there is general agreement between the numerical predictions and the experimental measurements for inward melting, there exists a quantitative mismatch due to the effects of the heat loss through the top wall and the air pockets formed in the solid PCM. For outward melting, the simulated melting front locations and the Nusselt number agree quite well with previous predictions for the low Rayleigh number cases. As for the high Rayleigh number cases, the differences between the two findings are substantial. Based on the modeling results of outward melting around isothermal vertical cylinders, consistent correlations for the Nusselt number as well as total and latent energy storage, all as functions of Ste $F_{O} R a^{1 / 2}$ were derived. These correlations provide convenient tools for engineering design purposes.

\subsection{Horizontal cylindrical vessels}

A two-dimensional melting configuration of phase change materials in a horizontal tube or horizontal cylinder is similar to that encountered in spherical vessels where constrained or unconstrained melting are considered.

Nicholas and Bayaziloglu [52] developed a mathematical model to examine the effect of unequal densities (unconstrained melting) on the shape and location of the solid-liquid interface for a 
horizontal cylindrical enclosure that was heated by a constant heat flux. The numerical solutions were obtained by applying the implicit alternating direction method for the finite difference scheme. For small values of the Stefan number, closest agreement was obtained between analytical results and numerical ones. As the Stefan number increases, the deviation between two results became more pronounced. The results showed that the wall temperature increases at the top due to the presence of a thick melt layer causing prevalent convection heat transfer, while the minimum wall temperature was registered at the bottom where close-contact melting due to heat conduction was occurring.

Ho and Viskanta [53] studied experimentally and numerically the inward constrained melting of n-octadecane in a horizontal cylindrical capsule heated isothermally. The experimental results emphasized the dominated-natural convection effect in the melt during inward melting. In addition to this effect in the liquid, a secondary vortex circulation initiated at the bottom part of the melt region which significantly affects the melting pattern as well as the heat transfer characteristics on the heated tube wall. As the thickness of the melt layer grows, the intensity of this vortex motion tends to decrease and eventually merges with the major convective recirculating flow. The initial subcooling affects diversely on both the melting rate and the intensity of the natural convection recirculation. Reasonable agreement was achieved between numerical predictions and experimental findings.

Bareiss and Beer [54] introduced an analytical and experimental study of close-contact melting of phase change material (n-octaecane and p-xylene) in a horizontal, isothermal-wall tube. The solid-liquid interface shape, melting rate, and heat flux intensity were evaluated experimentally. The analytical solutions of the melting rate and heat transfer coefficient agreed very well with the experimentally-evaluated quantities. The results revealed that the Nusselt number is a maximum at the beginning and decreases monotonically to zero at the end of the melting process. This behavior is due to the decreasing contact-heat transfer-area of the molten solid bulk.

Sparrow and Geiger [55] studied experimentally and numerically melting of n-eicosane encapsulated in a horizontal tube. Two types of melting were involved, namely constrained (centered mode) and unconstrained (free or wall-adjacent mode). The results illustrated that the quantity of mass melted in the unconstrained mode exceed that of the constrained mode by about 50$100 \%$ depending on the operating conditions. In addition, numerical solutions showed that approximately $90 \%$ of melting in the wall-adjacent mode occurred at the lower portion of the solid where conduction dominated heat transfer. The experimental findings demonstrated that the melting 

2-D problem through neglecting the end effect.

Prasad and Sengupta [56] studied numerically the unconstrained melting of a PCM inside a horizontal tube subjected to a constant wall temperature. The model evaluated the irregular, temporal shape of the solid-liquid interface, the downward-motion of unmelt PCM due to density difference, and natural convection currents in the liquid phase. The effects of the Rayleigh, Stefan, and Prandtl numbers on the Nusselt number were also investigated within the range of interest in solar storage devices. The findings showed that the Nusselt number increases as the Rayleigh number increases. This is due to the fact that the higher Rayleigh number is associated with strong natural convection velocities resulting in higher heat transfer rates at the upper wall. The computed results explained that both the Stefan and Prandtl numbers has a significant influence on the melting rate. Conversely, the melting rate varies unimportantly with the Rayleigh number (controls the heat flux at the upper wall and the interfaces). Also, useful correlations for melt time and the Nusselt number were obtained.

Hirata and Nishida [57] presented an analytical and experimental investigation of constrained melting of n-octadecane inside an isothermally heated horizontal cylinder. The analysis utilized the equivalent thermal conductivity of the liquid phase which is estimated from the results for natural convection heat transfer between concentric cylinders (solid PCM phase and heated cylinder); therefore, the melting was analyzed as pure conduction problem. Analytical results showed a good agreement with experimental data for wide range of the Rayleigh numbers. Also, the influence of buoyancy-driven convection was insignificant when $R a<10^{5}$.

An experimental study of unfixed melting inside a horizontal tube subjected to an external forced convective heating condition is presented by Maldonado et al. [58]. The experiments were conducted for a wide range of the Stefan (0.026-0.053) and Archimedes numbers $\left(8.76 \times 10^{6}\right.$ $3.34 \times 10^{8}$ ). In about half the tests, the melt rate was indicated to be approximately identical to that for constant-wall heated capsule. Generally, the melt rate appeared to be highly affected by the dynamics of the melting process. The experimental findings revealed that in most cases, the melt rate during the initial stages of melting was significantly lower than expected. An analysis of experimental results suggested this was due to asymmetric melting during this period. Whereas, the two remaining tests registered higher melt rates than expected.

Park et al. [59] investigated numerically the constrained melting of phase change material inside a horizontal cylindrical capsule that is heated isothermally. They simulated the problem by 
utilizing the pseudo-compressibility method based on finite volume approach with the enthalpy formulation utilized in the energy equation. Initial disturbance was assumed for the sake of examining its effect on the solution for two values of the Rayleigh number. The results exposed that at $R a=1 \times 10^{6}$ natural convection flow pattern was unicellular in the symmetric half domain throughout the melting process for all the types of perturbations. In contrast, when the Rayleigh number was increased to $8 \times 10^{6}$, two branching solutions (bi-cellular and tri-cellular flow) were obtained according to the type of the initial disturbances, where secondary vortex circulation was shown at the lower part of the melt region due to thermal instabilities. Also, the results revealed that initial small perturbations of very minor difference can induce different melting patterns.

Saitho and Kato [60] studied experimentally and numerically the close-contact melting behavior accompanying with natural convection of n-octadecane in the melt liquid region inside horizontal cylindrical capsule subjected to either constant temperature-bath or constant wall temperature. The experimental results were compared with the numerical ones in which both heat transfer mechanisms are included. The experimental and numerical findings revealed that small Stefan number confirms that the close-contact melting is the dominant mode of heat transfer with $10-15 \%$ being the contribution of natural convection to the melting rate. As the Stefan number increases, the role of natural convection becomes significant.

Costa et al. [61] studied numerically the inherent three-dimensional behavior that takes place in the center-mode melting process inside a horizontal isothermal cylinder enclosure and how it affects the main design parameters. The numerical results have been compared with a twodimensional numerical prediction and with some experimental data. The differences encountered between the three- and two-dimensional simulations had been studied in two different cases of imposed wall temperatures and the corresponding Rayleigh and Stefan numbers. In case A $\left(R a=3.68 \times 10^{5}\right.$ and $\left.S t e=0.04\right)$ the component of the velocities in the axial direction is small in comparison with the other components. However, the flow pattern developed is completely different from that predicted by a two-dimensional simulation, and consequently, a different melting front is developed. Case B $\left(R a=1.22 \times 10^{6}\right.$ and Ste $\left.=0.133\right)$ exhibits a distinct three-dimensional flow pattern with a marked wavy shape of the melting front at the bottom in the axial direction. Although the computational results showed that the effect of the three-dimensionality on both the melted mass fraction and the overall Nusselt number seems to be unimportant (Fig. 24), the mean Nusselt number along the axis varies significantly according to the flow pattern. 
Chung et al. [62] analyzed numerically by using the enthalpy method the multi-cell structure and the thermal instability at the early stage of the inward melting process in a horizontal cylinder heated isothermally for a relatively wide range of the Rayleigh numbers. The results exhibited that at the low Rayleigh number, the flow in the liquid gap is in the stable state as the viscous force is dominant. For the intermediate Rayleigh number, the thermal buoyancy and viscous forces were balanced in a neutrally stable state. Thus, the flow is prone to transit to different patterns by infinitesimal experimental or numerical disturbances. At the high Rayleigh number, the Benard convection shows an orderly behavior without being affected by the base flow.

Kawanami et al. [63] performed an experimental study to evaluate the close-contact melting characteristics of slush ice (mixture of fine ice particles and ethylene glycol aqueous solution) in a horizontal cylindrical capsule which was heated by a constant heat flux. Initially, conduction heat transfer dominates and buoyancy force draws the slush ice to the top of the heated capsule where close-contact melting occurs. As time progresses, natural convection developed causing formation of a number of stratified layers in the melt. The results revealed that the local heat transfer coefficient is greatest at the top of the vessel and tends to decrease along the wall and this coefficient is proportional to the heat flux and the initial solution concentration. Also, the melting rate varied monotonically with the melting time, irrespective of the heat flux and initial solution concentration.

Hirose et al. [64] studied experimentally and numerically the combined natural convection heat transfer of water around tubes with the constrained melting of ice inside horizontal elliptical tubes. The numerical solution of the governing equations depended on the boundary fixing method to obtain the transient melting front contours and the body-fitted coordinate system to solve convection heat transfer around horizontal elliptical tubes. The results were presented in terms of the melting front contours of the phase change material, wall temperature distributions, isotherms, flow patterns and melting fraction. Also, good agreement of the melting fraction was achieved between analysis and experiment.

The constrained melting characteristics of paraffin wax encapsulated in a cylindrical capsule used in a latent heat solar thermal energy storage system were investigated numerically and experimentally by Regin et al. [65]. The melting occurred due to heat transfer isothermally from the surrounding hot water. The numerical analysis was performed by adopting the enthalpy method and the results were verified with the experimental findings. The results revealed that the Stefan number, Ste, phase change temperature range and the capsule radius were the main parameters that govern the melting process. Also, the agreement between analytical and experimental results was 

and the natural convection in the liquid phase instead of considering the process to be dominated by conduction only.

A summary of the studies focusing on melting of phase change materials contained within cylindrical vessels [46-65] are provided in Table 4. Specifically, cylindrical vessels' orientations, the imposed boundary conditions, PCM type, adopted methodologies/techniques, along with the highlights of the findings are summarized. The location of the heat source or boundary condition (BC), density variation of the two phases and existence of an anchor or thermocouples determine the melting mode (unfixed or fixed) inside vertical cylinders, whereas the BC does not determine the melting mode inside horizontal vessels which are heated peripherally. For both orientations, the operating conditions (Ste, $R a, S c$ and somewhat $P r$ ) and geometrical parameter (AR in vertical cylinder and radius in horizontal tube) have various effects on the melting rate and resulting charging time.

For melting inside vertical cylinders, the heat transfer mechanisms depend on both the location of heat source and time period of melting process. The close-contact heat transfer is responsible for the majority of unfixed melting where the heat source is applied at the bottom surface, while the small fraction of PCM is melted due to conduction heat transfer through the stable liquid phase at the side. On the other hand, the lateral location of the heat source insures fixed melting and both conduction and buoyancy-driven convection play successive roles at different times with associated effects on the characteristics of the melting process. Initially, viscous effect acts significantly and later, melting process will be under dominance of the buoyancy force. Also, in fixed melting, the temporal evolution of the solid-liquid interface and developed flow pattern generated from the simultaneous heating from the bottom, side and top walls are more complicated than those found for the melting resulting from heating at a single boundary.

Constrained and unconstrained melting is considered in the horizontal tubes like that observed in spherical capsules. Constrained melting emphasizes the dominant natural convection effect in the melt where circulating secondary vortices lead to formation of surface waviness on the bottom of the solid PCM, whereas conduction appears only during the initial period of melting. In contrast, close-contact heat transfer forms the important contribution in unconstrained melting with small fraction of melting resulted from the buoyancy effect. For the same operational and geometrical parameters, unconstrained melting exhibits higher melting rate than that associated with constrained melting. 


\section{Melting in annular cavities}

The applications of this type of containers are related to the shell and tube heat exchangers where the phase change material exists in the annular space. Melting of the PCM occurs when there is heat exchange between the PCM and the hot fluid/ambient. On the other hand, 2D analysis of melting process in vertically-oriented annular spaces is similar to that in rectangular and verticallyoriented cylindrical cavities.

Khillarkar et al. [66] presented a streamline Upwind/Petrov Galerkin finite element computational study of the free convection-dominated melting of a pure phase change material contained in the concentric horizontal annuli of the two configurations shown in Fig. 25. Simulations were carried out for melting of a pure phase change material (n-octadecane) in a cylindrical-horizontal annular space heated isothermally from inside, outside or both walls. For both horizontal annuli arrangements, it was observed that the effect of heating both walls is the same as heating the inside wall and the outside wall separately until there is interaction between the two melt zones. However, during the late stages melting appears to occur at a faster rate due to good mixing between the melt zones formed by heating both the inside and outside walls. This suppressed thermal stratification, which occurred in both configurations for heating from the inside wall. Effect of the Rayleigh number on the two flow patterns within the melt and the local heat transfer rate on the inner wall were also examined. High Rayleigh number results in an earlier onset of convection, expediting the melting process for both heating cases and higher degree of thermal stratification was shown for the case of inside wall heating.

Dutta et al. [67] studied experimentally (Fig. 26) and numerically heat transfer and phase change within a PCM (paraffin wax) encapsulated in the horizontal annulus of two coaxial circular cylinders with isothermal and adiabatic conditions on the inner and the outer cylinders, respectively. The two-dimensional unsteady Navier-Stokes and energy (enthalpy formulation) equations were solved using the finite volume method (FVM) using the SIMPLE scheme to track the temperature at different points and the moving solid-liquid interface numerically. The predicted results exhibited good agreement with the experimental findings. The computational results revealed that both the eccentricity and the variation in the angle of inclination of the eccentricity played an important role for the net circulation of the molten phase as well as the thermal flux on the inner surface of the annulus, where the maximum heat flux value increased monotonically both with angle of inclination 

(inclination angle $=0^{\circ}$ ) and decreases to a minimum value at the top point, that is almost at $180^{\circ}$. Furthermore, the maximum value of the heat flux was attained for the highest eccentricity of 0.5 for a fixed angle of inclination. Also, the results exhibited the enhancement in the convective heat transfer with the increase of the Rayleigh number.

Akgun et al. [68] performed an experimental investigation directed at studying melting and solidification characteristics of three different types of paraffin as phase change materials. A shellin-tube thermal energy storage unit was considered. The PCM was placed in a vertically-oriented annular space between a shell and a tube in which the heat transfer fluid (water) was flowing (Fig. 27). The results showed two regions coexisted during the charging process which are the melted liquid and the non-melted PCM region in the solid phase. Heat conduction is responsible for the heat transfer process inside the solid PCM and this region receives heat from the melted part by convection. It was observed that the PCM in the lower outer region of the annulus took much longer time than the other regions to melt. Therefore, the total melting time of the whole PCM was prolonged. In order to improve heat transfer during the melting and solidification, the surface of the shell (the outer surface of the PCM storage container) was inclined with an inclination angle of 5 degrees (Fig. 27). In addition, the effects of the Reynolds number of the heat exchange fluid in the tube and the Stefan number on the melting and solidification behavior were determined.

Sugawara et al. [69] investigated numerically freezing/melting of water/ice around a horizontal cylinder placed in a square cavity of the inner side length $H$ as shown in the Fig. 28a, where heat was rejected or supplied isothermally. The governing equations were solved numerically adopting a continuum model for phase change in porous media. The computed results indicated that the degree of subcooling affected melting considerably during the early phase of the process, however, its effect became gradually small with advancing time. In addition, melting decreased considerably with increasing the distance $h$ from the center of the cylinder to the bottom of the container, as shown in Fig. 28b.

Wei et al. [70] studied numerically the melting process of a phase change material held in the concentric horizontal annuli of a square external adiabatic shell with a circular tube inside that was heated isothermally. The simulation model adopted the enthalpy-porosity method and finite-volume numerical procedure to solve the simultaneous governing equations. The results exhibited that melting in the top part of shell is under convection-dominated mode and conduction-dominated mode takes place in the bottom of the shell. In effect, the top portion melted far faster than the 

and reduce the total melting time. The middle zone was dominated by both convection and conduction. Also, the melt fraction grows with time and the heat flux on the tube wall decreases sharply initially, then increases slowly and drops sharply after the solid PCM melts completely.

Darzi et al. [71] presented a numerical study of melting of PCM contained between two horizontally-oriented cylinders for concentric and eccentric arrangements to investigate the effect of the position of the inner cylindrical tube on phase change. The inner cylindrical tube was heated isothermally, while the outer tube was insulated. The governing partial differential equations were solved using the enthalpy-porosity method which utilizes the finite volume method to obtain the computational findings. Predicted results showed that heat conduction to the PCM is dominant at the beginning of melting for all zones through contact melting. After a few minutes, natural convection becomes dominant at the top half of the hot cylinder while heat conduction remains dominant in the bottom of the hot cylinder. Thus, melting rate in the top half became faster than the bottom half of the horizontal annulus. It is interesting to note that when the inner cylinder tube is moved downward, the melting rate increases sharply due to the dominance of natural convection heat transfer in most areas of PCM which reflects the effect of eccentricity.

Hosseini et al. [72] undertook an experimental (Fig. 30a) and numerical study to evaluate the role of buoyancy-driven convection during constrained melting of phase change material inside a shell and tube heat exchanger. The commercial paraffin RT50 (Rubitherm $\mathrm{GmbH}$ ) was used as a latent heat energy storage material that melted due to heat transfer from hot water in the tube. The computational investigation relied on an iterative, finite-volume numerical procedure that incorporated a single-domain enthalpy formulation for simulation of the phase change phenomenon. Experimental results showed that the sharp rise in temperatures takes place at the uppermost section of the store because of the buoyancy effects. The computational results indicated the strong thermal stratification of the molten liquid in the upper half of the heat exchanger (Fig. 30b). Also, upon increasing the inlet temperature of water, the total melting time was decreased.

Outline of studies [66-72] associated with melting inside annular cavities are listed in Table 5 with relevant details on the melting type (constrained and unconstrained), the imposed boundary conditions, PCM type, adopted methodologies/techniques along with the highlights of the reported findings. Two melting configurations are presented in the above literature. The first is due to heating from the inside tube that causes the melt front to progress outward away from the tube toward the shell. High degree of thermal stratification and low melting rate are associated with this 


\section{Conclusions}

Melting of phase change materials and the ensuing natural convection within containers of different shapes is reviewed. In the absence of the close-contact melting effect, it is noticed in all containers that there are two heat transfer mechanisms that control the melting process, namely heat conduction and natural convection. Heat conduction plays a significant role during the early stage accompanied with high heat transfer rate, temperature contours fully orthogonal to the applied temperature gradient and the solid-liquid interface, high Nusselt numbers and temperature gradient, and significant melting rate. As time progressed, the volume of the melted liquid layer increases and convection-dominated melting will develop causing curvature of the melting interface and the isotherms, lowering of the heat transfer rate, and decrease in melting rate or increase of charging time. Buoyancy-driven flow depends on the thermophysical properties of the PCM, heat supplied or operating condition $(R a, S t e)$ and the geometry configuration of the enclosure. Thus, the shape and extent of the enclosure containing the PCM have an important effect on the dynamic behavior of the melting process and on the temperature of the cooled wall. The location of heat source and density difference between the solid and liquid phases determines the melting mode (constrained (fixed) or unconstrained (close-contact)). Close-contact melting where the solid PCM is continuously touching the container wall is accompanied with high heat transfer rate and leads to high melting rate. Also, geometrical orientations and parameters have a great influence on the heat transfer mechanismsmelting characteristics such as the aspect ratio in rectangular containers and vertical cylindrical vessels, radius in spherical capsules and eccentricity in annular cavities. Furthermore, to improve the melting rate, research should concentrate on upgrading the effective thermal conductivity of 
phase change materials through using thermal conductivity enhancers such as fixed promoters such as fins or using dispersions of high-conductivity nanostructures in the phase change materials.

\section{Acknowledgement}

The first author (NSD), at that time a Ph.D.-candidate in Mechanical Engineering at the Baghdad University, acknowledges the support of the Ministry of Higher Education and Scientific Research (MOHESR) in Iraq through availability of a short-term scholarship to conduct research at Auburn University. He also acknowledges the Mechanical Engineering Department of the Samuel Ginn College of Engineering at Auburn University for providing laboratory space, machine shop support and assistance during his stay.

The second author acknowledges support by the US Department of Energy under Award Number DE-SC0002470 (http://www.eng.auburn.edu/nepcm). This report was prepared as an account of work sponsored by an agency of the United States Government. Neither the United States Government nor any agency thereof, nor any of their employees, makes any warranty, express or implied, or assumes any legal liability or responsibility for the accuracy, completeness, or usefulness of any information, apparatus, product, or process disclosed, or represents that its use would not infringe privately owned rights. References herein to any specific commercial product, process, or service by trade name, trademark, manufacturer, or otherwise do not necessarily constitute or imply its endorsement, recommendation, or favoring by the United States Government or any agency thereof. The views and opinions of authors expressed herein do not necessarily state or reflect those of the United States Government or any agency thereof.

\section{References}

[1] Abhat A. Low temperature latent heat thermal energy storage-heat storage Materials. Sol Energy 1983; 30: 313-32.

[2] Kamimoto M. Thermal energy storage technology, Int J Sol Energy 1987; 5: 21-33.

[3] Hasnain SM. Review on sustainable thermal energy storage technologies, Part I: Heat storage materials and techniques. Energy Convers Manage 1998; 39: 1127-38.

[4] Zalba B, Marin JM, Cabeza LF, Mehling H. Review on thermal energy storage with phase change: materials, heat transfer analysis and applications. Appl Therm Eng 2003; 23: 251-83. 
[5] Farid MM, Khudhair AM, Razack SAK, Al-Hallaj S. A review on phase change energy storage: materials and applications. Energy Convers Manage 2004; 45: 1597-615.

[6] Sharma SD, Sagara K. Latent heat storage materials and systems: a review. Int J Green Energy 2005; 2: 1-56.

[7] Kenisarin M, Mahkamov K. Solar energy storage using phase change materials. Renew Sust Energy Rev 2007; 11: 1913-65.

[8] Regin AF, Solanki SC, Saini JS. Heat transfer characteristics of thermal energy storage system using PCM capsules: a review. Renew Sust Energy Rev 2008; 12: 2438-58.

[9] Agyenim F, Hewitt N, Eames P, Smyth M. A review of materials, heat transfer and phase change problem formulation for latent heat thermal energy storage systems (LHTESS). Renew Sust Energy Rev 2010; 14: 615-28.

[10] Fan L, Khodadadi JM. Thermal conductivity enhancement of phase change materials for thermal energy storage: a review. Renew Sust Energy Rev 2011; 15: 24-46.

[11] Zhang Y, Chen Z, Wang Q, Wu Q. Melting in an enclosure with discrete heating at a constant rate. Exp Fluid Therm Sci 1993; 6: 196-201.

[12] Ho CJ, Chu CH. Numerical simulation of heat penetration through a vertical rectangular phase change material/air composite cell. Int J Heat Mass Transfer 1996; 39: 1785-95.

[13] Jianhua Z, Zhongqi C, Dengying L, Ji L. Experimental study on melting in a rectangular enclosure heated below with discrete heat sources. Int J Therm Sci 2001; 10: 254-9.

[14] Mbaye M, Bilgen E. Phase change process by natural convection-diffusion in rectangular enclosures. Int J Heat Mass Transfer 2001; 37: 35-42.

[15] Pal D, Joshi YK. Melting in a side heated tall enclosure by a uniformly dissipating heat source. Int J Heat Mass Transfer 2001; 44: 375-87.

[16] Hamdan MA, Al-Hinti I. Analysis of heat transfer during the melting of a phase-change material. App Therm Eng 2004; 24: 1935-44.

[17] Faraji M, El Qarnia H. Numerical study of melting in an enclosure with discrete protruding heat sources. App Math Model 2010; 34: 1258-75.

[18] El Qarnia H, Draoui A, Lakhal EK. Computation of melting with natural convection inside a rectangular enclosure heated by discrete protruding heat sources. App Math Model 2013; 37: 3968-81. 
[19] Samara F, Groulx D, Biwole PH. Natural convection driven melting of phase change material: comparison of two methods. Excerpt from the proceeding of the COMSOL conference, 2012, Boston, USA.

[20] Brent AD, Voller VR, Reid KJ. Enthalpy-porosity technique for modeling convection-diffusion phase change: application to the melting of a pure metal. Numer Heat Transfer 1988; 13: 297318.

[21] Beckermann C, Viskanta R. Effect of solid subcooling on natural convection melting of a pure metal. ASME J Heat Transfer 1989; 111: 416-24.

[22] Asako Y, Faghri M, Charmchi M, Bahrami PA. Numerical solution for melting of unfixed rectangular phase-change material under low-gravity environment. Numer Heat Transfer, Part A 1994; 25: 191-208.

[23] Wang S, Faghri A, Bergman TL. An experimental investigation of the melting process in a rectangular enclosure. Int J Heat Mass Transfer 1999; 42: 3659-72.

[24] Gong ZX, Devahastin S, Mujumdar AS. Enhanced heat transfer in free convection-dominated melting in a rectangular cavity with an isothermal vertical wall. App Therm Eng 1999; 19: 1237-51.

[25] Ghasemi B, Molki M. Melting of unfixed solids in square cavities. Int J Heat Fluid Flow 1999; 20: $446-52$.

[26] Zivkovic B., Fujii I. An analysis of isothermal phase change materials within rectangular and cylindrical containers. Sol Energy 2001; 70: 51-61.

[27] Lacroix M. Contact melting of a phase change material inside a heated parallelepedic capsule. Energy Convers Manage 2001; 42: 35-47.

[28] Jiji LM, Gaye S. Analysis of solidification and melting of PCM with energy generation. Appl Therm Eng 2006; 26: 568-75

[29] Yanxia D, Yanping Y, Daiyong J, Baoyi C, Jinfeng M. Experimental investigation on melting characteristics of ethanolamine-water binary mixture used as PCM. Int Commun Heat Mass 2007; 34: 1056-1063.

[30] Jellouli Y, Chouikh R, Guizani A, Belghith A. Numerical study of the moving boundary problem during melting process in a rectangular cavity heated from below. Am J Appl Sci 2007; 4: $251-6$.

[31] Chen CR, Sharma A, Tyagi SK, Buddhi D. Numerical heat transfer studies of PCMs used in a box-type solar cooker. Renew Energy 2008; 33: 1121-9. 
[32] Younsi Z, Joulin A, Zalewski L, Lassue S, Rousse DR. Phase change materials: a numerical method for the behavior predictions. Proceedings of the Fourth International Conference on Thermal Engineering: Theory and Applications, January 2009, Abu Dhabi, UAE.

[33] Wang S, Faghri A, Bergman TL. A comprehensive numerical model for melting with natural convection. Int J Heat Mass Transfer 2010; 53: 1986-2000.

[34] Joulin A, Younsi Z, Zalewski L, Lassue S, Rousse DR, Cavrot JP. Experimental and numerical investigation of a phase change material: Thermal-energy storage and release. Appl Energy 2011; 88: 2454-62.

[35] Murray RE, Groulx D. Modeling convection during melting of a phase change material. Abstract from the proceedings of the COMSOL conference, 2011, Boston, USA.

[36] Saitoh TS, Hoshi A. Analysis of close-contact melting with inner wall temperature variation in a horizontal cylindrical capsule. IEEE Energy Conversion Engineering Conference 4(1997). IECEC-97, Proceedings of the 32nd Intersociety: 1641-45.

[37] Saitoh TS, Hoshi A. Experimental investigation on combined close-contact and natural convection in horizontal cylindrical and spherical capsules. IEEE Energy Conversion Engineering Conference 3(1996), IECEC-96, Proceedings of the 31st Intersociety: 2090-4.

[38] Fomin SA, Saitoh TS. Melting inside a spherical capsule with nonisothermal wall. Int J Heat Mass Transfer 1999; 42: 4197-205.

[39] Khodadadi JM, Zhang Y. Effects of buoyancy-driven convection on melting within spherical containers. Int J Heat Mass Transfer 2001; 44: 1605-18.

[40] Assis E, Katsman L, Ziskind G, Letan R. Numerical and experimental study of melting in a spherical shell. Int J Heat Mass Transfer 2007; 50: 1790-804.

[41] Tan FL. Constrained and unconstrained melting inside a sphere. Int Commun Heat Mass Transfer 2008; 35: 466-75.

[42] Tan FL, Hosseinizadeh SF, Khodadadi JM, Fan L. Experimental and computational study of constrained melting of phase change materials (PCM) inside a spherical capsule. Int J Heat Mass Transfer 2009; 52: 3464-72.

[43] Veerappan M, Kalaiselvam S, Iniyan S, Goic R. Phase change characteristic study of spherical PCMs in solar energy storage. Sol Energy 2009; 83: 1245-52.

[44] Hosseinizadeh SF, Darzi AR, Tan FL, Khodadadi JM. Unconstrained melting inside a sphere. Int J Therm Sci 2013; 63: 55-64. 
[45] Rizan MM, Tan FL, Tso CP. An experimental study of n-octadecane melting inside a sphere subjected to constant heat rate at surface. Int Commun Heat Mass Transfer 2012; 39: 1624-30.

[46] Sparrow EM, Broadbent JA. Inward melting in a vertical tube which allows free expansion of the phase-change medium. ASME J Heat Transfer 1982; 104: 309-15.

[47] Wenzhen C, Shangmo C, Zhen L, Wangmin G. Study of contact melting inside isothermally heated vertical cylindrical capsules. J Therm Sci 1993; 2: 190-5.

[48] Wu Y, M. Lacroix, Melting of a PCM inside a vertical cylindrical capsule. Int J Numer Meth Fluids 1995; 20: 559-72.

[49] Jones BJ, Sun D, Krishnan S, Garimella SV. Experimental and numerical study of melting in a cylinder. Int J Heat Mass Transfer 2006; 49: 2724-38.

[50] Shmueli H, Ziskind G, Letan R. Melting in a vertical cylindrical tube: Numerical investigation and comparison with experiments. Int J Heat Mass Transfer 2010; 53: 4082-91.

[51] Wang Y, Amiri A, Vafai K. Melting in Cylindrical Enclosures: Numerical Modeling and Heat Transfer Correlations. Numer Heat Transfer, Part A-Applications 2012; 61: 837-59.

[52] Nicholas D, Bayazitoglu Y. Heat transfer and melting front within a horizontal cylinder. ASME J Sol Energy 1980; 102: 229-32.

[53] Ho CJ, Viskanta R. Heat transfer during inward melting in a horizontal tube. Int J Heat Mass Transfer 1984; 27(5): 705-16.

[54] Bareiss M, Beer H. An analytical solution of the heat transfer process during melting of an unfixed solid phase change material inside a horizontal tube. Int J Heat Mass Transfer 1984; 27(5): 739-46.

[55] Sparrow EM, Geiger GT. Melting in a horizontal tube with the solid either constrained or free to fall under gravity. Int J Heat Mass Transfer 1986; 29(7): 1007-16.

[56] Prasad A, Sengupta S. Nusselt number and melt time correlations for melting inside a horizontal cylinder subjected to an isothermal wall temperature condition. ASME J Heat Transfer 1988; 110: $340-5$.

[57] Hirata T, Nishida K. An analysis of heat transfer using equivalent thermal conductivity of liquid phase during melting inside an isothermally heated horizontal cylinder. Int J Heat Mass Transfer 1989; 32(9): 1663-70.

[58] Maldonado JJ, Sengupta S, Roy SK. Gravity-assisted melting in horizontal cylinder heated by external forced convection. Int Commun Heat Mass Transfer 1990; 17: 637-45. 
[59] Park CE, Kim SS, Chang KS. Branching solutions to inward melting problem in a horizontal tube. Int Commun Heat Mass Transfer 1991; 18: 343-50.

[60] Saitoh T, Kato K. Experiments on melting in heat storage capsule with close contact and natural convection. Exp Therm Fluid Sci 1993; 6: 273-81.

[61] Costa M, Oliva A, Pérez-Segarra CD. Three-Dimensional numerical study of melting inside an isothermal horizontal cylinder, Numer Heat Transfer, Part A-Applications 1997; 32: 531-53.

[62] Chung JD, Lee JS, Yoo H. Thermal instability during the melting process in an isothermally heated horizontal cylinder. Int J Heat Mass Transfer 1997; 40(16): 3899-907.

[63] Kawanami T, Fukusako S, Yamada M, Itoh K. Experimental on melting of slush ice in a horizontal cylindrical capsule. Int J Heat Mass Transfer 1999; 42: 2981-90.

[64] Hirose K, Yoshii T, Watanabe H. Melting heat transfer of phase change material in elliptical tubes immersed in working fluid. Nippon Dennetsu Shinpojiumu Koen Ronbunshu 2003; 40(3): 671-2.

[65] Regin AF, Solanki SC, Saini JS. Latent heat thermal energy storage using cylindrical capsule: numerical and experimental investigations. Renew Energy 2006; 31: 2025-41.

[66] Khillarkar DB, Gong ZX, Mujumdar AS. Melting of a phase change material in concentric horizontal annuli of arbitrary cross-section. Appl Therm Eng 2000; 20: 893-912.

[67] Dutta R, Atta A, Dutta TK. Experimental and numerical study of heat transfer in horizontal concentric annulus containing phase change material. Can J Chem Eng 2008; 86: 700-10.

[68] Akgun M, Aydin O, Kaygusuz K. Thermal energy storage performance of paraffin in a novel tube-in-shell system. Appl Therm Eng 2008; 28: 405-13.

[69] Sugawara M, Komatsu Y, Beer H. Melting and freezing around a horizontal cylinder placed in a square cavity. Int J Heat Mass Transfer 2008; 45: 83-92.

[70] Wei L, Xinguo L, Jun Z. Numerical study of melting in a square annulus. IEEE, International conference on Mechanic Automation and Control Engineering (MACE), 2010.

[71] Darzi AR, Farhadi M, Sedighi K. Numerical study of melting inside concentric and eccentric horizontal annulus. Appl Math Model 2012; 36: 4080-6.

[72] Hosseini MJ, Ranjbar AA, Sedighi K, Rahimi M. A combined experimental and computational study on the melting behavior of a medium temperature phase change storage material inside shell and tube heat exchanger. Int Commun Heat Mass Transfer 2012; 39: 1416-24. 


\section{List of Tables}

Table 1. Effects of the Rayleigh number on energy charge rate (Gong et al. [24]).

Table 2. Summary of studies on PCM melting inside rectangular containers.

Table 3. Outline of studies on PCM melting inside spherical containers.

Table 4. Summary of studies on PCM melting inside cylindrical containers.

Table 5. Outline of studies on PCM melting inside annular cavities. 
Table 1. Effects of the Rayleigh number on energy charge rate (Gong et al. [24]).

\begin{tabular}{cccccc}
\hline \multirow{2}{*}{$\boldsymbol{R} \boldsymbol{a}$} & \multicolumn{2}{c}{ First period } & \multicolumn{3}{c}{ Second period, $\left(\Delta Q / Q_{M}\right) / \Delta F o$} \\
\cline { 2 - 6 } & $\Delta Q / Q_{M}$ & $F o$ & No inverting & Inverting & Enhancement \\
$7.11 \times 10^{5}$ & 0.582 & 0.302 & 0.687 & 1.047 & $52.4 \%$ \\
$2.844 \times 10^{6}$ & 0.532 & 0.467 & 0.961 & 1.504 & $56.5 \%$ \\
$5.688 \times 10^{6}$ & 0.515 & 0.251 & 1.099 & 1.766 & $60.1 \%$
\end{tabular}

$Q_{M}=$ the maximum amount of energy which can be charged during the melting process. 
Table 2. Summary of studies on PCM melting inside rectangular containers.

\begin{tabular}{|c|c|c|c|c|c|}
\hline \multirow{4}{*}{$\begin{array}{l}\text { Container } \\
\text { Shape }\end{array}$} & \multicolumn{5}{|c|}{ Constant Heat Flux (CHF) Boundary Condition (BC) } \\
\hline & Authors (Year) & Location of BC & PCM & Type of Study & Highlighted Results/Findings \\
\hline & $\begin{array}{l}\text { Zhang et al. [11] } \\
\text { (1993) }\end{array}$ & $\begin{array}{l}\text { Vertical side (discrete } \\
\text { heaters) }\end{array}$ & Octadecane & $\begin{array}{l}\text { E (TCs, } 3 \text { heaters, } \\
\text { camera, etc.) }\end{array}$ & $\begin{array}{l}\text { Interface is highly affected by NC especially } \\
\text { at higher Ste and lower } S c \text {. } \\
\text { Electronic cooling by PCM is more effective } \\
\text { than that by forced air flow. } \\
\text { The highest surface temperature was recorded } \\
\text { at the uppermost heat source. }\end{array}$ \\
\hline & $\begin{array}{l}\text { Ho and Chu [12] } \\
\text { (1996) }\end{array}$ & $\begin{array}{l}\text { Vertical side } \\
\text { (PCM/Air composite) }\end{array}$ & Octadecane & $\mathrm{C}(\mathrm{FDM})$ & $\begin{array}{l}\text { Effective thermal protection duration was } \\
\text { found to be a strong function of } R a \text {, Ste, } S c \text {, } \\
\text { PCM thickness, and } A R \text {. } \\
\text { Shallow geometry is preferable for thermal } \\
\text { protection. }\end{array}$ \\
\hline Rectangular & $\begin{array}{l}\text { Jianhua et al. [13] } \\
\text { (2000) }\end{array}$ & $\begin{array}{l}\text { Bottom side (discrete } \\
\text { heaters) }\end{array}$ & Octadecane & $\begin{array}{l}\text { E (TCs, } 3 \text { heaters, } \\
\text { camera, etc.) }\end{array}$ & $\begin{array}{l}\text { Fixed melting (solid between heaters) and } \\
\text { contact melting (solid above heaters) occurred } \\
\text { simultaneously. } \\
\text { Higher Ste and smaller } A R \text { have a positive } \\
\text { effect on melting, while } S c \text { is only important } \\
\text { during early stages. }\end{array}$ \\
\hline \multirow{4}{*}{ PCM } & $\begin{array}{l}\text { Mbaye and Bilgen } \\
\text { [14] (2001) }\end{array}$ & $\begin{array}{l}\text { One side at } \mathrm{CHF} \text { and } \\
\text { the other at } \mathrm{CWT}\end{array}$ & Gallium & $\begin{array}{l}\mathrm{C}(\mathrm{EPM} \text { with CVA- } \\
\text { based FDM) }\end{array}$ & $\begin{array}{l}\text { Melted volume is independent for } A R \text { at } \mathrm{CON} \\
\text { regime, but it becomes a decreasing function } \\
\text { of } A R \text { as } \mathrm{NC} \text { in the liquid develops. } \\
\text { Applied heat flux is an important parameter, } \\
\text { and optimum } A R \text { is unity. }\end{array}$ \\
\hline & $\begin{array}{l}\text { Pal and Joshi [15] } \\
\text { (2001) }\end{array}$ & Vertical side & Triacontane & $\begin{array}{l}\text { E (TCs, heater, camera, } \\
\text { etc.) and C (EPM with } \\
\text { CVA) }\end{array}$ & $\begin{array}{l}\text { Comparisons between experimental and } \\
\text { computational heat transfer data and melt } \\
\text { interface locations were good. } \\
\text { For tall enclosures, NC plays an important role } \\
\text { in the beginning and then diminishes as } \\
\text { melting is completed. }\end{array}$ \\
\hline & $\begin{array}{l}\text { Hamdan and Al- } \\
\text { Hinti [16] (2004) }\end{array}$ & Vertical side & Octadecane & $\begin{array}{l}\text { A (Interface is smooth } \\
\text { and planar) }\end{array}$ & $\begin{array}{l}\text { During the initial stages, the model predicted } \\
\text { the propagation of the interface very well, but } \\
\text { later the interface was under-predicted. } \\
\text { The analysis model can be used with good } \\
\text { accuracy for investigating melting of PCM. }\end{array}$ \\
\hline & $\begin{array}{l}\text { Faraji and El } \\
\text { Qarnia [17] } \\
(2010)\end{array}$ & $\begin{array}{l}\text { Vertical side ( } 3 \\
\text { discrete heaters) }\end{array}$ & Eicosane & C (EPM with CVA) & $\begin{array}{l}\text { Heat flux transmitted to interface and resulting } \\
\text { melting rate decreased with time. } \\
\text { Lower heater transmits high rate of heat }\end{array}$ \\
\hline
\end{tabular}




\section{Constant Wall Temperature (CWT) Boundary Condition (BC)}

Brent et al. [20] Two vertical sides are Gallium C (EPM with CVA-

(1988) based FDM)

$\begin{array}{llll}\begin{array}{l}\text { Beckermann and } \\ \begin{array}{l}\text { Viskanta [21] } \\ \text { (1989) }\end{array}\end{array} & \begin{array}{l}\text { Two vertical sides are } \\ \text { at two different } T_{w}\end{array} & \text { Gallium } & \begin{array}{l}\text { E (TCs, two constant- } \\ \text { temperature baths, etc.) } \\ \text { and C (CVA) }\end{array} \\ \begin{array}{l}\text { Asako et al. [22] } \\ (1994)\end{array} & \begin{array}{l}\text { Bottom side } \\ \text { (unfixed solid) in } \\ \text { low- } g \text { environment }\end{array} & \begin{array}{l}\text { Depending on } \\ \text { the } P r\end{array} & \begin{array}{l}\text { C (EPM with CVA- } \\ \text { based FDM) }\end{array} \\ \end{array}$

Excellent agreement between the numerical predictions and experimental findings available in literature.

Capability of EPM for predicting accurately position/morphology of the melting interface. Classified melting process to 4 regimes according heat transfer mechanisms. High $S c$ reduces the melting rate.

Melting rate increases with the Archimedes and Ste numbers and it is very slow in low- $g$ environment.

Melt thickness increases with time and decreases with increasing Archemides, Ste, and $P r$ numbers, while the effect of AR on the melt thickness was small.

$\begin{array}{llll}\begin{array}{l}\text { Wang et al. [23] } \\ (1999)\end{array} & \begin{array}{l}\text { Two vertical sides are } \\ \text { at two different } T_{w}\end{array} & \text { Hydrated salt } & \begin{array}{l}\text { E (TCs, constant-temp. } \\ \text { heat exchanger, etc.) }\end{array} \\ \begin{array}{l}\text { Gong et al. [24] } \\ (1999)\end{array} & \text { Vertical side } & \text { Octadecane } & \text { C (EPM with FEM) }\end{array}$

Good agreement between correlated melted volume fraction and $\mathrm{Nu}$ with the experimental data.

Transient $\mathrm{Nu}$ distinguishes 3 regimes during the melting which are (CON-dominated, transition, and NC-dominated).

The first melting period is characterized with low thermal stratification effect and high rate of NC and melting. As time progressed, the second period will appear with significant thermal stratification and low rate of $\mathrm{NC}$ and melting rate.

Inverting the container in the second melting stage for augmenting the effect of NC and 


$\begin{array}{llll}\begin{array}{l}\text { Ghasemi and } \\ \text { Molki [25] (1999) }\end{array} & \begin{array}{l}\text { All sides } \\ \text { (unfixed solid) }\end{array} & \begin{array}{l}\text { Depending on } \\ \text { the } P r\end{array} & \begin{array}{l}\text { C (EPM with CVA } \\ \text { based FDM) }\end{array} \\ & & & \\ \begin{array}{l}\text { Zivkovic and Fujii } \\ \text { [26] (2001) }\end{array} & \text { Vertical side } & \begin{array}{l}\text { Calcium } \\ \text { chloride } \\ \text { hexahydrate }\end{array} & \begin{array}{l}\text { E (TCs, constant-temp. } \\ \text { bath, etc.) and C (1-D } \\ \text { CVA based FDM) }\end{array}\end{array}$

increasing the melting rate.

Low melting rate, small solid falling velocity and symmetric melting pattern are associated with low values of $R a$ and Archimedes numbers, whereas, higher values of these numbers result in enhancing melting rate, increasing solid falling velocity and asymmetric melting pattern.

CON within the PCM in the direction of HTF flow, thermal resistance of the container's wall, and the effects of $\mathrm{NC}$ within the melt can be ignored for the study conditions.

Rectangular container required nearly $1 / 2$ the melting time compared to the cylindrical one of the same volume and heat transfer area.

\begin{tabular}{|c|c|c|c|c|}
\hline $\begin{array}{l}\text { Lacroix [27] } \\
(2001)\end{array}$ & $\begin{array}{l}\text { Upper and lower } \\
\text { (contact melting) } \\
\text { sides }\end{array}$ & Octadecane & $\begin{array}{l}\text { A (neglecting the effect } \\
\text { of NC) }\end{array}$ & $\begin{array}{l}\text { Bottom melting fraction was greater by one } \\
\text { order of magnitude of that near the top. } \\
\text { Ste had a positive significant impact on the } \\
\text { melting process, whereas the total melting } \\
\text { time increased linearly with the degree of } S c \text {. }\end{array}$ \\
\hline $\begin{array}{l}\text { Jiji and Gaye [28] } \\
(2006)\end{array}$ & $\begin{array}{l}\text { Vertical side with } \\
\text { volumetric heat } \\
\text { generation }\end{array}$ & Ice & $\begin{array}{l}\text { A (1-D quasi steady state } \\
\text { approximation) }\end{array}$ & $\begin{array}{l}\text { The model simplifies phase change problems } \\
\text { and often eliminates the need for numerical } \\
\text { solutions. }\end{array}$ \\
\hline $\begin{array}{l}\text { Yanxia et al. [29] } \\
(2007)\end{array}$ & Vertical side & $\begin{array}{l}\text { Ethanolamine-- } \\
\text { water binary } \\
\text { mixture }\end{array}$ & $\begin{array}{l}\text { E (TCs, constant-temp. } \\
\text { tank, etc.) }\end{array}$ & $\begin{array}{l}\text { NC enhanced the melting process compared } \\
\text { with the conduction-only cases. } \\
\text { Pure CON only occurs at the initial stage of } \\
\text { melting stage and CON-NC coupled model is } \\
\text { necessary for predicting melting process } \\
\text { exactly. }\end{array}$ \\
\hline $\begin{array}{l}\text { Jellouli et al. [30] } \\
\text { (2007) }\end{array}$ & $\begin{array}{l}\text { Hot bottom wall } \\
\text { (contact melting) and } \\
\text { cold top one }\end{array}$ & $\begin{array}{l}\text { PCM with } \\
\operatorname{Pr}=54\end{array}$ & $\mathrm{C}(\mathrm{CVA})$ & $\begin{array}{l}\text { Initially, buoyancy forces cannot overcome } \\
\text { the resistance imposed by viscous forces. } \\
\text { As thickness of the melt layer increased with } \\
\text { time, NC dominated in the liquid phase and } \\
\text { the melting front reached a steady position. }\end{array}$ \\
\hline $\begin{array}{l}\text { Chen et al. [31] } \\
\text { (2008) }\end{array}$ & Vertical side & $\begin{array}{l}\text { Magnesium } \\
\text { nitrate } \\
\text { hexahydrate, } \\
\text { stearic acid, } \\
\text { acetamide, } \\
\text { acetanilide and } \\
\text { erythritol } \\
\text { hydrated salt }\end{array}$ & $\mathrm{C}(\mathrm{FDM})$ & $\begin{array}{l}\text { Thermal conductivity of the PCM and the } \\
\text { container has a significant effect on the melt } \\
\text { fraction, while the thickness of the container } \\
\text { and } S c \text { has a little effect. } \\
T_{w} \text { has a strong impact on the observed melt } \\
\text { fraction. }\end{array}$ \\
\hline
\end{tabular}


A, C and E stand for analytical, computational and experimental, respectively.

AR

aspect ratio

$\mathrm{CON}$

conduction

CVA control volume approach

EPM enthalpy-porosity method

FDM finite difference method

FEM finite element method

FVM finite volume method

HTF heat transfer fluid

NC natural convection 


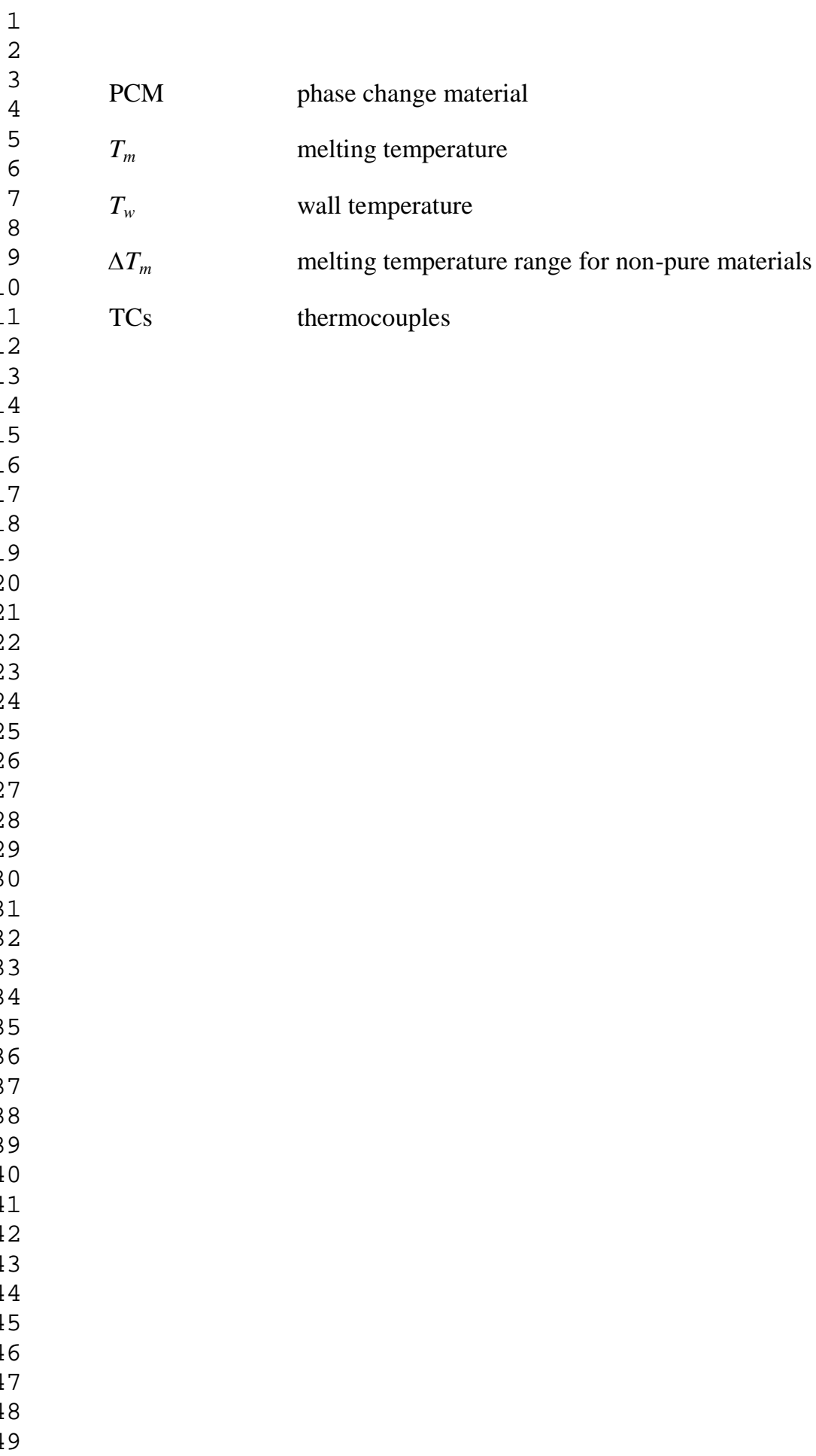


Table 3. Outline of studies on PCM melting inside spherical containers.

\begin{tabular}{|c|c|c|c|c|c|}
\hline \multirow{2}{*}{$\begin{array}{l}\text { Container } \\
\text { Shape }\end{array}$} & \multicolumn{5}{|c|}{ Constrained Melting } \\
\hline & Authors (Year) & $\overline{B C}$ & PCM & Type of Study & Highlighted Results \\
\hline \multirow[t]{7}{*}{ Spherical } & $\begin{array}{l}\text { Khodadadi and } \\
\text { Zhang [39] (2001) }\end{array}$ & CWT & Beeswax & $\begin{array}{l}\mathrm{C}(\mathrm{EPM} \text { with FVM) and } \\
\mathrm{E} \text { (water bath, camera, } \\
\text { etc.) }\end{array}$ & $\begin{array}{l}\text { Melting in the top region of the sphere is much } \\
\text { faster than in the bottom region. } \\
\text { Strength of NC is clearly dependent on the } R a \\
\text { when compared to the Ste. } \\
\text { Pr plays an important role in the melting process. }\end{array}$ \\
\hline & $\begin{array}{l}\text { Tan et al. [42] } \\
\text { (2009) }\end{array}$ & CWT & Octadecane & $\begin{array}{l}\text { E (TCs, water bath, } \\
\text { camera, etc.) and C } \\
\text { (EPM with CVM) }\end{array}$ & $\begin{array}{l}\text { Initially, CON and symmetric melting is shown; } \\
\text { later on, melting at top much faster than bottom } \\
\text { due to development of NC. } \\
\text { Waviness of bottom surface of the PCM, chaotic } \\
\text { fluctuations and high discrepancy between } \\
\text { experimental and numerical temperatures are } \\
\text { observed due to unstable fluid layer, while no } \\
\text { waviness, less fluctuations and low discrepancy are } \\
\text { recorded in the top stable fluid layer. }\end{array}$ \\
\hline & $\begin{array}{l}\text { Veerappan et al. } \\
\text { [43] (2009) }\end{array}$ & CWT & $\begin{array}{l}65 \mathrm{~mol} \% \text { capric acid and } \\
35 \mathrm{~mol} \% \text { lauric acid, } \\
\text { calcium chloride } \\
\text { hexahydrate, octadecane, } \\
\text { hexadecane and eicosane }\end{array}$ & $\begin{array}{l}\text { A (conduction model } \\
\text { combined with an } \\
\text { empirical thermal } \\
\text { conductivity of the liquid } \\
\text { including NC) }\end{array}$ & $\begin{array}{l}\text { The analytical results deviated against the previous } \\
\text { experimental results by } 15 \% \text { for solidification and } \\
20 \% \text { for melting. } \\
\text { The pure-conduction model overpredicts the } \\
\text { complete melting time. } \\
\text { The } 65 \mathrm{~mol} \% \text { capric acid with } 35 \mathrm{~mol} \% \text { lauric acid } \\
\text { and calcium chloride hexahydrate were better } \\
\text { options for melting and solidification, respectively. }\end{array}$ \\
\hline & \multicolumn{5}{|c|}{ Unconstrained Melting } \\
\hline & $\begin{array}{l}\text { Saitoh and Hoshi } \\
\text { [36] (1997) }\end{array}$ & $\begin{array}{l}\text { Variable } \\
T_{w}\end{array}$ & Octadecane & $\begin{array}{l}\text { A (neglecting } \mathrm{NC} \text { in the } \\
\text { upper region) }\end{array}$ & $\begin{array}{l}\text { Excellent agreement between the analytical results } \\
\text { and numerical solutions for molten mass fraction } \\
\text { and melt layer thickness } \\
\text { The progress of melting is faster than that of } \\
\text { constant } T_{w} \text { case. }\end{array}$ \\
\hline & $\begin{array}{l}\text { Saitoh and Hoshi } \\
\text { [37] (1996) }\end{array}$ & $\begin{array}{l}\text { Variable } \\
T_{w}\end{array}$ & Octadecane & $\begin{array}{l}\text { E (TCs, oil bath, camera, } \\
\text { etc.) }\end{array}$ & $\begin{array}{l}\text { Ste has a significant effect on the molten mass } \\
\text { fraction. } \\
T_{w} \text { varies in a complicated manner, and there is } \\
\text { temperature distribution along the peripheral } \\
\text { direction that influences the melting time. }\end{array}$ \\
\hline & $\begin{array}{l}\text { Fomin and Saitoh } \\
{[38](1999)}\end{array}$ & $\begin{array}{l}\text { Variable } \\
T_{w}\end{array}$ & Octadecane & $\begin{array}{l}\mathrm{C} \text { (boundary fixing } \\
\text { method) and A }\end{array}$ & $\begin{array}{l}\text { The approximate analytical solutions were found to } \\
\text { be in good agreement with the numerical solutions. }\end{array}$ \\
\hline
\end{tabular}


(neglecting melting at the upper region of the solid core)

$\begin{array}{llll}\begin{array}{l}\text { Assis et al. [40] } \\ (2007)\end{array} & \text { CWT } & \text { Paraffin RT27 } & \begin{array}{l}\text { E (camera, water bath, } \\ \text { etc.) and C (EPM with } \\ \text { FVM) }\end{array} \\ & & \\ \begin{array}{l}\text { Hosseinizadeh et } \\ \text { al. [44] }(2013)\end{array} & \text { CWT } & \text { Octadecane } & \begin{array}{l}\text { E (camera, water bath, } \\ \text { etc.) and C (EPM with } \\ \text { FVM) }\end{array}\end{array}$

\begin{abstract}
Rizan et al. [45] CHF Octadecane
\end{abstract} (2012) water bath, etc.) (TCs, heater, camera,

Ignoring the effect of streamwise $\mathrm{NC}$ in the liquid layer leads to overestimating of melting rate.

Assumption of the constant $T_{w}$ of the capsule can lead to the results which significantly differ from those obtained for the real conditions of melting when the wall of the capsule is non-isothermal.

The transient phase-change process depended on the thermal and geometrical parameters of the system, including Ste and the diameter of the sphere.

Simulated melting time was slightly shorter than experimental one.

CON with high melting rate is dominant at the beginning through contact melting with the surface of container. Later on, NC becomes dominant at the top half of sphere where the melting rate is lower than the bottom half .

The geometrical parameter such as diameter has more influence on the melting rate and heat release compared to the operating condition such as Ste. Melting was primarily dependent on the temperature level to which the PCM is subjected to and the contact plane surface area.

CON dominates the initial melting condition with increasing liquid boundary layer shifting dominant heat transfer mode to NC.

Larger surface area in contact with the liquid front of the same volume will yield a higher melting rate.

\section{Constrained and Unconstrained Melting}

$\begin{array}{lll}\text { Tan [41] (2008) CWT Octadecane } & \begin{array}{l}\text { E (TCs, water bath, } \\ \text { camera, etc.) }\end{array} & \begin{array}{l}\text { In unconstrained melting, the melting in bottom } \\ \text { half is much faster due to CON, while the NC is } \\ \text { responsible for melting in upper half. } \\ \text { In constrained melting, top melted faster than } \\ \text { bottom and CON only exists at the beginning; } \\ \text { therefore, melting is mainly through NC in the } \\ \text { liquid at the top and bottom halves of the solid } \\ \text { PCM. }\end{array} \\ \end{array}$

The abbreviations of Table 2 apply to the table above. 
Table 4. Summary of studies on PCM melting inside cylindrical containers.

\begin{tabular}{|c|c|c|c|c|c|}
\hline \multicolumn{6}{|c|}{ Vertical Cylindrical Capsules } \\
\hline \multirow{7}{*}{ PCM } & Authors (Year) & $\mathbf{B C}$ & PCM & Type of Study & Highlighted Results \\
\hline & $\begin{array}{l}\text { Sparrow and } \\
\text { Broadbent [46] } \\
\text { (1982) }\end{array}$ & CWT at side & Eicosane & $\begin{array}{l}\text { E (test cell, TCs, water bath, } \\
\text { etc.) and A (pure CON } \\
\text { model) }\end{array}$ & $\begin{array}{l}\text { Melting process with no } S c \text { displayed heat } \\
\text { transfer and melting fraction were about } \\
50 \% \text { greater than that predicted by pure- } \\
\text { CON model. } \\
\text { Initial } S c \text { decreases the melting rate and } \\
\text { sensible heat storage. }\end{array}$ \\
\hline & $\begin{array}{l}\text { Wenzhen et al. [47] } \\
\text { (1993) }\end{array}$ & $\begin{array}{l}\text { CWT at bottom and } \\
\text { side }\end{array}$ & Eicosane & $\begin{array}{l}\text { A (melting is dominated by } \\
\text { CON in the close-contact } \\
\text { layer film at bottom and by } \\
\text { CON through the stable } \\
\text { liquid at the side) }\end{array}$ & $\begin{array}{l}\text { The effect of CON through the liquid phase } \\
\text { on the total melted mass fraction is little. } \\
\text { Increasing the Ste and/or reducing the } A R \\
\text { were advantageous to increasing the melting } \\
\text { rate and lowering the charging time. }\end{array}$ \\
\hline & $\begin{array}{l}\text { Wu and Lacroix } \\
{[48](1995)}\end{array}$ & CWT for all sides & $\begin{array}{l}\text { Depending on the } \\
\operatorname{Pr}\end{array}$ & $\begin{array}{l}\mathrm{C} \text { (body-fitted coordinates } \\
\text { with FDM) }\end{array}$ & $\begin{array}{l}\text { CON is dominated at the top, while the } \\
\text { highest melting rate occurs at the bottom. } \\
\text { Benard convection occurred at a much } \\
\text { earlier time than that for the case of melting } \\
\text { within a cylinder heated from below only. }\end{array}$ \\
\hline & $\begin{array}{l}\text { Jones et al. [49] } \\
\text { (2006) }\end{array}$ & $\begin{array}{l}\text { CWT at side and } \\
\text { constant-temp. base }\end{array}$ & Eicosane & $\begin{array}{l}\text { E (test cell, TCs, water bath, } \\
\text { etc.) and C (EPM based } \\
\text { FVM) }\end{array}$ & $\begin{array}{l}\text { Very good agreement was obtained between } \\
\text { the predictions and the experiment for Ste up } \\
\text { to } 0.1807 \text {. } \\
\text { Melting regimes are: a) pure CON, b) mixed } \\
\text { NC/CON, c) NC dominant, and d) shrinking } \\
\text { solid. }\end{array}$ \\
\hline & $\begin{array}{l}\text { Shmueli et al. [50] } \\
\text { (2010) }\end{array}$ & CWT at side & $\begin{array}{l}\text { Commercial } \\
\text { paraffin RT27 }\end{array}$ & $\mathrm{C}$ (EPM based FVM) & $\begin{array}{l}\text { Initially, heat transfers by CON from the } \\
\text { wall to solid PCM. Then NC in the liquid } \\
\text { dominates, changing the solid shape to } \\
\text { conical and making it shrink from top to } \\
\text { bottom. }\end{array}$ \\
\hline & $\begin{array}{l}\text { Wang et al. [51] } \\
(2012)\end{array}$ & $\begin{array}{l}\text { CWT at side } \\
\text { (inward melting) or } \\
\text { at center (outward } \\
\text { melting), insulated } \\
\text { top, and constant- } \\
\text { temp. base }\end{array}$ & Eicosane & $\mathrm{C}(\mathrm{FVM})$ & $\begin{array}{l}\text { Good agreement was obtained between } \\
\text { simulated results of inward melting and } \\
\text { previous experimental findings. } \\
\text { For outward melting, the agreement between } \\
\text { the simulated and previous predicted results } \\
\text { agree well at low Ra and consistent } \\
\text { correlations for the } N u \text { as well as total and } \\
\text { latent energy storage, all as functions of Ste, } \\
F o \text { and } R a \text {. }\end{array}$ \\
\hline
\end{tabular}


Horizontal Cylindrical Capsules

\begin{tabular}{|c|c|c|c|c|}
\hline \multicolumn{5}{|c|}{ Unconstrained Melting } \\
\hline $\begin{array}{l}\text { Nicholas and } \\
\text { Bayaziloglu [52] } \\
\text { (1980) }\end{array}$ & $\mathrm{CHF}$ & $\begin{array}{l}\text { Depending on the } \\
\text { selected Ste }\end{array}$ & $\mathrm{C}(\mathrm{FDM})$ & $\begin{array}{l}\text { Small Ste assured closest agreement between } \\
\text { analytical and numerical results. } \\
\text { Temperature is higher at the top where NC is } \\
\text { dominated. }\end{array}$ \\
\hline $\begin{array}{l}\text { Bareiss and Beer } \\
\text { [54] (1984) }\end{array}$ & CWT & $\begin{array}{l}\text { Octadecane and p- } \\
\text { xylene }\end{array}$ & $\begin{array}{l}\text { A (Assumptions) and } \mathrm{E} \text { (test } \\
\text { cell, water bath, etc.) }\end{array}$ & $\begin{array}{l}\text { The analytical model agreed very well with } \\
\text { the experimental findings. } \\
\mathrm{Nu} \text { is a maximum at the beginning and } \\
\text { decreases monotonically to zero at the end of } \\
\text { the melting process. }\end{array}$ \\
\hline $\begin{array}{l}\text { Prasad and } \\
\text { Sengupta [56] } \\
\text { (1988) }\end{array}$ & CWT & Octadecane & A (Assumptions) & $\begin{array}{l}\mathrm{Nu} \text { increases as the } R a \text { increases. } \\
\text { Useful correlations for the melt time and } \mathrm{Nu} \\
\text { were obtained. } \\
\text { Melting rate changes significantly with Ste } \\
\text { and } \mathrm{Pr} \text {, while it varies weakly with } \mathrm{Ra} \text {. }\end{array}$ \\
\hline $\begin{array}{l}\text { Maldonado et al. } \\
\text { [58] (1990) }\end{array}$ & $\begin{array}{l}\text { External } \\
\text { convection }\end{array}$ & Octadecane & $\begin{array}{l}\text { E (test cell, TCs, wind } \\
\text { tunnel, etc.) }\end{array}$ & $\begin{array}{l}\text { Half of the tests show the melt rate was } \\
\text { approximately identical to that for constant } \\
T_{w} \text {. } \\
\text { In most cases, the melt rate during the initial } \\
\text { stages of melting was significantly lower } \\
\text { than expected. }\end{array}$ \\
\hline $\begin{array}{l}\text { Saitho and Kato } \\
{[60] \text { (1993) }}\end{array}$ & $\begin{array}{l}\text { CWT and constant- } \\
\text { temperature bath }\end{array}$ & Octadecane & $\begin{array}{l}\text { E (test cell, TCs, water bath, } \\
\text { etc.) and C(Growth Ring } \\
\text { Method) }\end{array}$ & $\begin{array}{l}\text { Small Ste confirms close-contact melting is } \\
\text { dominant with } 10-15 \% \text { being the } \\
\text { contribution of NC to the melting rate. } \\
\text { As Ste increases, NC becomes significant. }\end{array}$ \\
\hline $\begin{array}{l}\text { Kawanami et al. } \\
\text { [63] (1999) }\end{array}$ & $\mathrm{CHF}$ & Slush ice & $\begin{array}{l}\mathrm{E} \text { (test cell, TCs, heater, } \\
\text { etc.) }\end{array}$ & $\begin{array}{l}\text { Local heat transfer coefficient is greatest at } \\
\text { the top and tends to decrease along the wall } \\
\text { and it is proportional to heat flux and initial } \\
\text { solution concentration. }\end{array}$ \\
\hline
\end{tabular}

\section{Constrained Melting}

\begin{tabular}{|c|c|c|c|c|}
\hline $\begin{array}{l}\text { Ho and Viskanta } \\
\text { [53] (1984) }\end{array}$ & CWT & Octadecane & $\begin{array}{l}\text { E (test cell, TCs, water bath, } \\
\text { heating coil, etc.) and C } \\
(\text { FDM) }\end{array}$ & $\begin{array}{l}\mathrm{NC} \text { was dominant in the melt during inward } \\
\text { melting. } \\
\text { In addition to NC, a secondary vortex } \\
\text { circulation initiated at the bottom part of the } \\
\text { melt region and this secondary flow will } \\
\text { finally merge with main convective flow. }\end{array}$ \\
\hline Hirata and Nishida & CWT & Octadecane & E (test cell, TCs, water bath, & Analytical results showed a good agreement \\
\hline
\end{tabular}


camera, etc.) and A ( pure

CON model with equivalent $k$ of the liquid phase)

Park et al. [59] CWT PCM of $P r=50 \quad$ C(pseudo-compressibility

Costa et al. [61

CWT

(1997)

method based FVM) with experimental data for wide range of $R a$. The influence of $\mathrm{NC}$ is insignificant when $R a<10^{5}$.

NC flow is unicellular, bi-cellular and tricellular depending on $\mathrm{Ra}$.

Initial small perturbations of very minor difference can induce different melting patterns.

At relatively low $R a$, the axial flow velocity is low, but for high $R a$, distinct 3-D flow is recognized with axial waviness at bottom of solid PCM.

The 3-dimensionality has no effect on the melt fraction and the overall $\mathrm{Nu}$.

$\mathrm{Nu}$ along the axial direction varies significantly according to the flow pattern.

Chung et al. [62] CWT Octadecane $\quad$ C (EPM with FVM)

(1997)

Octadecan

(EPM with FVM)

At low $R a$, the flow in the liquid gap is stable as the viscous force is dominant.

The intermediate $R a$ showed the thermal buoyancy and viscous forces are balanced in a neutrally stable state.

At the high $R a$, the Benard convection shows an orderly behavior without being affected by the base flow.

$\begin{array}{lll}\begin{array}{l}\text { Hirose et al. [64] CWT } \\ (2003)\end{array} & \text { Ice/water } & \begin{array}{l}\text { A (boundary fixing method) } \\ \text { and E (test cell, TCs, water }\end{array}\end{array}$

bath, camera, etc.)

$\begin{array}{lll}\begin{array}{l}\text { Regin et al. [65] CWT } \\ (2006)\end{array} & \text { Paraffin wax } & \begin{array}{l}\text { C (FDM with merging NC } \\ \text { effect in the } k \text { of the liquid) } \\ \text { and E (test cell, TCs, }\end{array} \\ & \text { constant temp. bath, etc.) }\end{array}$

Unconstrained and Constrained Melting 
2

3 camera, etc.) and C (FDM)
$\mathrm{E}$ (rig test, TCs, water paths,

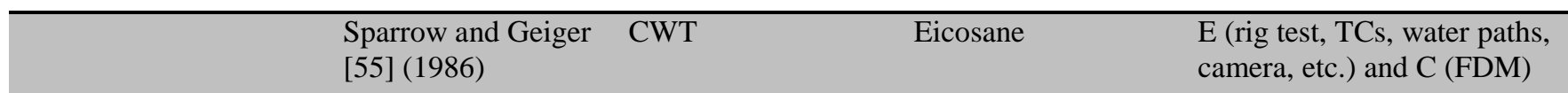

The abbreviations of Table 2 apply to the table above.
Melted mass in unconstrained mode exceed that of constrained mode.

Majority of melting in wall-adjacent mode occurred at the lower portion.

The experiments showed that constrained melting can be treated three-dimensionally; in contrast, unconstrained mode showed 2-D behavior. 
Table 5. Outline of studies on PCM melting inside annular cavities.

\begin{tabular}{|c|c|c|c|c|c|}
\hline & Authors (Year) & $\mathbf{B C}$ & $\overline{P C M}$ & Type of Study & Highlighted Results \\
\hline \multirow[t]{7}{*}{ Annular } & $\begin{array}{l}\text { Khillarkar et al. } \\
\text { [66] (2000) }\end{array}$ & $\begin{array}{l}\text { Isothermal tube } \\
\text { heating, shell } \\
\text { heating and both } \\
\text { sides heating }\end{array}$ & Octadecane & C (EPM based FEM) & $\begin{array}{l}\text { Heating both walls suppressed thermal } \\
\text { stratification, which occurred in both } \\
\text { configurations for heating from the inside wall. } \\
\text { High } R a \text { results in an earlier onset of } \mathrm{NC} \text {, } \\
\text { increasing the melting rate for inside and outside } \\
\text { heating cases, but higher degree of thermal } \\
\text { stratification was shown for inside wall heating. }\end{array}$ \\
\hline & $\begin{array}{l}\text { Dutta et al. [67] } \\
(2008)\end{array}$ & $\begin{array}{l}\text { Isothermal heating } \\
\text { tube with insulated } \\
\text { shell }\end{array}$ & Paraffin wax & $\begin{array}{l}\text { E (TCs, water bath, etc.) } \\
\text { and C (EPM with FVM) }\end{array}$ & $\begin{array}{l}\text { Eccentricity, inclination angle and inner surface } \\
\text { heat flux played an important role for the net } \\
\text { circulation of the molten phase. } \\
\text { Convective heat transfer is enhanced with the } \\
\text { increase in } R a \text {. }\end{array}$ \\
\hline & $\begin{array}{l}\text { Akgun et al. [68] } \\
(2008)\end{array}$ & $\begin{array}{l}\text { Isothermal heating } \\
\text { or cooling tube } \\
\text { with insulated shell }\end{array}$ & $\begin{array}{l}\text { P42-44 (P1), } \\
\text { P46-48 } \\
(\mathrm{P} 2), \mathrm{P} 56-58 \\
(\mathrm{P} 3)\end{array}$ & E (TCs, water bath, etc.) & $\begin{array}{l}\text { CON is responsible for the heat transfer process } \\
\text { inside solid PCM and this region receives heat } \\
\text { from the melted part by NC. } \\
\text { In order to improve heat transfer during the } \\
\text { melting and solidification, the surface of the shell } \\
\text { was inclined with an inclination angle of } 5^{\circ} \text {. }\end{array}$ \\
\hline & $\begin{array}{l}\text { Sugawara et al. } \\
\text { [69] (2008) }\end{array}$ & $\begin{array}{l}\text { Isothermal heating } \\
\text { or cooling tube } \\
\text { with insulated shell }\end{array}$ & Ice/water & $\mathrm{C}$ (continuum model) & $\begin{array}{l}\text { Melting decreased considerably with increasing the } \\
\text { distance from the center of the cylinder to the } \\
\text { bottom of the container. }\end{array}$ \\
\hline & $\begin{array}{l}\text { Wei et al. [70] } \\
(2010)\end{array}$ & $\begin{array}{l}\text { Isothermal heating } \\
\text { tube with insulated } \\
\text { shell }\end{array}$ & $\begin{array}{l}\text { Commercial } \\
\text { paraffin }\end{array}$ & C (EPM based FVM) & $\begin{array}{l}\text { The top portion melted far faster than the bottom } \\
\text { suggesting that the heated surface should be placed } \\
\text { lower in order to reduce the total melting time. } \\
\text { The melt fraction grows with time, while the wall } \\
\text { heat flux decreases sharply initially, then increases } \\
\text { slowly, and drops sharply after the melt fraction } \\
\text { reaches } 100 \% \text {. }\end{array}$ \\
\hline & $\begin{array}{l}\text { Darzi et al. [71] } \\
(2012)\end{array}$ & $\begin{array}{l}\text { Isothermal heating } \\
\text { tube with insulated } \\
\text { shell }\end{array}$ & Eicosane & $\mathrm{C}(\mathrm{EPM}$ based FVM) & $\begin{array}{l}\mathrm{NC} \text { becomes dominant in the top half while CON } \\
\text { remains dominant in the bottom half. } \\
\text { When the inner cylinder tube moves downward, } \\
\text { melting rate increases sharply due to the } \\
\text { dominance of NC heat transfer in most of PCM. }\end{array}$ \\
\hline & $\begin{array}{l}\text { Hosseini et al. } \\
\text { [72] (2012) }\end{array}$ & $\begin{array}{l}\text { Isothermal heating } \\
\text { tube with insulated } \\
\text { shell }\end{array}$ & $\begin{array}{l}\text { Commercial } \\
\text { paraffin } \\
\text { RT50 }\end{array}$ & $\begin{array}{l}\mathrm{E}(\mathrm{TCs}, \text { hot water tank, } \\
\text { etc.) and C (EPM based } \\
\text { FVM) }\end{array}$ & $\begin{array}{l}\text { The sharp rise in temperatures takes place at the } \\
\text { uppermost section of the store. } \\
\text { Strong thermal stratification of the melt was shown } \\
\text { in the upper half. }\end{array}$ \\
\hline
\end{tabular}



expediting of the melting process.

The abbreviations of Table 2 apply to the table above. 


\section{List of Figures}

Fig. 1. Schematic diagram of the generic shape of the container with prescribed boundary conditions and relevant parameters.

Fig. 2. Schematic diagram of physical configuration of a PCM/air composite cell (Ho and Chu [12]).

Fig. 3. Experimental cell (all dimensions are in $\mathrm{mm}$ ) (Pal and Joshi [15]).

Fig. 4. Schematic diagram of the physical model (Faraji and El Qarnia [17]).

Fig. 5. Problem geometry and boundary conditions (Samara et al. [19]).

Fig. 6. Schematic diagram of the physical model and coordinate system (Beckermann and Viskanta [21]).

Fig. 7. Schematic diagram of the experimental apparatus (Wang et al. [23]).

Fig. 8. Instantaneous isotherms (a) inside the not-inverted container and (b) within the inverted container (Gong et al. [24]).

Fig. 9. Comparison of the melting time for rectangular and cylindrical containers of equal volume and heat transfer area (Zivkovic and Fujii [26]).

Fig. 10. (a) Schematic diagram of the experimental apparatus and (b) Temporal variation of the melt fraction (Yanxia et al. [29]).

Fig. 11. (a) Configuration geometry and (b) Instantaneous isotherms over the domain (contour level 0.00 represents the positions of the liquid-solid interface) (Jellouli et al. [30]).

Fig. 12. Location of the fusion front at several time instants: (a) $1000 \mathrm{~s}$, (b) 10,000 s, (c) 20,000 s, (d) $30,000 \mathrm{~s}$ and (e) 40,000 s. The dashed vertical line is the corresponding 1-D solution (Younsi et al. [32]).

Fig. 13. Problem definition for four cases, where $\theta=\frac{T-T_{m}}{T_{h}-T_{c}}, \delta \theta=\frac{\delta T}{T_{h}-T_{c}}$ and $\delta T$ is half width of the mushy zone temperature ranges (Wang et al. [33]).

Fig. 14. (a) Experimental set-up and (b) Temperature and heat flux variations (Joulin et al. [34]).

Fig. 15. Experimental setup (Saitoh and Hoshi [37]).

Fig. 16. (a) Unconstrained and constrained melting inside a sphere and (b) Schematic sketch showing natural convection patterns in constrained melting (Tan [41]).

Fig. 17. Thermally stable and unstable liquid layer structures along the symmetry axis (Tan et al. [42]). 
Fig. 18. Experimental validation of the position of the liquid-solid interface during melting inside a spherical container (Veerappan et al. [43]).

Fig. 19. Experimental setup (Rizan et al. [45]).

Fig. 20. Analytical model (Wenzhen et al. [47]).

Fig. 21. (a) Schematic representation of the vertical cylindrical capsule and (b) Timewise variation of the average Nusselt number on the bottom $\left(N u_{B}\right)$, side $\left(N u_{S}\right)$ and top $\left(N u_{T}\right)$ surfaces $(\mathrm{Wu}$ and Lacroix [48]).

Fig. 22. (a) Schematic diagram of the experimental setup and (b) Photographs during melting of wax within the vertical cylindrical enclosure for a wall temperature of $45{ }^{\circ} \mathrm{C}$ (Jones et al. [49]).

Fig. 23. Instantaneous simulated density distributions and velocity vector maps vs. experimental images during mleting in a verical cylindrical container for $D=3 \mathrm{~cm}, H=17 \mathrm{~cm}$ and $\Delta T=$ $10{ }^{\circ} \mathrm{C}$ (Shmueli et al. [50]).

Fig. 24. Time evolutions of the overall Nusselt number on the surface of a horizontal cylinder in cases A and B predicted by three- and two-dimensional simulations (Costa et al. [61]).

Fig. 25. Two horizontal annuli configurations with streamlines (right half) and isotherms (left half) for $R a=2.844 \times 10^{6}$ with the annuli heated isothermally from the inside, outside or both walls (Khillarkar et al. [66]).

Fig. 26. Experimental set-up (Dutta et al. [67]).

Fig. 27. Schematic diagram of the inclined shell surrounding a vertically-oriented annular PCM and the effect of this inclination on the melting time for various inlet water temperatures (Akgun et al. [68]).

Fig. 28. (a) Physical model and coordinate system and (b) Characteristics of velocity vectors at different locations of the horizontally-oriented cylinder (Sugawara et al. [69]).

Fig. 29. Detailed phase fields throughout the melting process (Wei et al. [70]).

Fig. 30. (a) Diagram of the experimental set-up and (b) Computed streamlines and isotherms for different water inlet temperatures (Hosseini et al. [72]). 


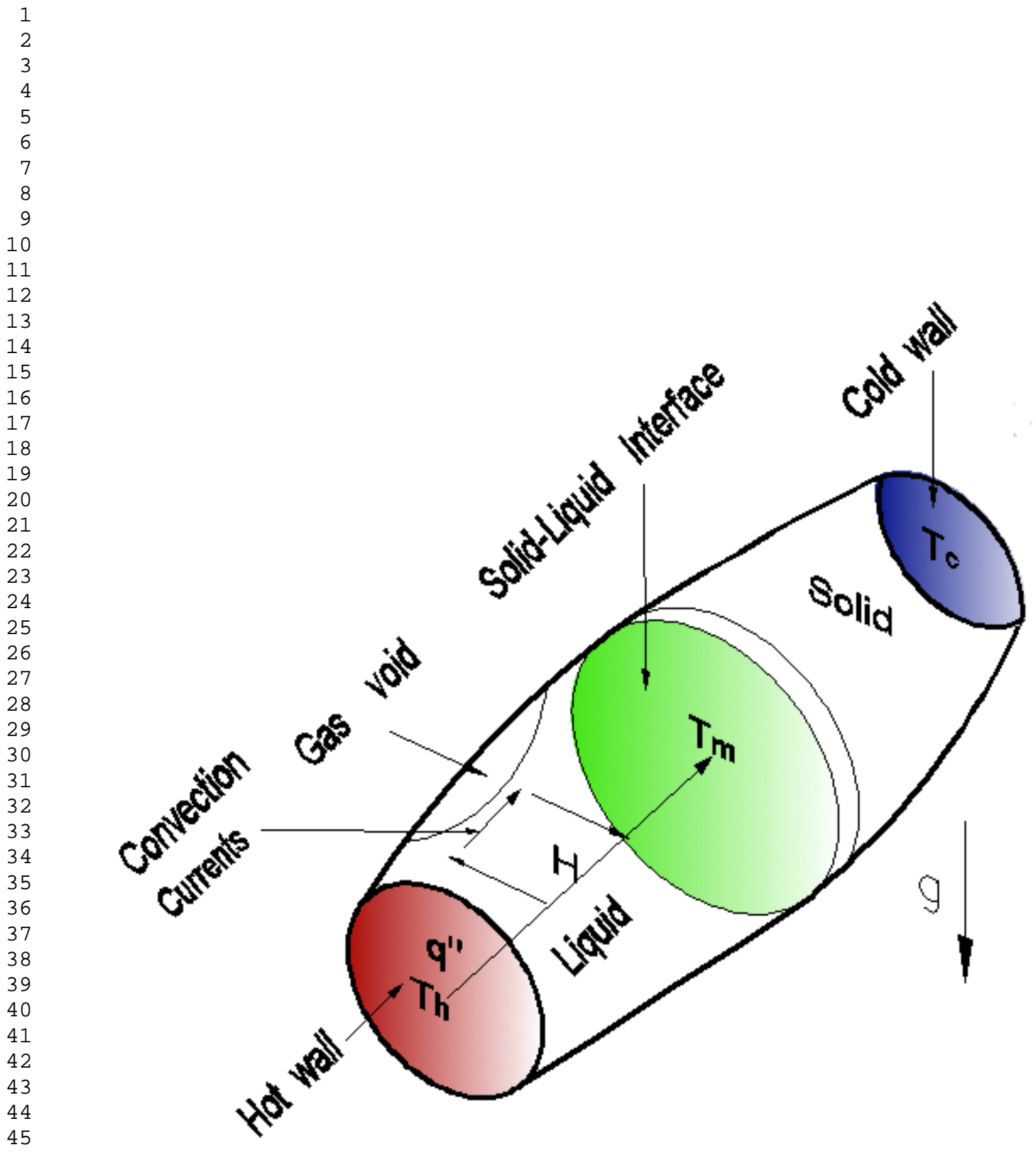




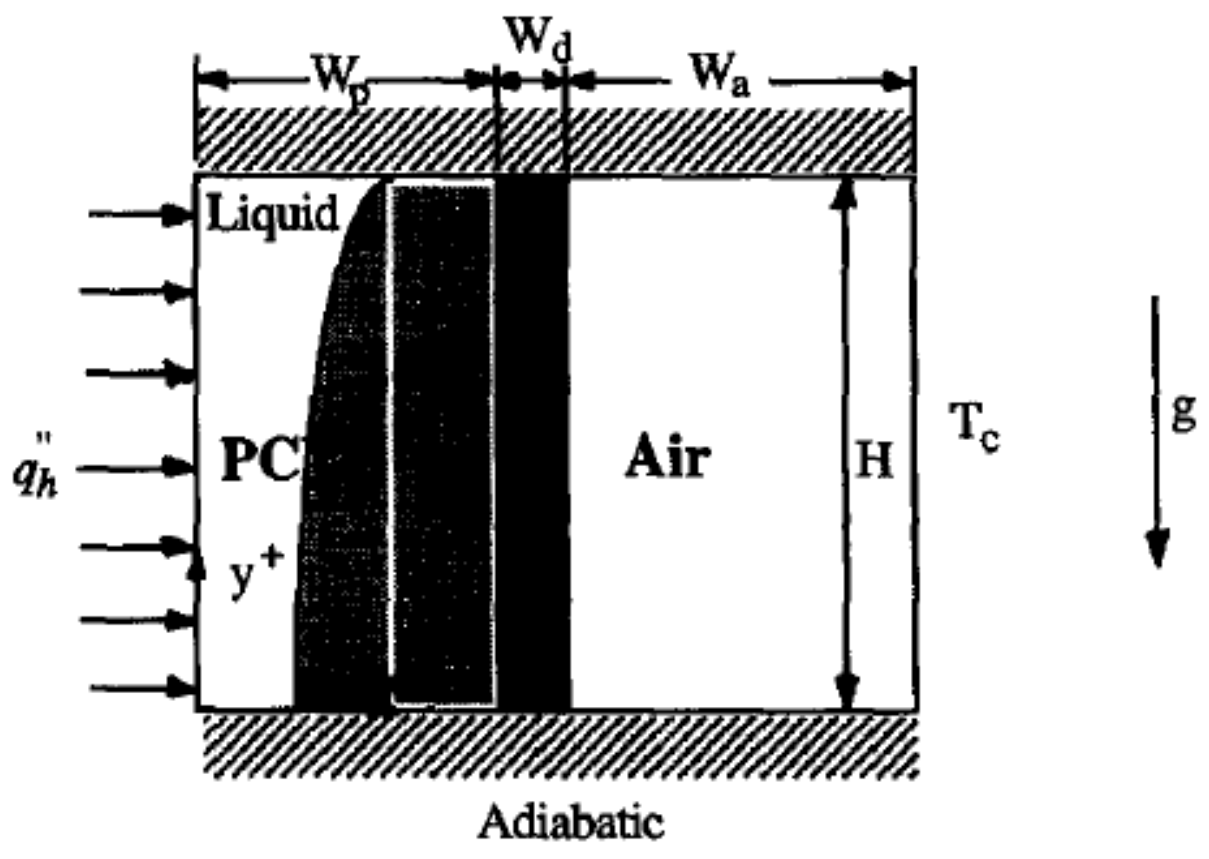

Fig. 2. Schematic diagram of physical configuration of a PCM/air composite cell (Ho and Chu [12]). 


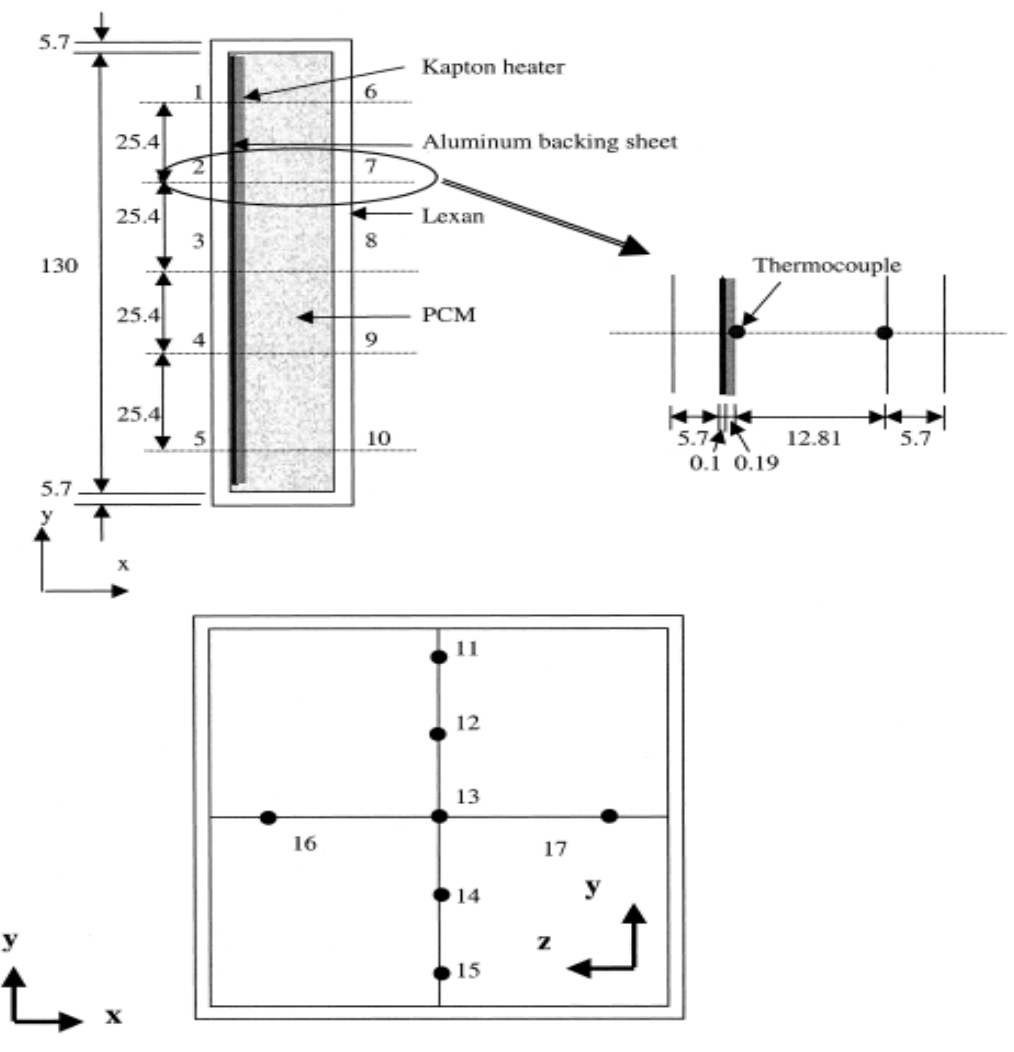

Fig. 3. Experimental cell (all dimensions are in mm) (Pal and Joshi [15]). 


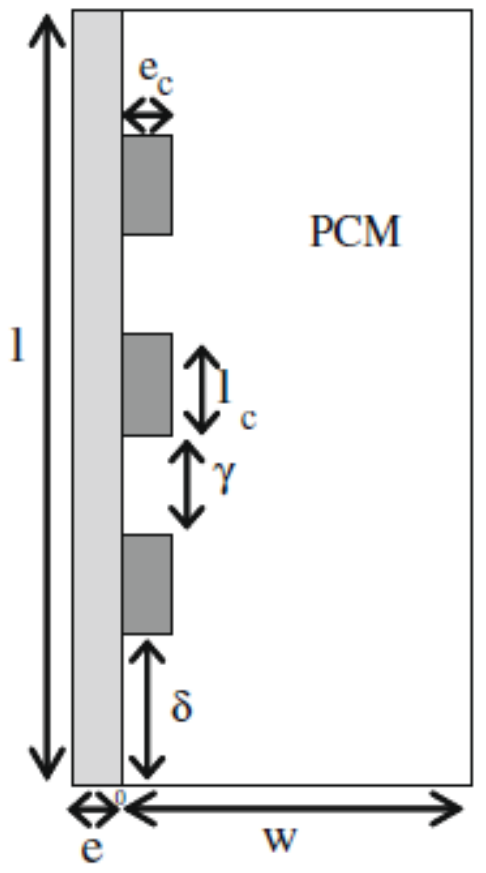

Fig. 4. Schematic diagram of the physical model (Faraji and El Qarnia [17]). 


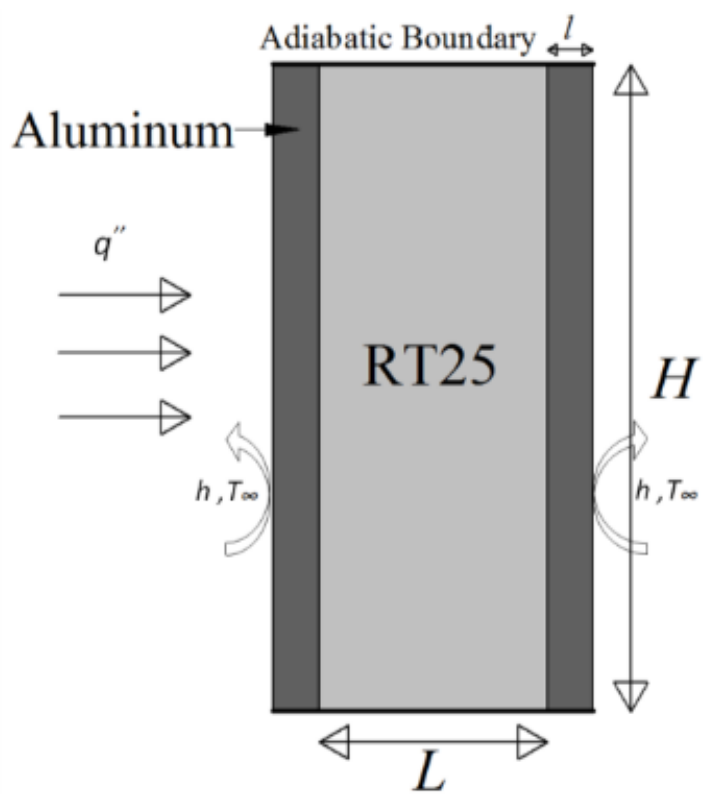

Fig. 5. Problem geometry and boundary conditions (Samara et al. [19]). 


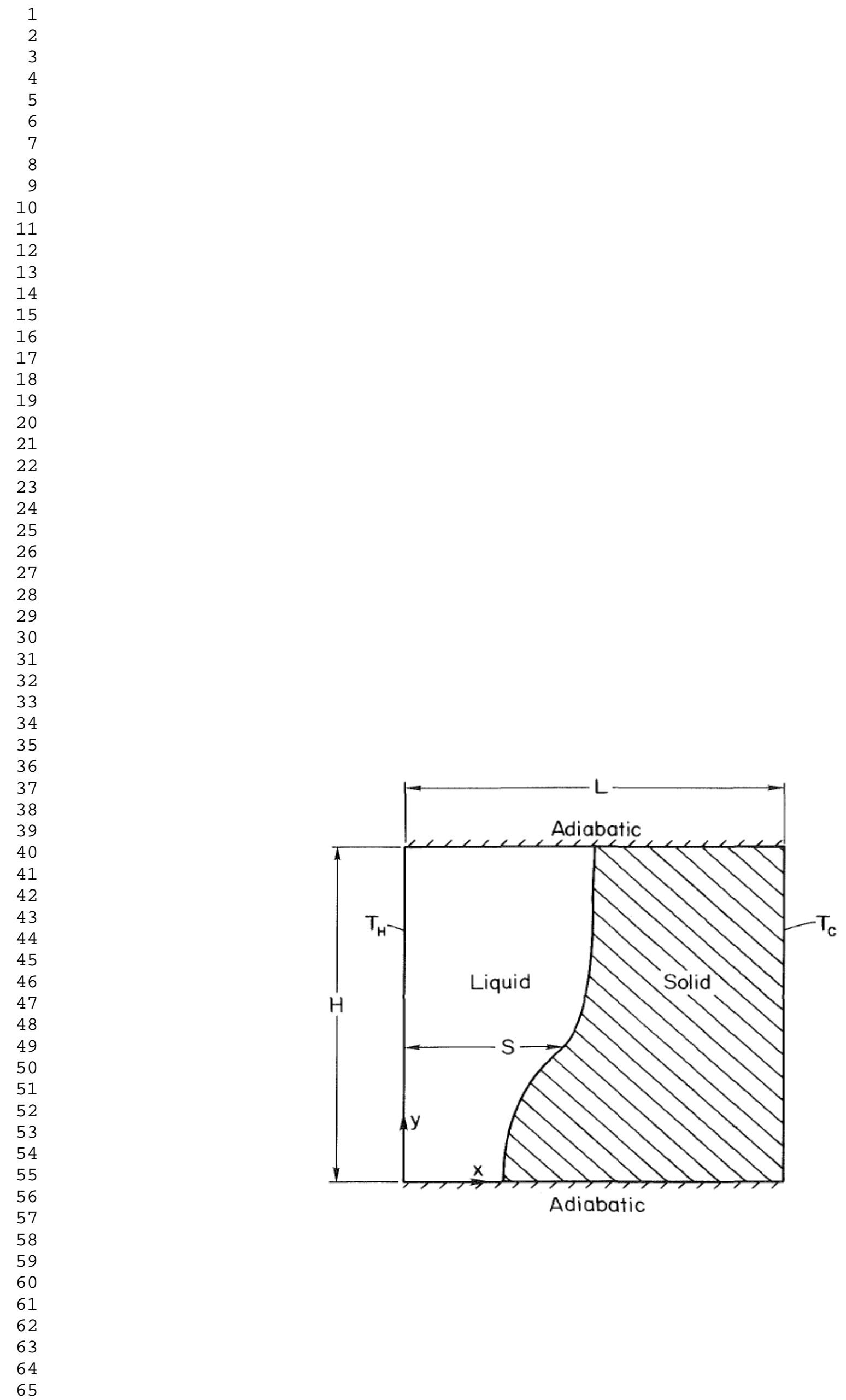


Fig. 6. Schematic diagram of the physical model and coordinate system (Beckermann and Viskanta [21]).

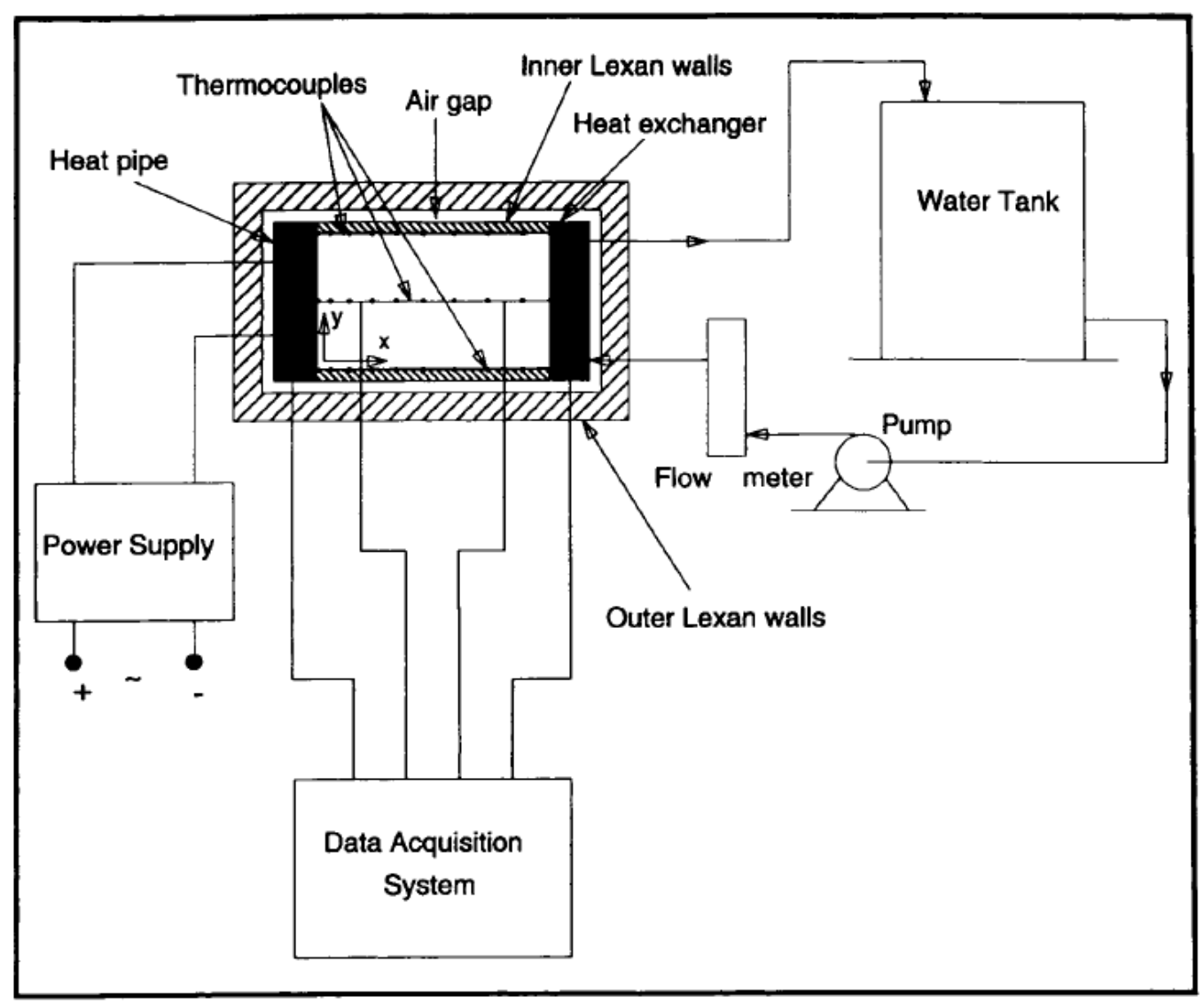

Fig. 7. Schematic diagram of the experimental apparatus (Wang et al. [23]). 

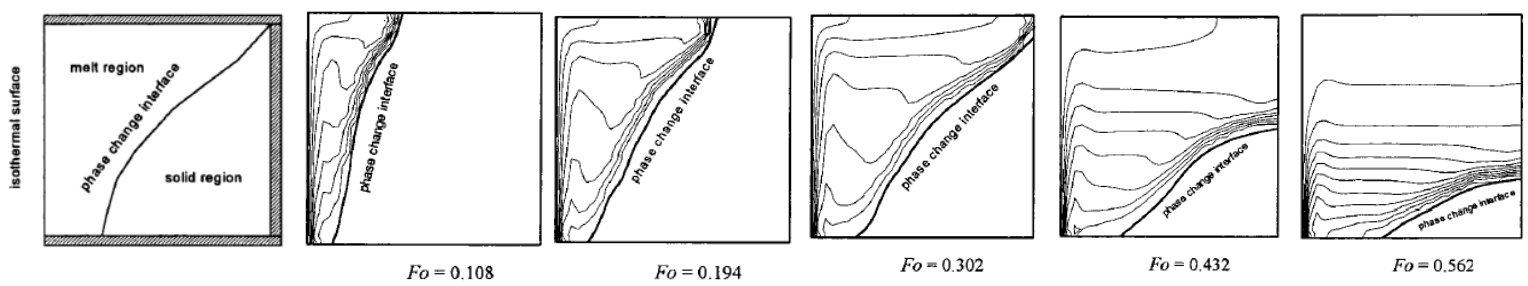

a
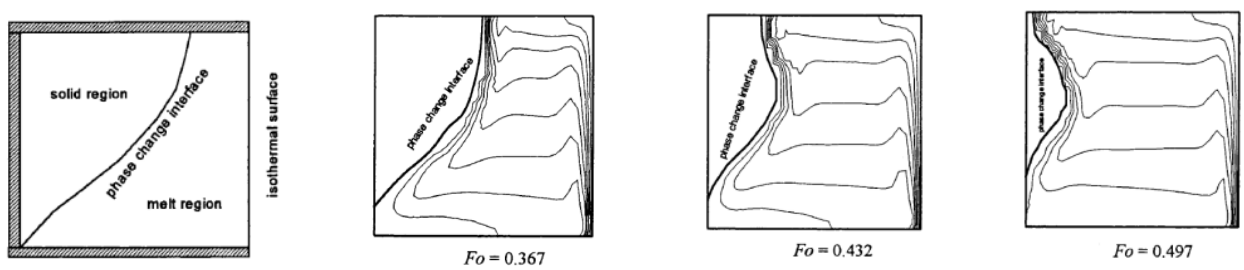

b

Fig. 8. Instantaneous isotherms (a) inside the not-inverted container and (b) within the inverted container (Gong et al. [24]). 


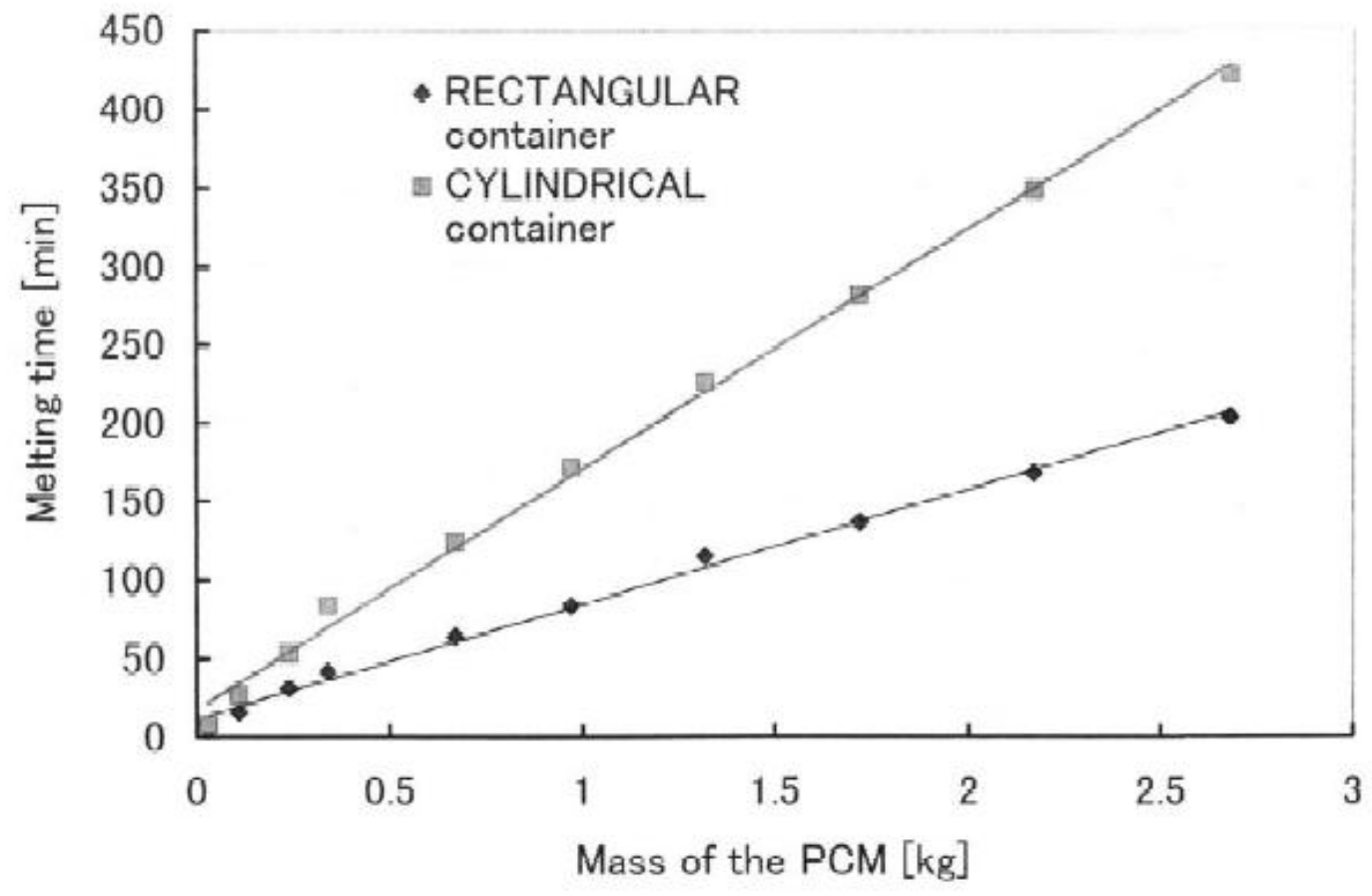

Fig. 9. Comparison of the melting time for rectangular and cylindrical containers of equal volume and heat transfer area (Zivkovic and Fujii [26]). 


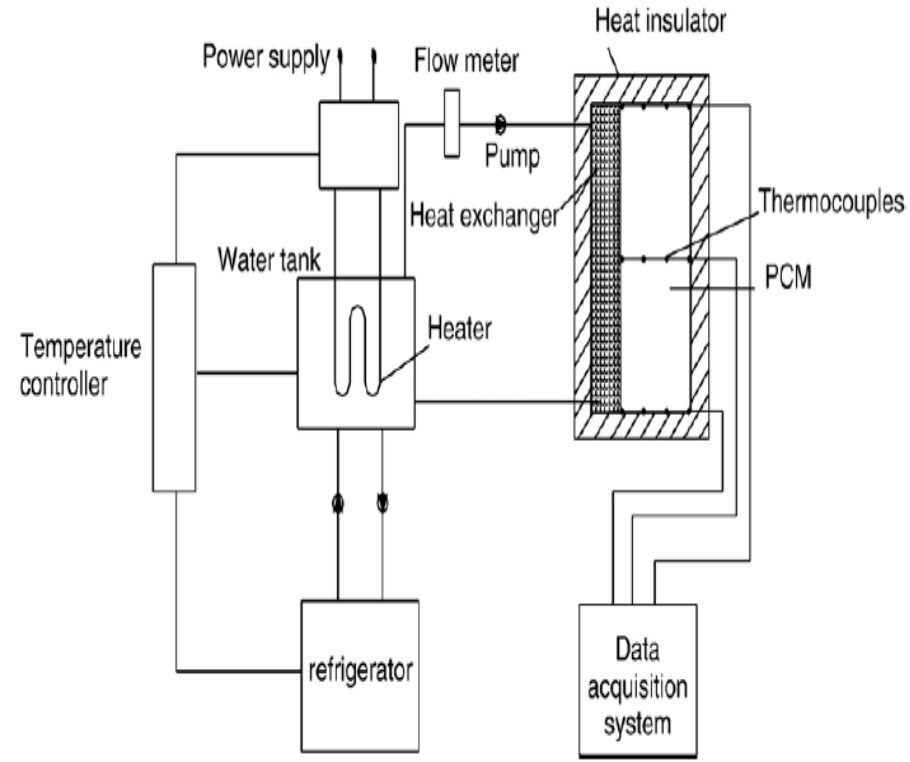

a

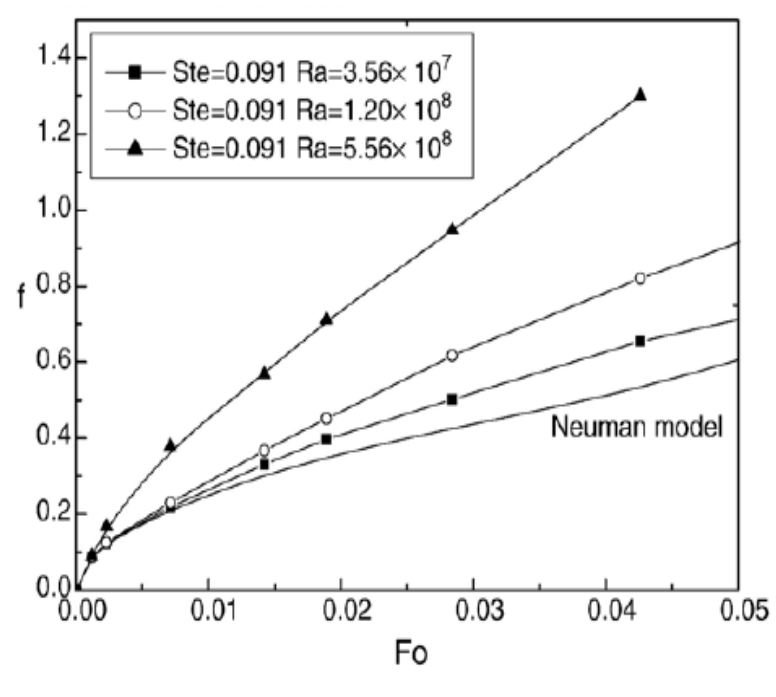

b

Fig. 10. (a) Schematic diagram of the experimental apparatus and (b) Temporal variation of melt fraction (Yanxia et al. [29]). 


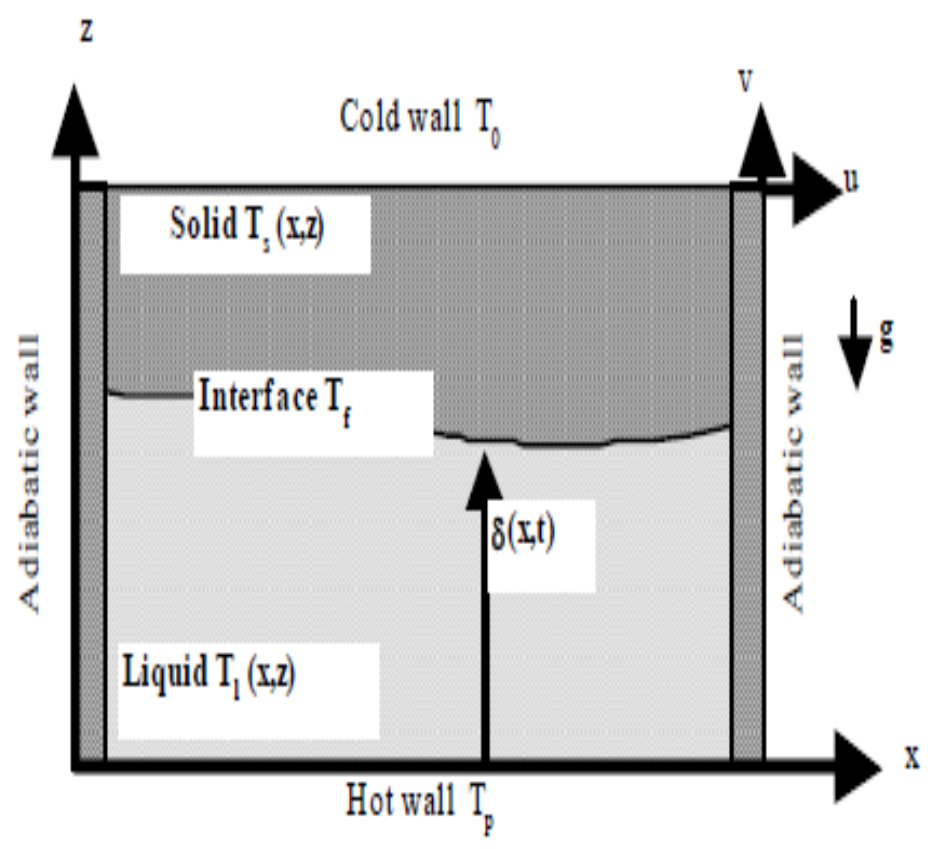

a

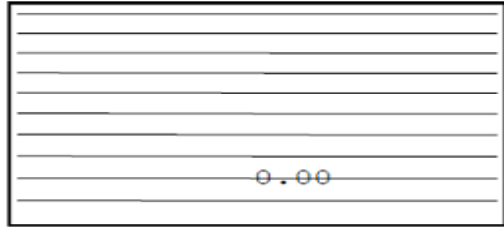

a) at 10 minutes

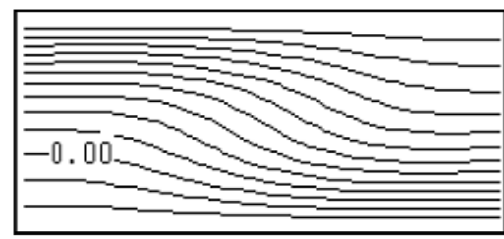

b) at 30 minutes

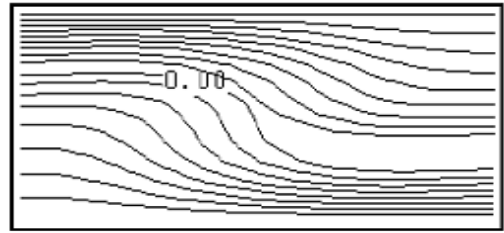

c) at 30 hours

b

Fig. 11. (a) Configuration geometry and (b) Instantaneous isotherms over the domain (contour level 0.00 represents the position of the liquid-solid interface) (Jellouli et al. [30]). 


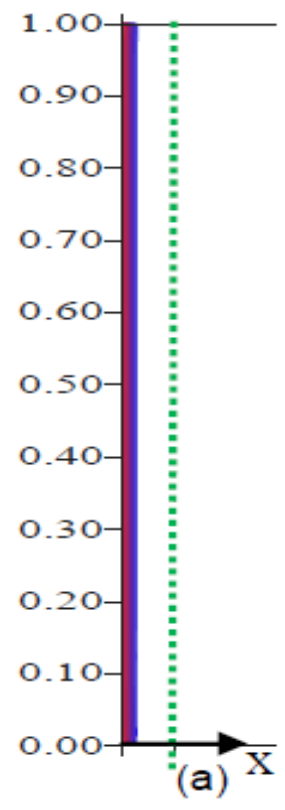

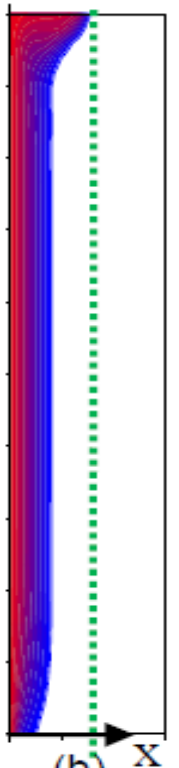

(b)

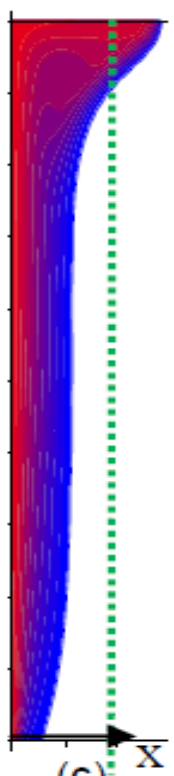

(c)

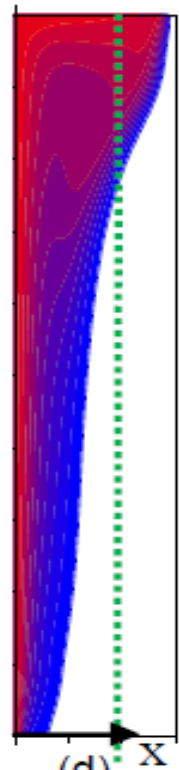

(d) $\mathrm{X}$

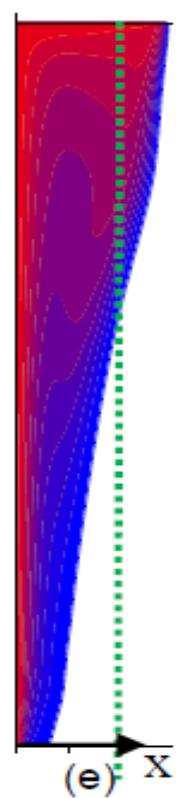

Fig. 12. Location of the fusion front at several time instants: (a) $1000 \mathrm{~s}$, (b) 10,000 s, (c) 20,000 s, (d) $30,000 \mathrm{~s}$ and (e) 40,000 s. The dashed vertical line is the corresponding 1-D solution (Younsi et al. [32]). 


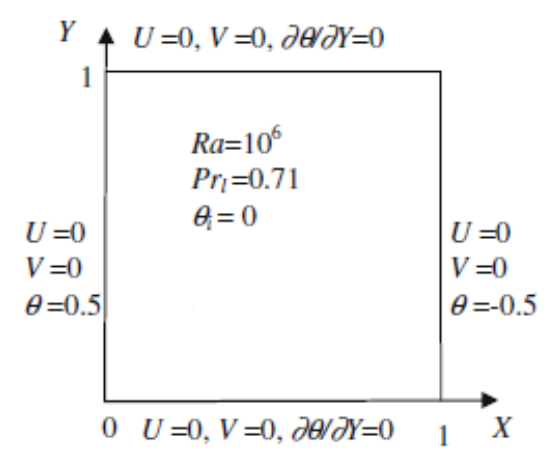

(a) Case 1

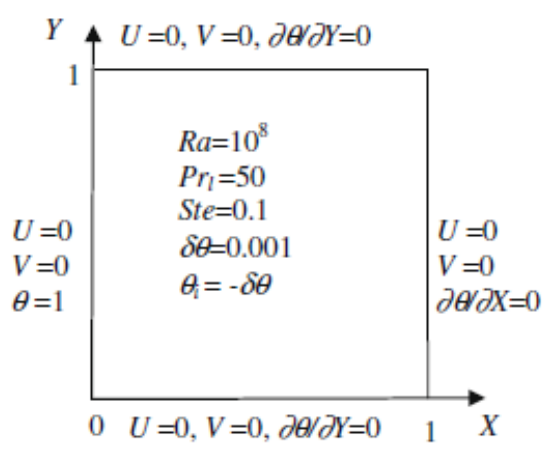

(c) Case 3

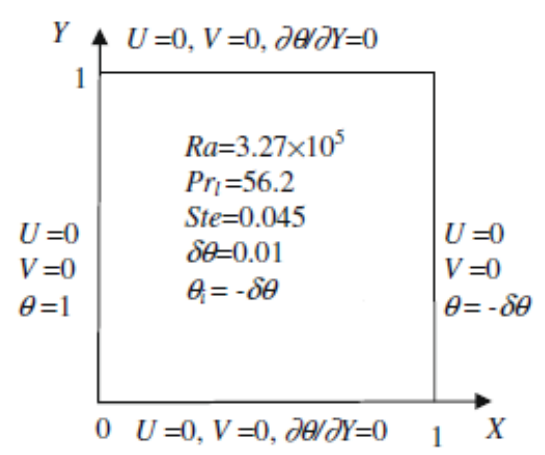

(b) Case 2

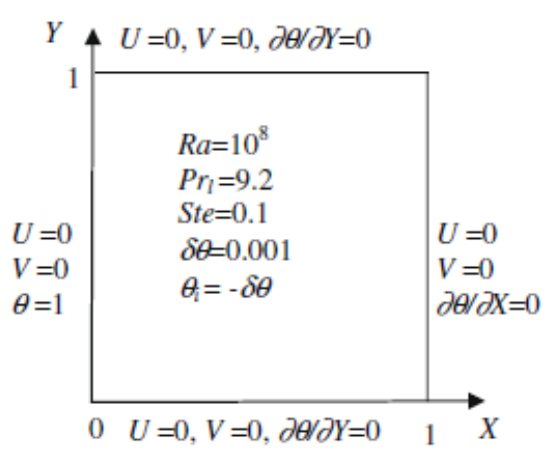

(d) Case 4

Fig. 13. Problem definition for four cases where $\theta=\frac{T-T_{m}}{T_{h}-T_{c}}, \delta \theta=\frac{\delta T}{T_{h}-T_{c}}$ and $\delta T$ is half of the mushy zone temperature ranges (Wang et al. [33]). 


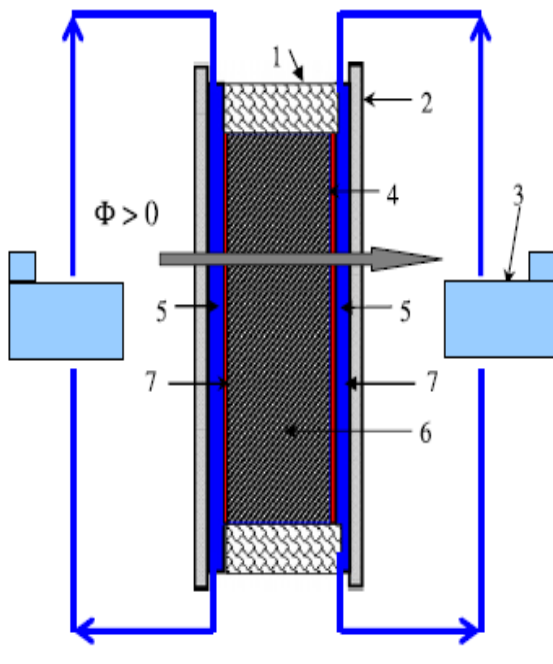

a
1. Insulation foam

2. Insulation

3. Thermo-regulated baths

4. Heat flux sensors

5. Exchanger plates

6. PCM

7. Thermocouples (type T)

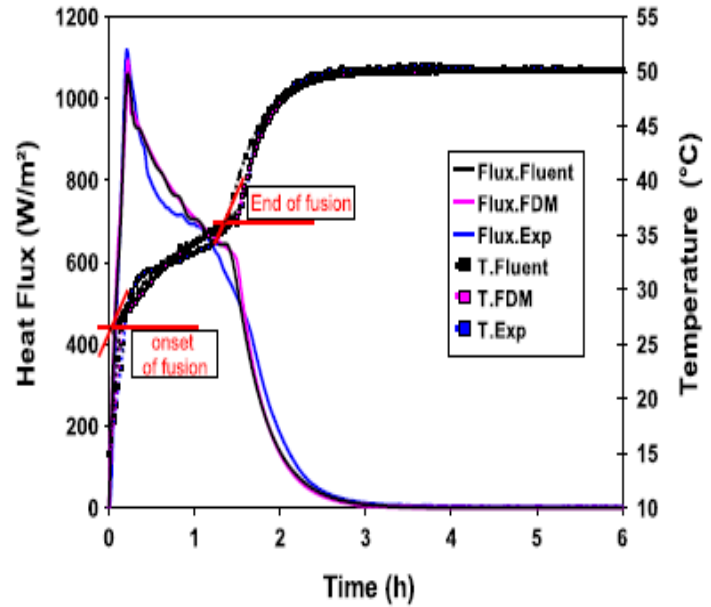

b

Fig. 14. (a) Experimental set-up and (b) Temperature and heat flux variations (Joulin et al. [34]). 


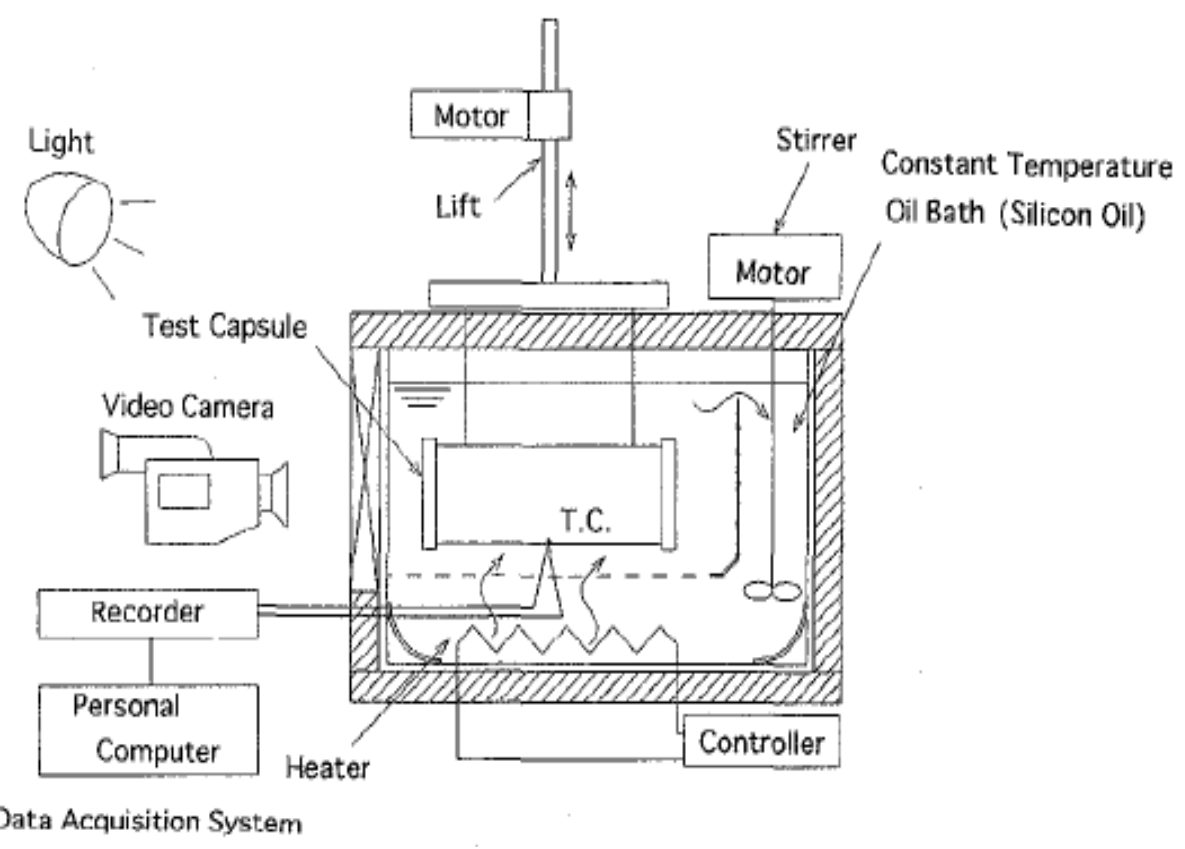

Fig. 15. Experimental setup (Saitoh and Hoshi [37]). 


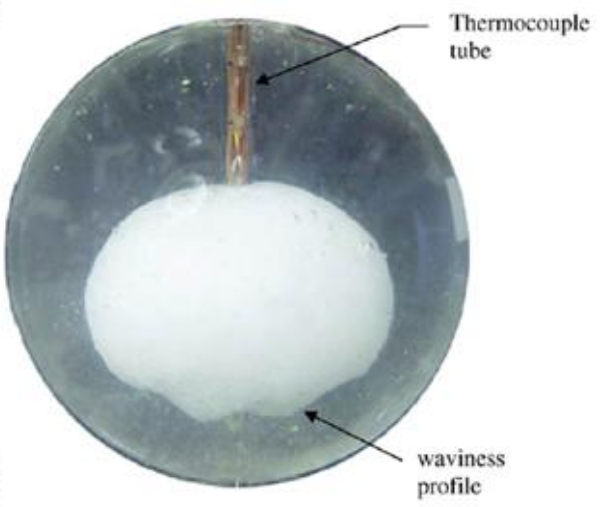

Constrained melting

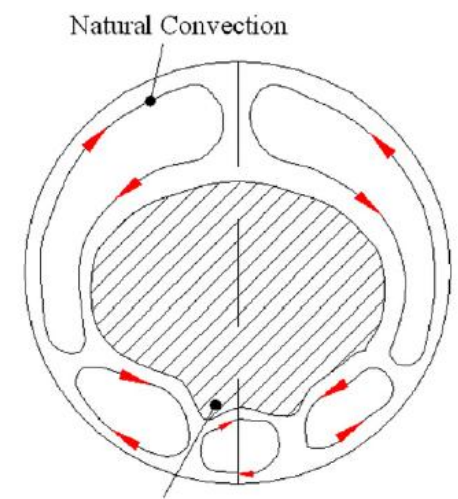

Melting Phase Front
Unconstrained melting

Liquid

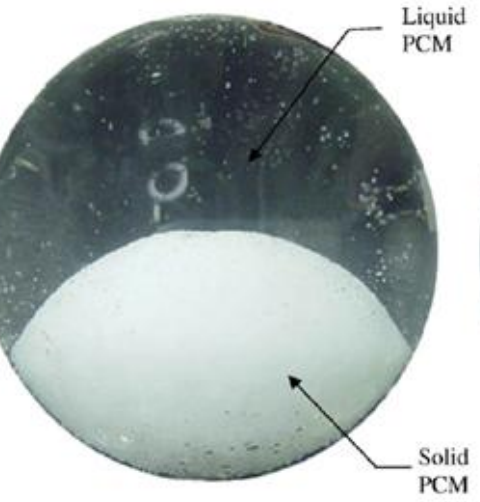

Unconstrained melting

Fig. 16. (a) Unconstrained and constrained melting inside a sphere and (b) Schematic sketch showing natural convection patterns in constrained melting (Tan [41]). 


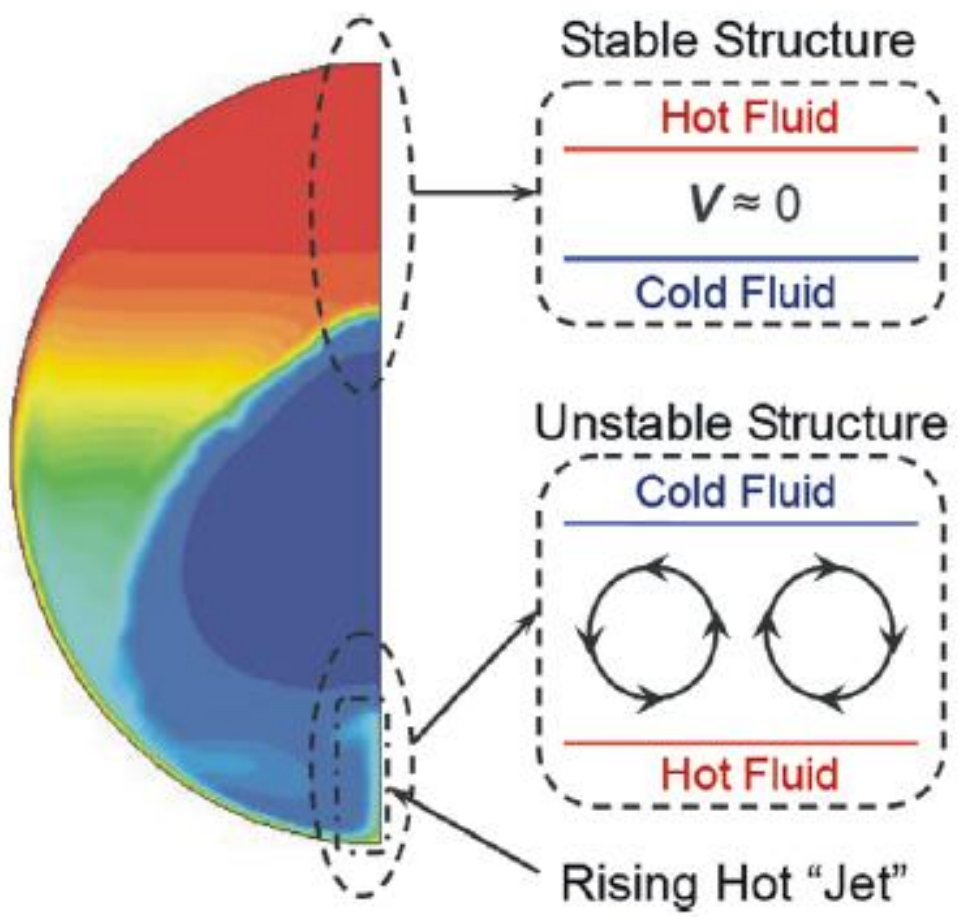

Fig. 17. Thermally stable and unstable liquid layer structures along the symmetry axis (Tan et al. [42]). 


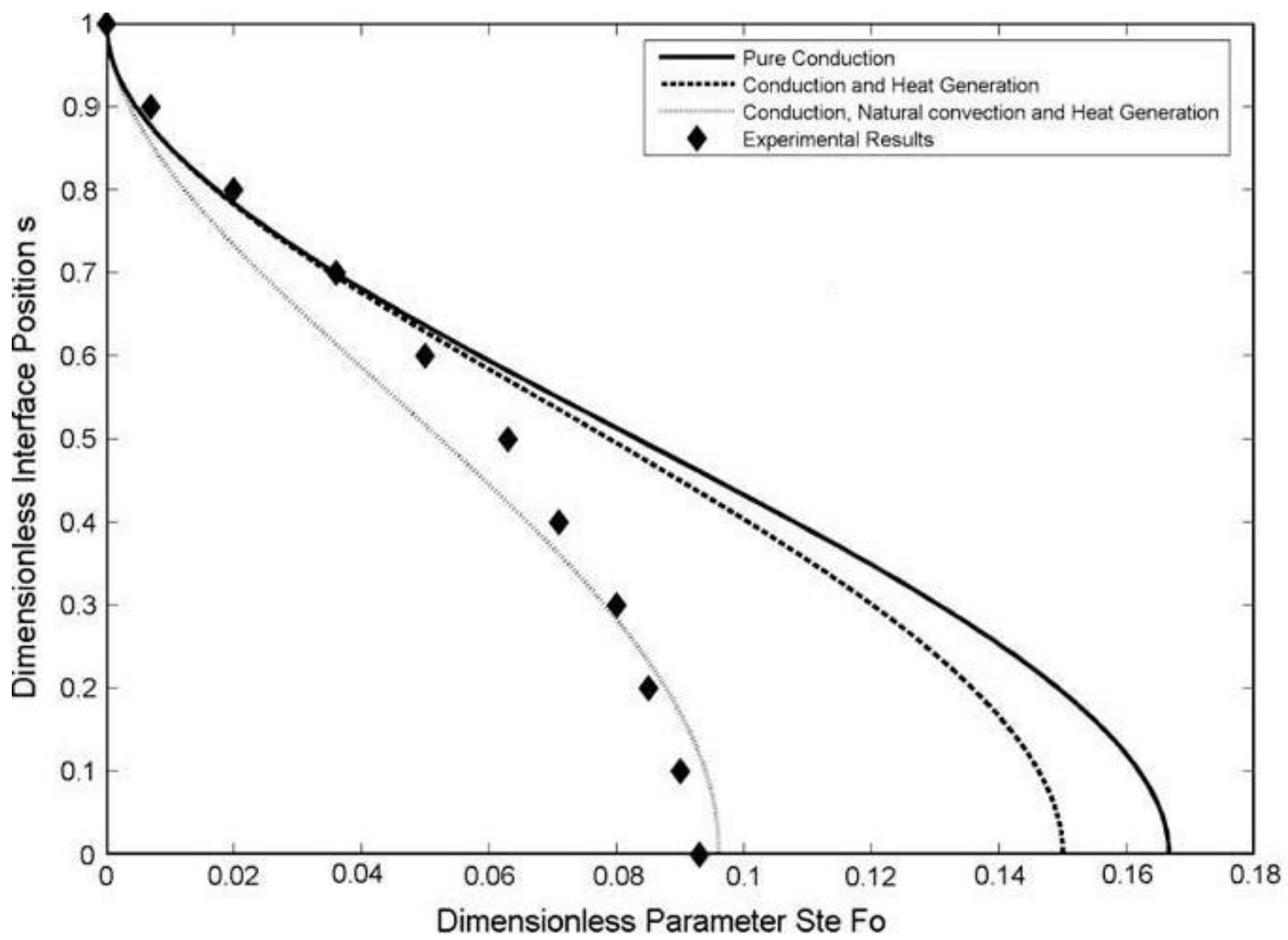

Fig. 18. Experimental validation of the position of the liquid-solid interface during melting inside a spherical container (Veerappan et al. [43]). 


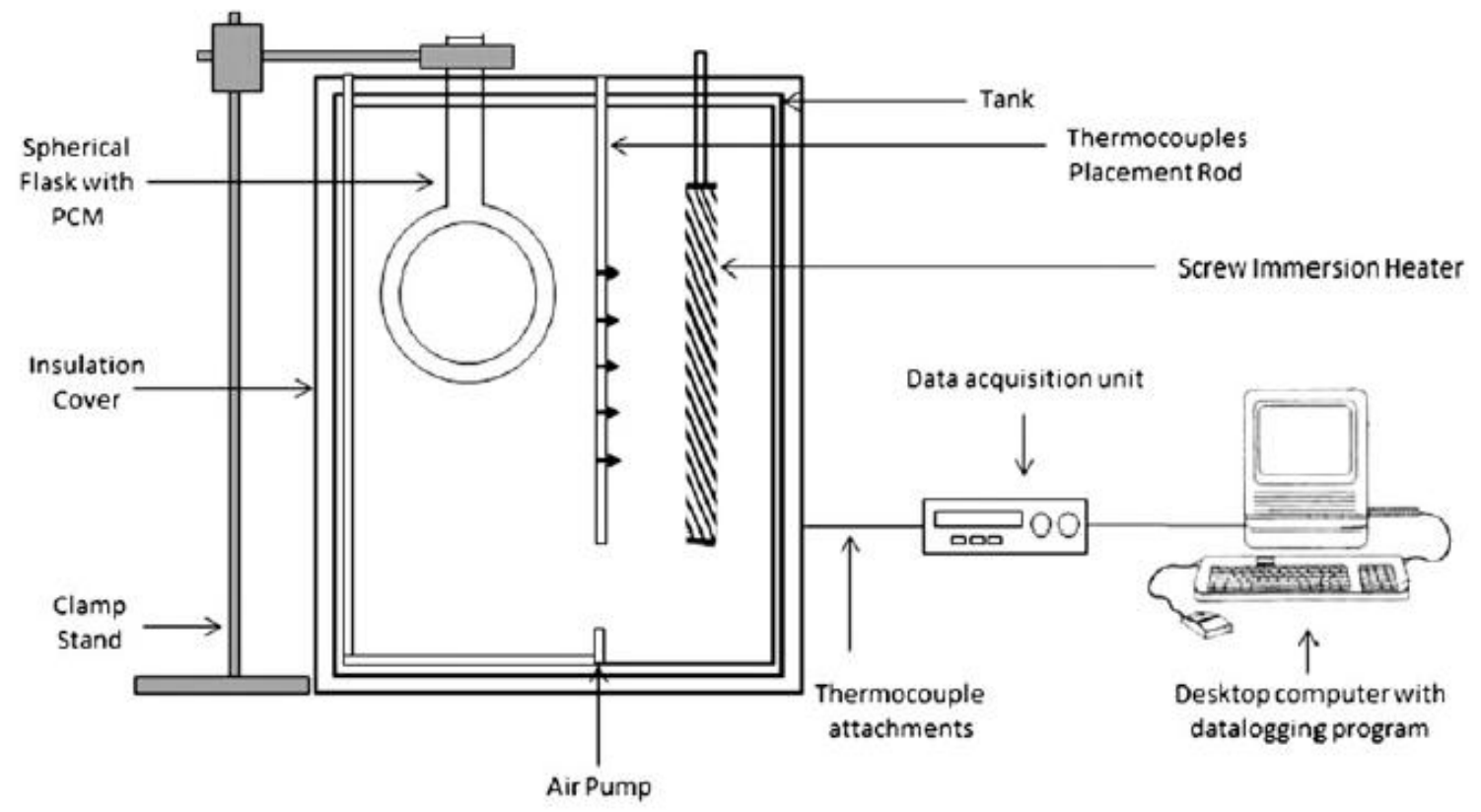

Fig. 19. Experimental setup (Rizan et al. [45]). 


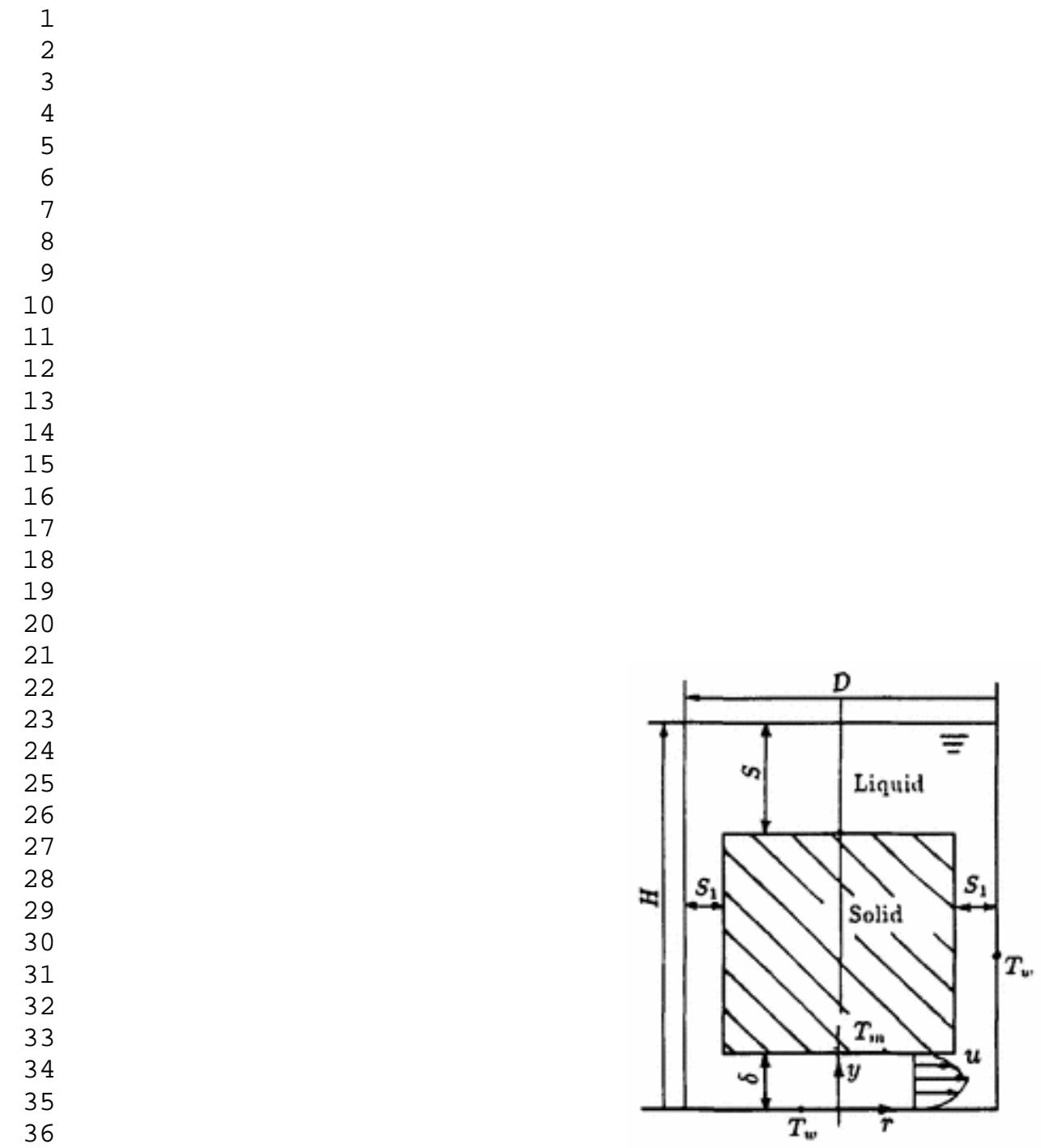

Fig. 20. Analytical model (Wenzhen et al. [47]).

39

40

41

42

43

44

45

46

47

48

49

50

51

52

53

54

55

56

57

58

59

60

61

62

63

64

65 


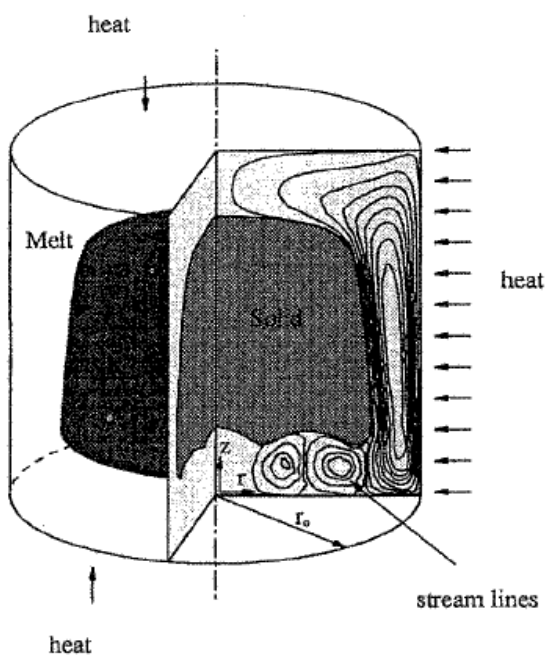

a

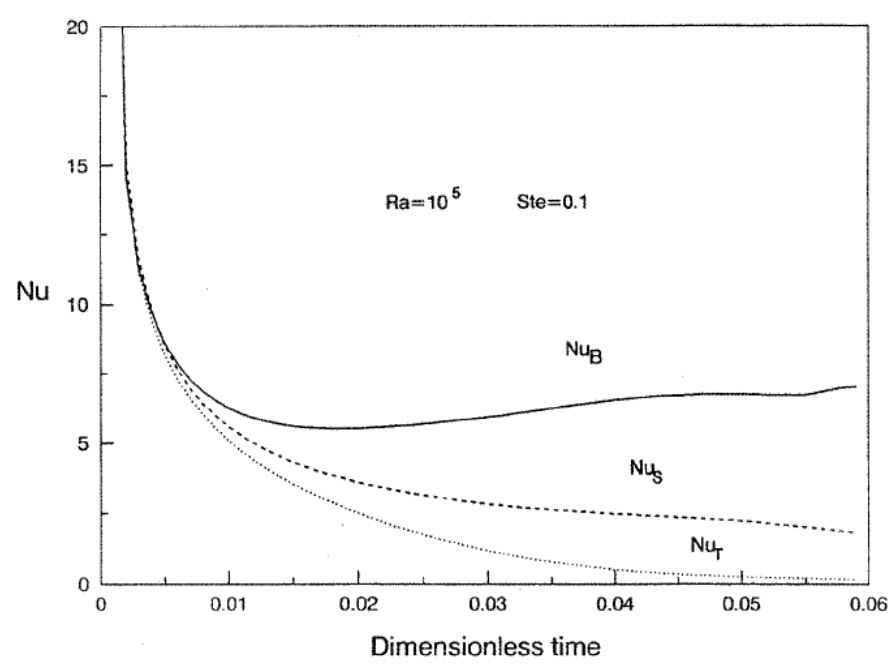

b

Fig. 21. (a) Schematic representation of the vertical cylindrical capsule and (b) Timewise variation of the average Nusselt number on the bottom $\left(N u_{B}\right)$, side $\left(N u_{S}\right)$ and top $\left(N u_{T}\right)$ surfaces $(\mathrm{Wu}$ and Lacroix [48]). 


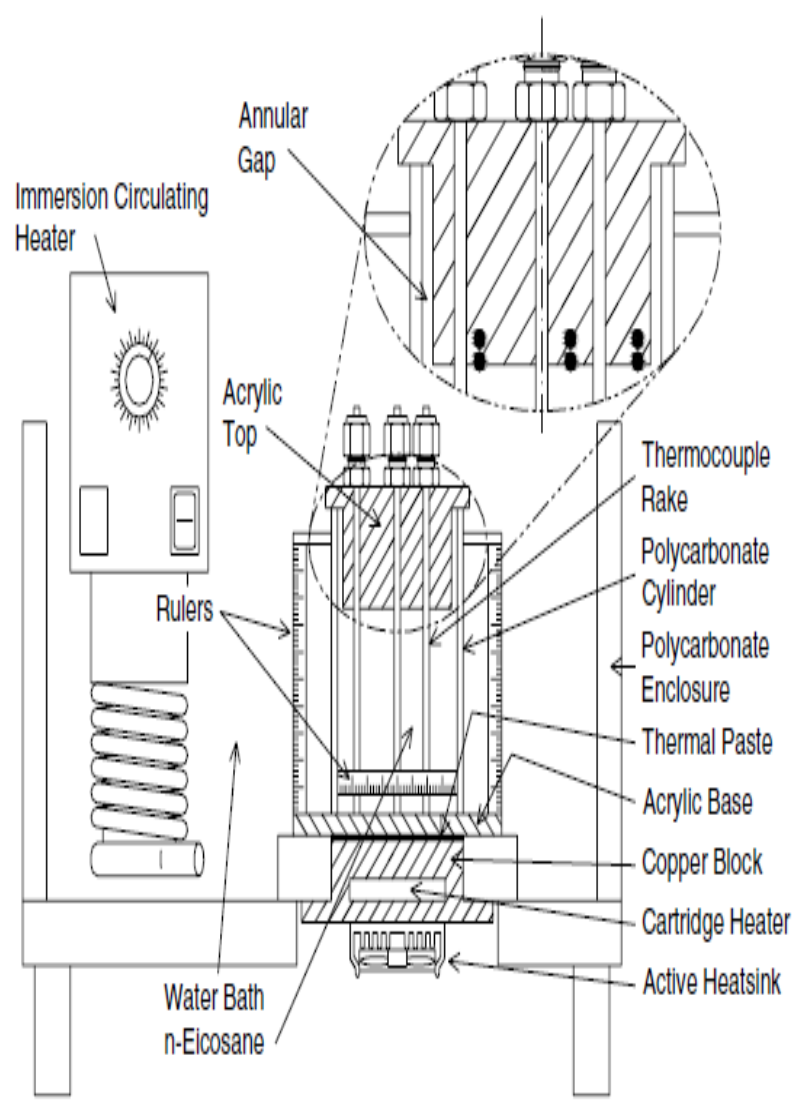

a

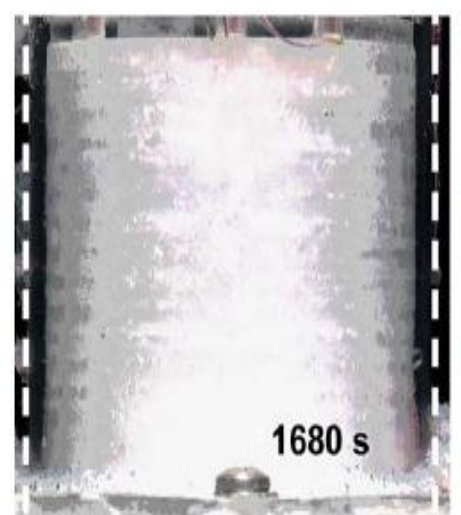

(a)

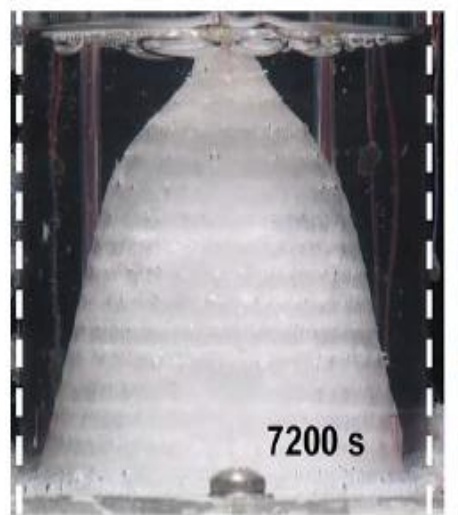

(c)

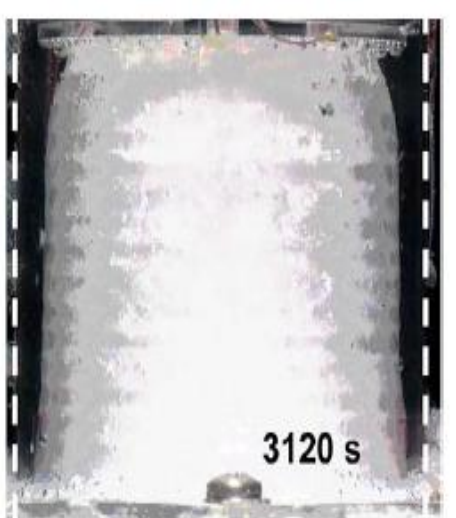

(b)

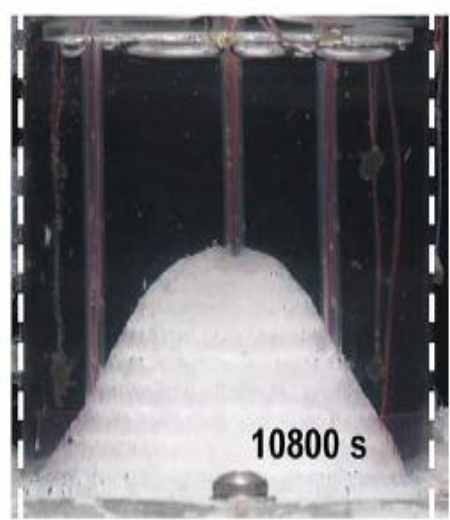

(d)

b

Fig. 22. (a) Schematic diagram of the experimental facility and (b) Photographs during the melting of wax within the cylindrical enclosure for a wall temperature of $45{ }^{\circ} \mathrm{C}$ (Jones et al. [49]). 

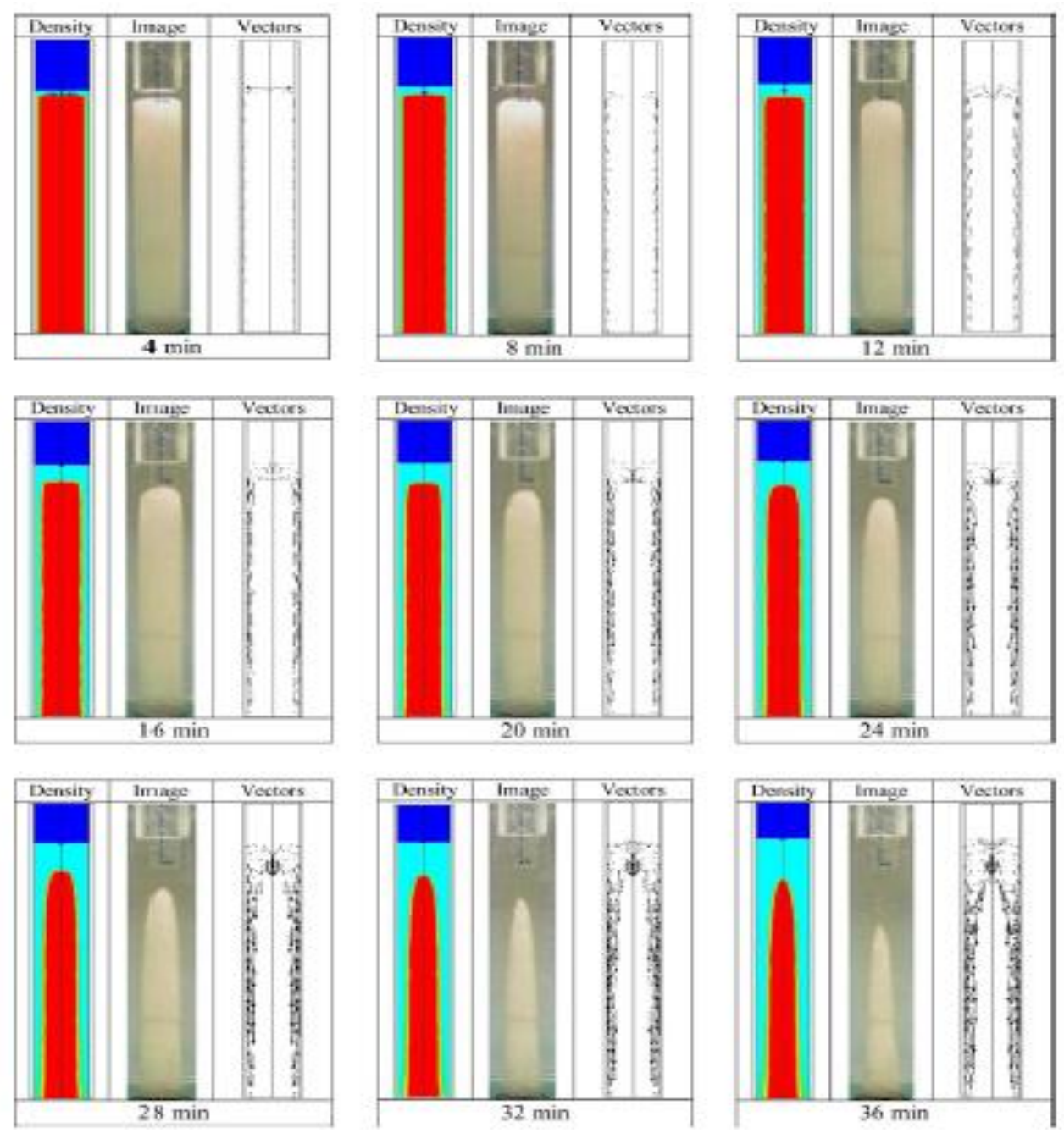

Fig. 23. Instantaneous simulated density distributions and velocity vector maps vs. experimental images during melting in a vertical cylindrical container for $D=3 \mathrm{~cm}, H=17 \mathrm{~cm}$ and $\Delta T=$ $10{ }^{\circ} \mathrm{C}$ (Shmueli et al. [50]) . 


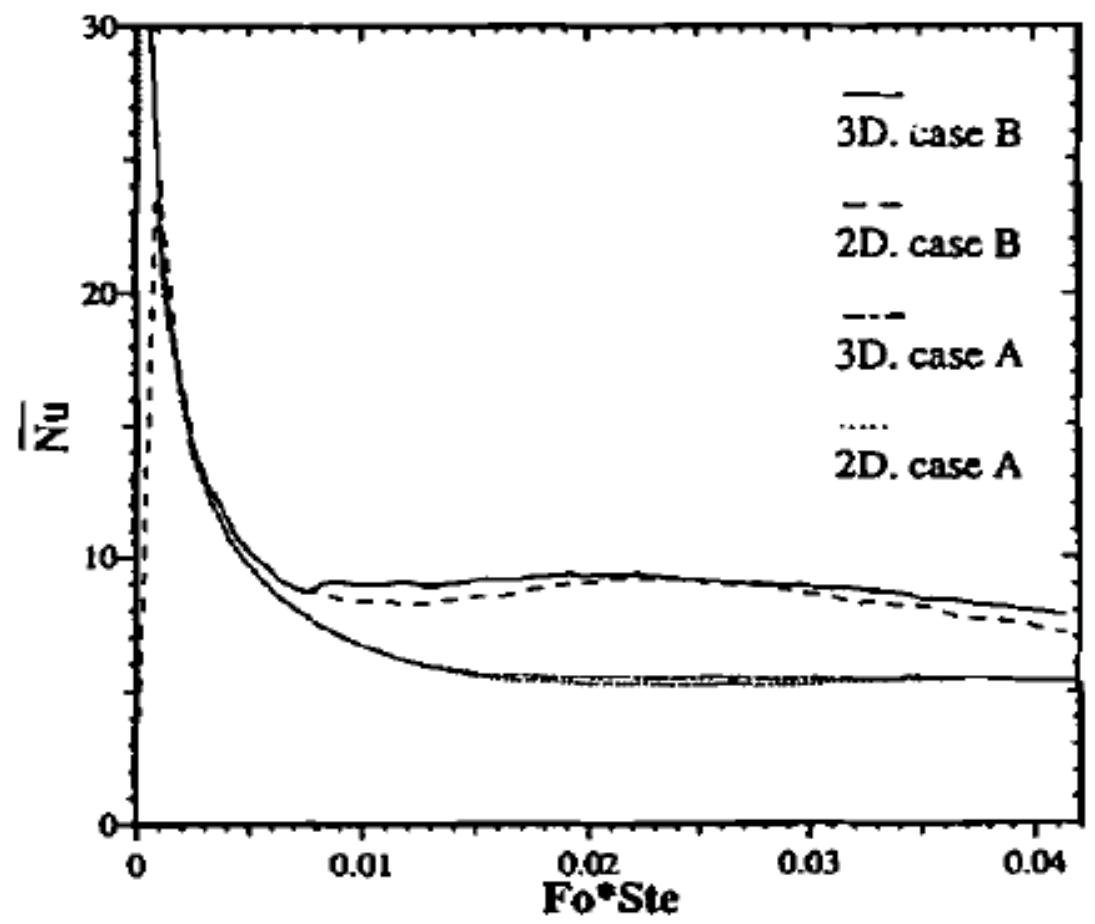

Fig. 24. Time evolutions of the overall Nusselt number on the surface of a horizontal cylinder in cases A and B predicted by three- and two-dimensional simulations (Costa et al. [61]). 


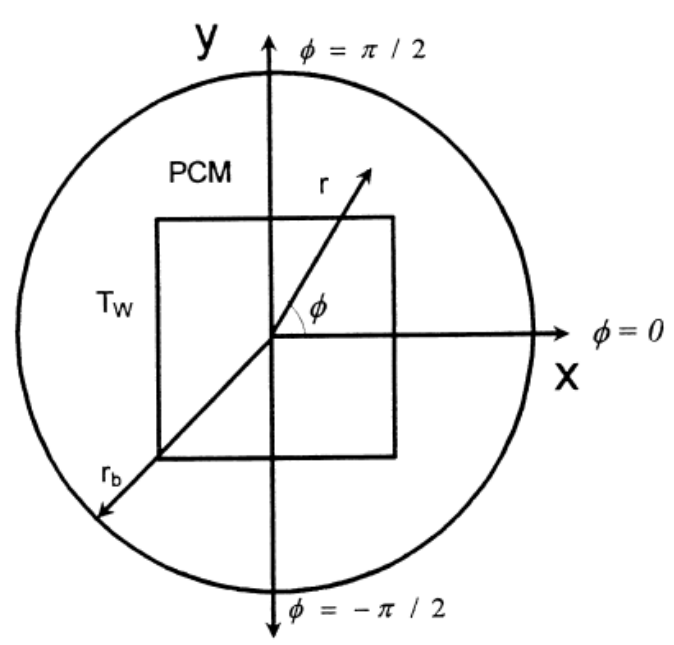

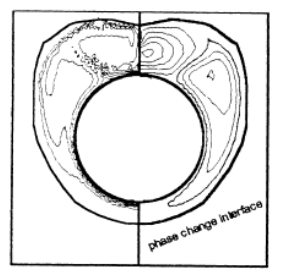
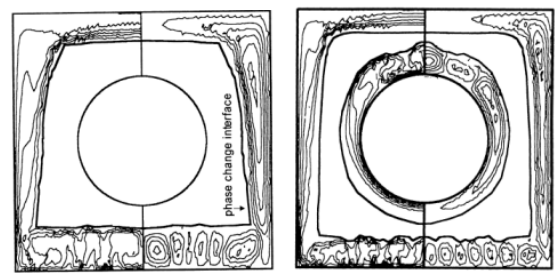

$F_{O}=0.1296$

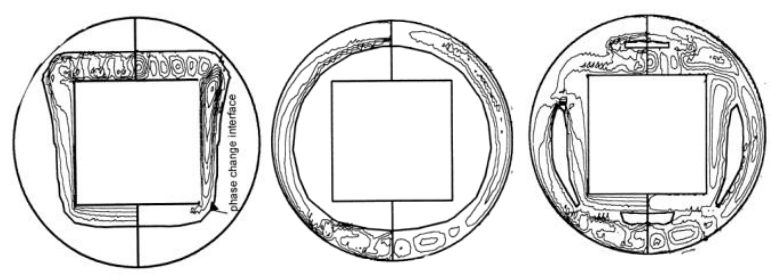

$F o=0.0864$

Fig. 25. Two horizontal annuli configurations with streamlines (right half) and isotherms (left half) for $R a=2.844 \times 10^{6}$ with the annuli heated isothermally from the inside, outside or both walls (Khillarkar et al. [66]). 


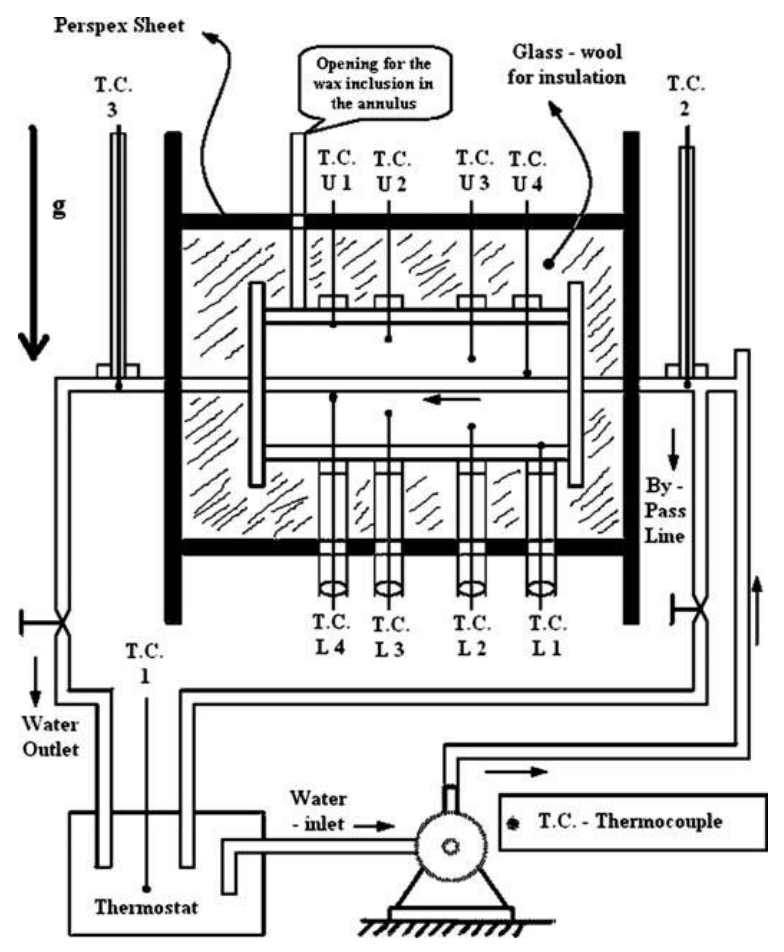

Fig. 26. Experimental set-up (Dutta et al. [67]). 


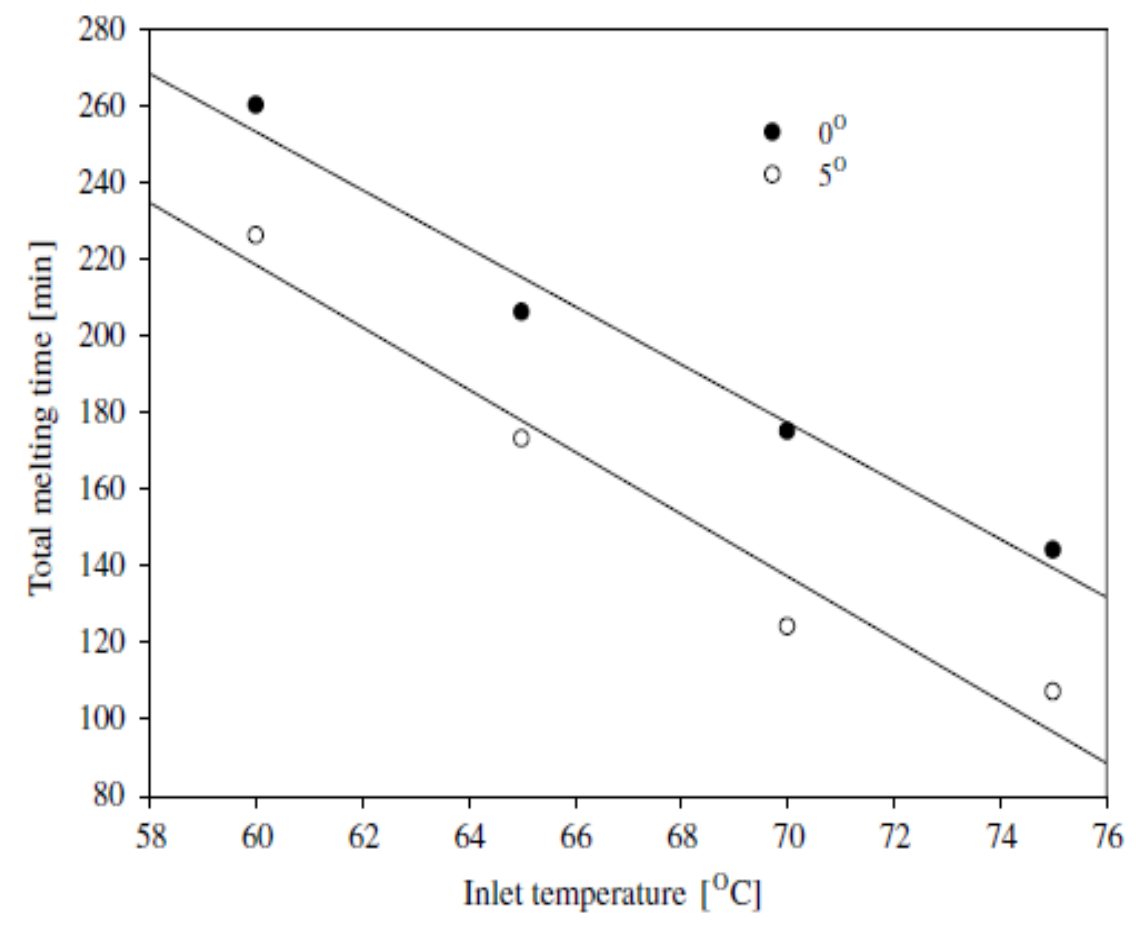

Fig. 27. Schematic diagram of the inclined shell surrounding a vertically-oriented annular PCM and the effect of this inclination on the melting time for various inlet water temperatures (Akgun et al. [68]). 


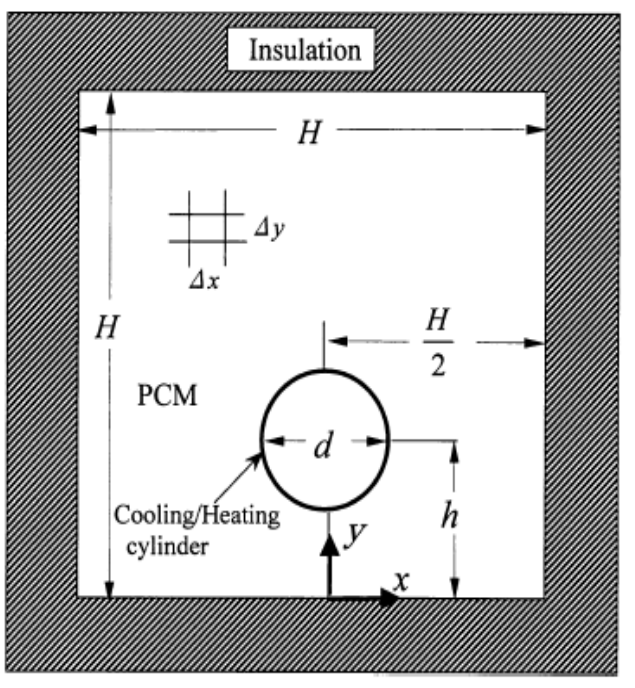

a

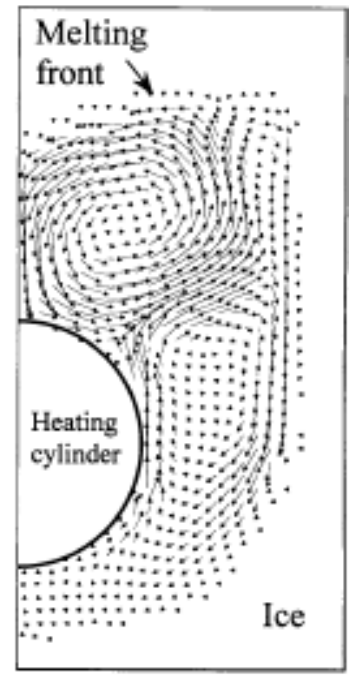

Velocity vectors

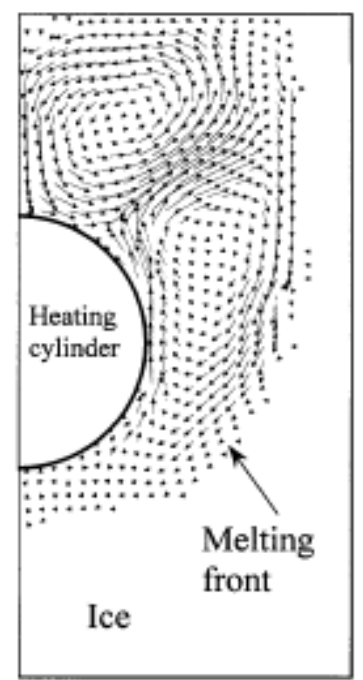

Velocity vectors

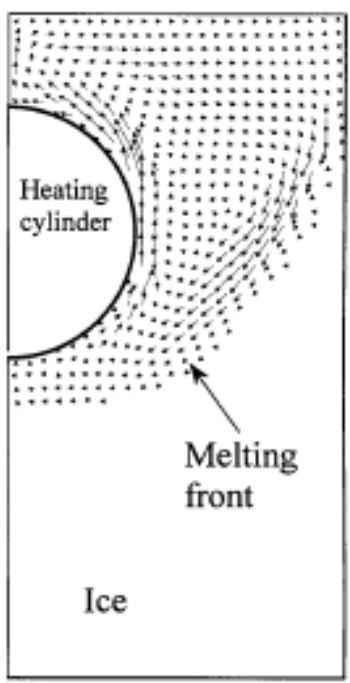

Velocity vectors

b

Fig. 28. (a) Physical model and coordinate system and (b) Characteristics of velocity vectors at different locations of the horizontally-oriented cylinder (Sugawara et al. [69]). 


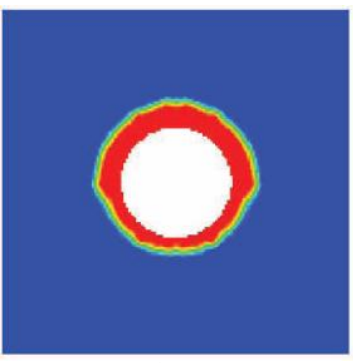

$2(\min )$

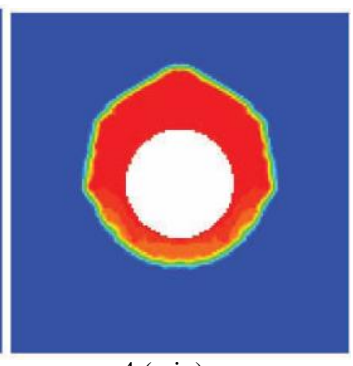

4 (min)

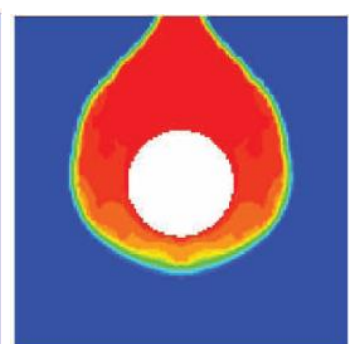

7 (min)

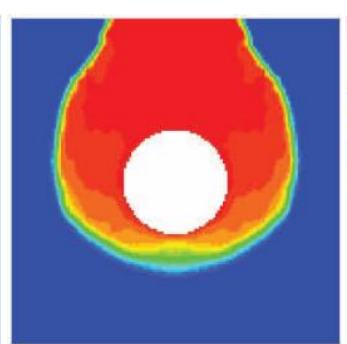

$10(\min )$

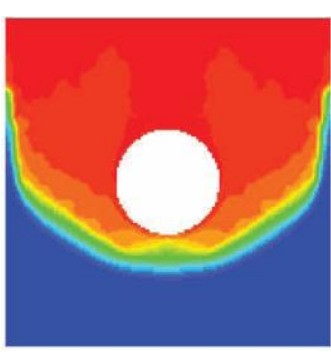

$21(\min )$

Fig. 29. Detailed phase fields throughout the melting process (Wei et al. [70]). 


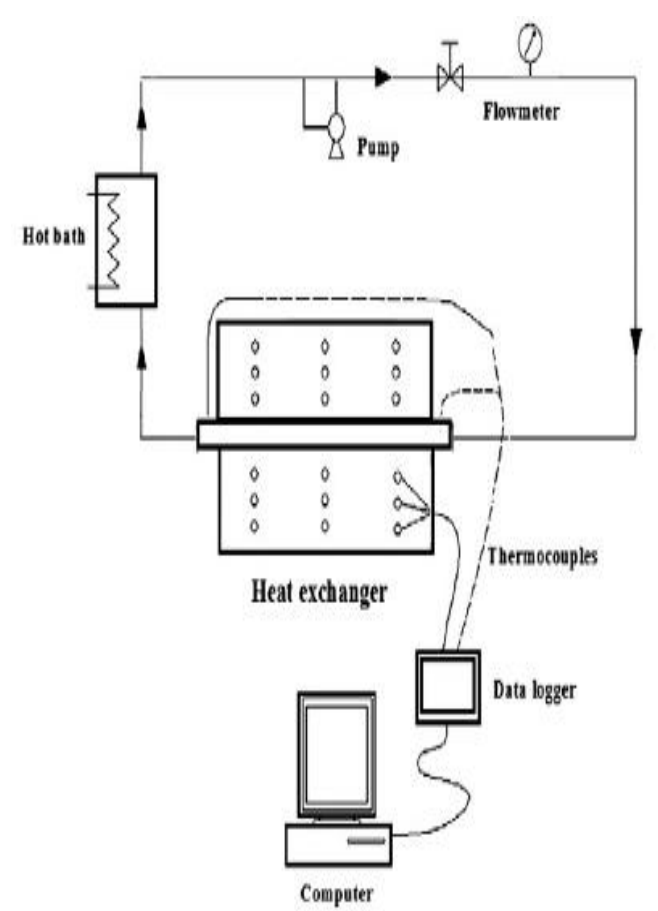

a

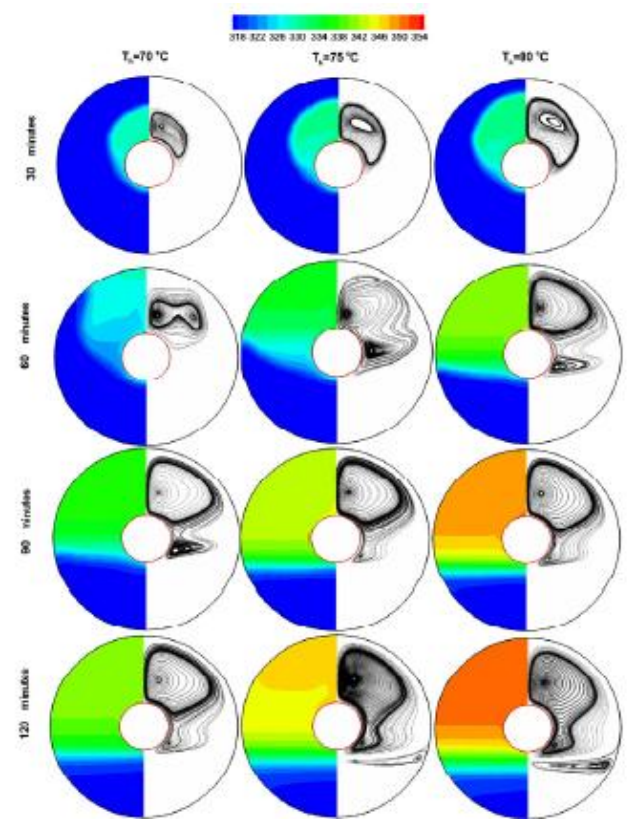

b

Fig. 30. (a) Diagram of the experimental set-up and (b) Computed streamlines and isotherms for different water inlet temperatures (Hosseini et al. [72]). 